Universidade de Aveiro Departamento de Eletrónica, Telecomunicações e 2017 Informática

Rafael Salgueiro Felgueiras Pinto
GeriatricHelper: desenvolvimento iterativo de uma aplicação móvel de suporte à avaliação geriátrica

GeriatricHelper: iterative development of a mobile application to support geriatric assessment 
Universidade de Aveiro Departamento de Eletrónica, Telecomunicações e 2017 Informática

Rafael Salgueiro Felgueiras Pinto
GeriatricHelper: desenvolvimento iterativo de uma aplicação móvel de suporte à avaliação geriátrica

\section{GeriatricHelper: iterative development of a mobile application to support geriatric assessment}

Dissertação apresentada à Universidade de Aveiro para cumprimento dos requisitos necessários à obtenção do grau de Mestre em Engenharia de Computadores e Telemática, realizada sob a orientação científica do Doutor Ilídio Castro Oliveira, Professor Auxiliar do Departamento de Eletrónica, Telecomunicações e Informática da Universidade de Aveiro e do Doutor Samuel Silva, investigador da unidade Instituto de Eng. Eletrónica e Informática de Aveiro, da Universidade de Aveiro. 


\section{o júri}

presidente

Professora Doutora Maria Beatriz Alves de Sousa Santos

Professora Associada C/Agregação do Departamento de Eletrónica, Telecomunicações e Informática da Universidade de Aveiro

vogais

Professor Doutor Telmo Eduardo Miranda Castelão da Silva

Professor Auxiliar do Departamento de Comunicação e Arte da Universidade de Aveiro

Doutor Samuel Sousa Silva

Investigador de Pós-Doutoramento do Departamento de Eletrónica, Telecomunicações e Informática da Universidade de Aveiro 
agradecimentos 
palavras-chave

resumo
mHealth, geriatria, Avaliação Geriátrica Global, Android, iOS, user-centred design

A Avaliação Geriátrica Global (AGG) é uma ferramenta de diagnóstico multidisciplinar que considera várias dimensões de fragilidade em idosos de modo a desenvolver um plano individualizado que fomente a saúde no envelhecimento. A AGG é aplicada usando um conjunto de escalas de diferentes subáreas, incluindo aspetos médicos, nutricionais, psicossociais e funcionais. Atualmente, a AGG é aplicada por um número limitado de profissionais em cuidados geriátricos, usando um método baseado em papel e caneta, com cálculos feitos à mão. Consultar o progresso do paciente envolve consultar documentos de consultas prévias

O objetivo deste trabalho é desenvolver uma aplicação móvel que será um guia de bolso e ferramenta para levar a cabo a AGG. Esta solução tecnológica fornece uma alternativa ao método atual, reduzindo o tempo gasto ao obter documentação relativa às escalas e o trabalho no cálculo de resultados.

GeriatricHelper é uma aplicação mHealth Android e iOS desenvolvida na base de uma aproximação iterativa do User-Centred Design. Foi obtido o feedback de um grupo alargado de utilizadores, que inclui peritos no domínio, contribuindo para um sistema com altos níveis de usabilidade a aceitação.

O resultado final é uma aplicação móvel que resolve os problemas atualmente enfrentados por médicos de geriatria e que é facilmente adaptável para incluir novas escalas. Um protótipo funcional encontra-se em fase piloto, permitindo a qualquer clínico aplicar este método de avaliação outrora limitado a peritos. 
keywords

abstract
mHealth, geriatrics, Comprehensive Geriatric Assessment, Android, iOS, user-centred design

Comprehensive Geriatric Assessment (CGA) is a multidisciplinary diagnosis approach that considers several dimensions of fragility in older adults to develop an individualized plan to favour health with aging. CGA is applied using a set of scales for different subareas, including medical, nutritional, psychosocial and functional aspects. Currently, CGA is applied by a limited number of professionals in geriatrics care, using a paper-based approach, with calculations made by hand. Patient follow-up is done by consulting documents from previous appointments.

The goal of this work is to develop a mobile application to act as a pocket guide and a tool for the CGA. This technological approach provides an alternative to the current method, reducing time spent on retrieving the scales documentation and the overhead of computing result.

GeriatricHelper is an Android mHealth application developed under an iterative, UserCentred Design approach. Feedback from a broad set of users including domain experts has been obtained throughout, contributing to a system with high usability and acceptability.

The result is a mobile application that solves the issues currently met by physicians and which is easily adaptable to include new geriatric scales. A functional prototype is currently being tested, allowing for any clinician to apply the otherwise experts-limited geriatric assessment. 




\section{TABLE OF CONTENTS}

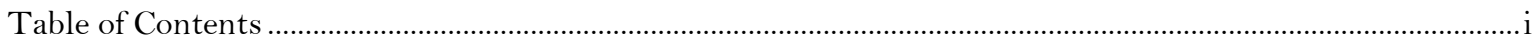

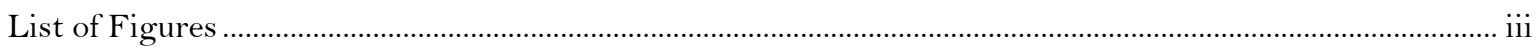

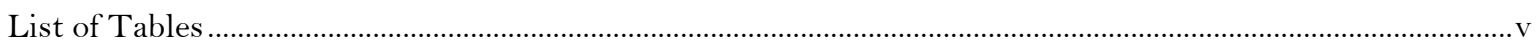

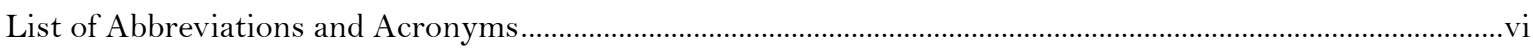

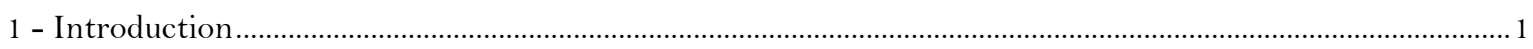

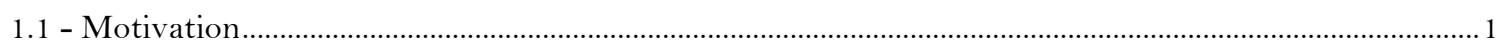

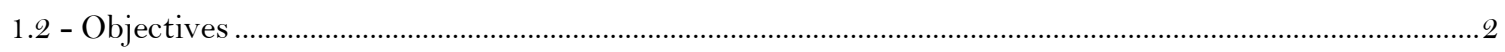

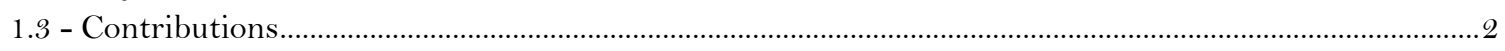

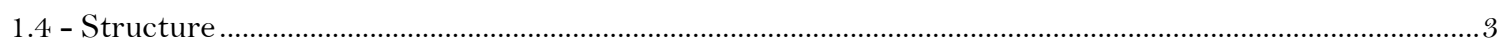

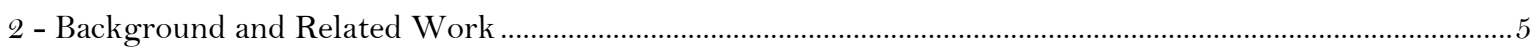

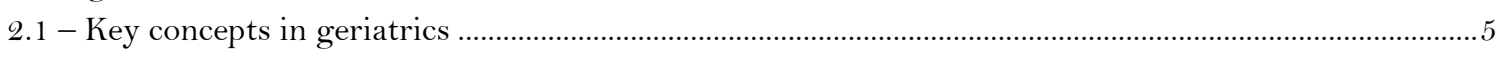

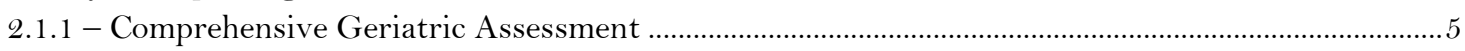

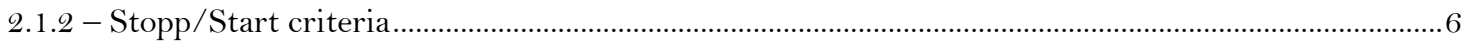

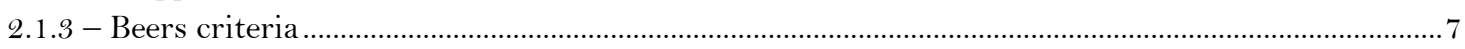

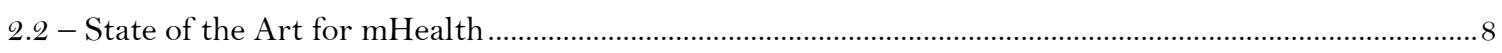

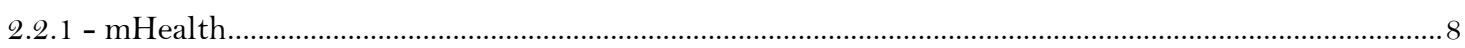

2.2.2 - Applications for healthcare professionals ............................................................................................

2.2.3 - Applications for medical and nursing students ............................................................................... 10

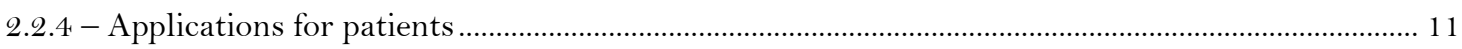

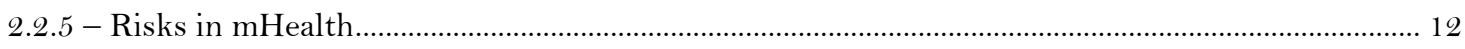

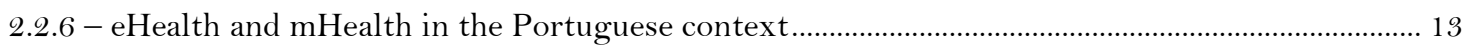

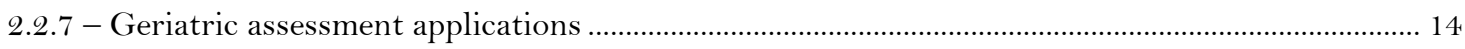

2.3 - User-centred Design and Development ........................................................................................ 18

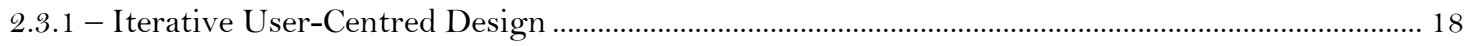

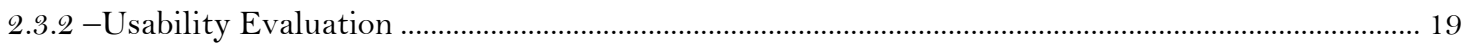

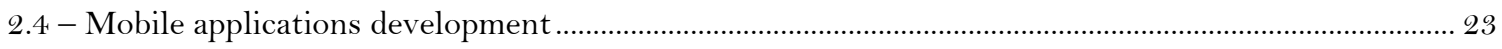

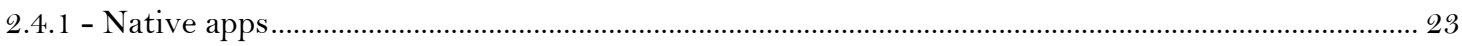

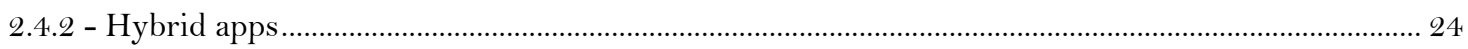

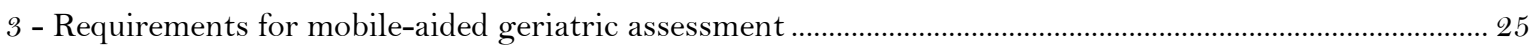

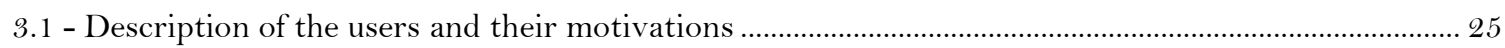

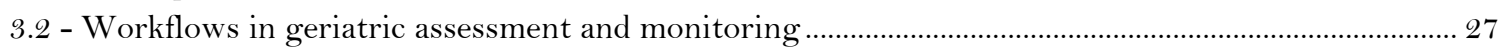

3.2.1 - Current practice for Comprehensive Geriatric Assessment ............................................................... 27

3.2.2 - Proposed practice for Comprehensive Geriatric Assessment ............................................................ 27

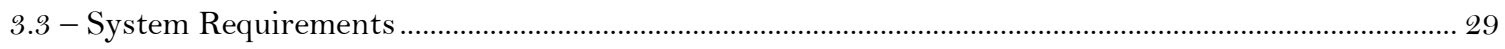

3.3.1 - Use cases description for an assessment assistant application ....................................................... 29

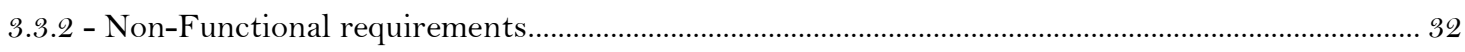

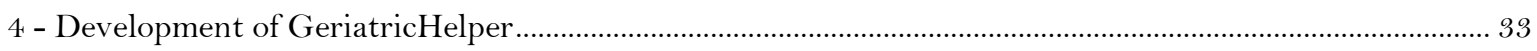

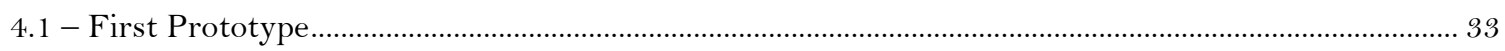

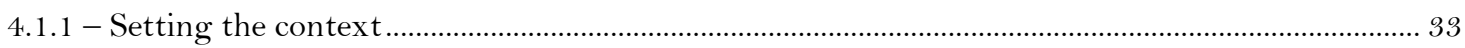

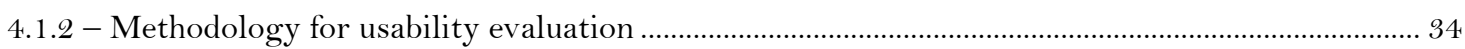

4.1.3 - Usability evaluation results ........................................................................................... 34

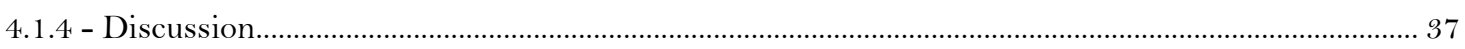

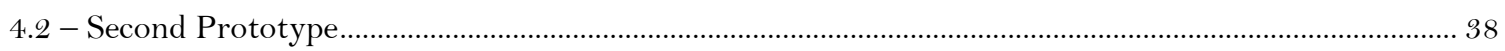

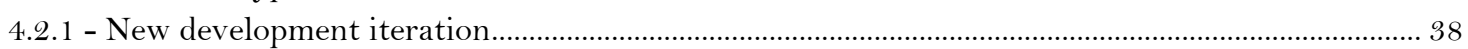




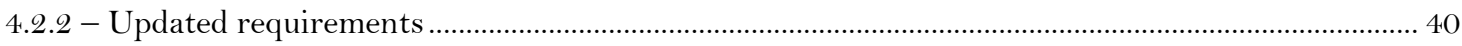

4.2.3 - Methodology for usability evaluation ............................................................................................ 41

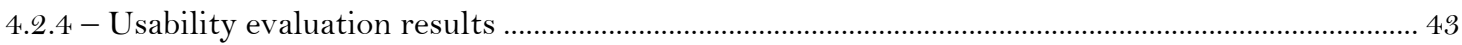

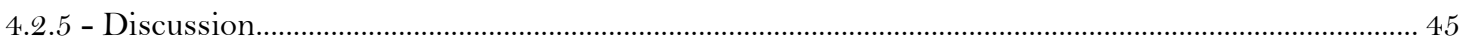

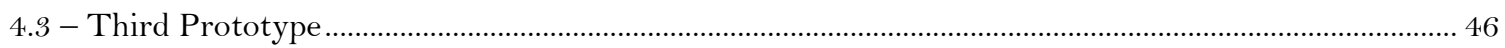

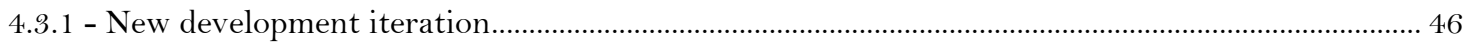

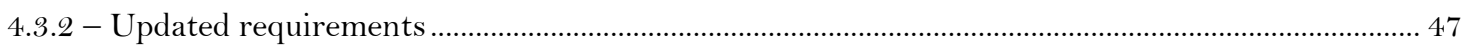

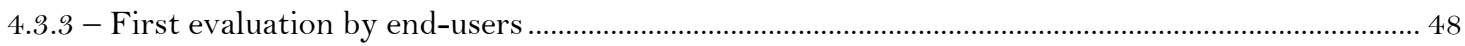

4.3.4 - Preliminary assessment by health professionals .............................................................................. 49

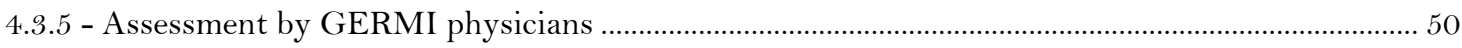

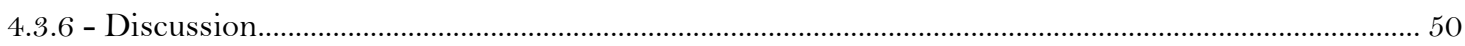

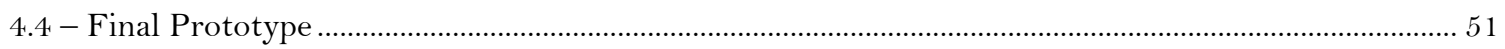

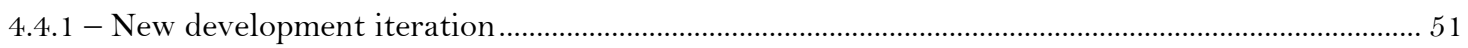

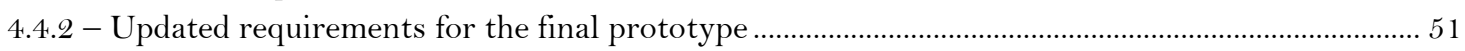

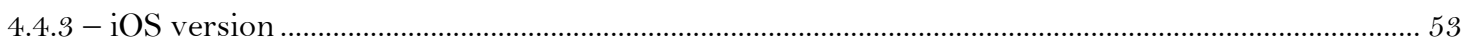

5 - System Architecture and Implementation ............................................................................................ 55

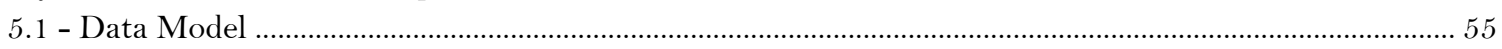

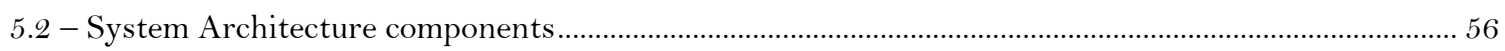

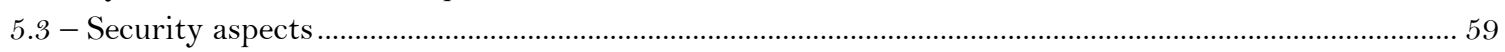

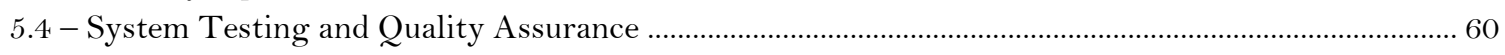

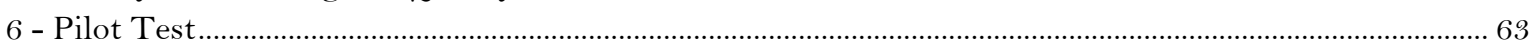

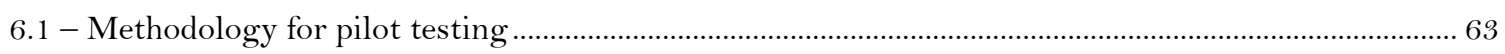

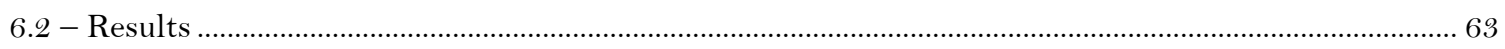

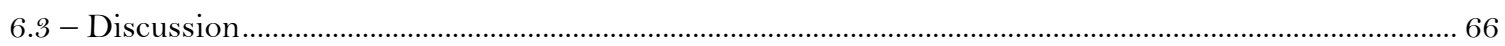

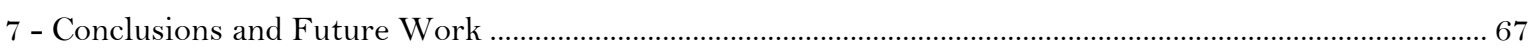

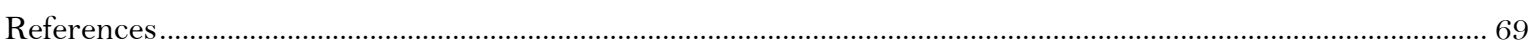

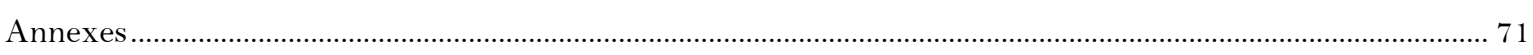

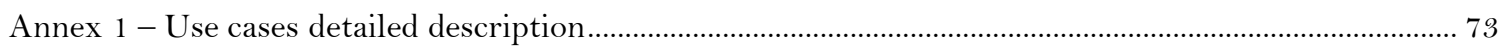

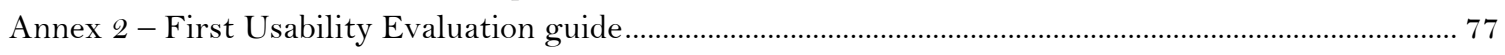

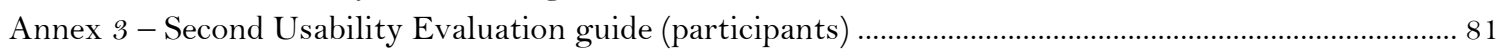

Annex 4 - Second Usability Evaluation guide (person conducting evaluation) ......................................... 85

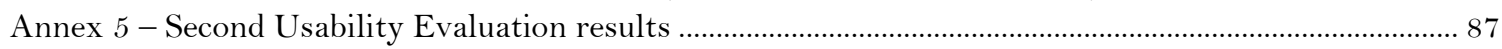

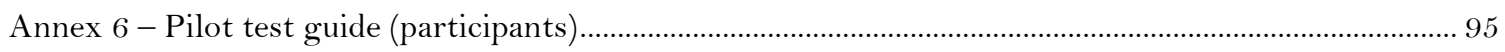

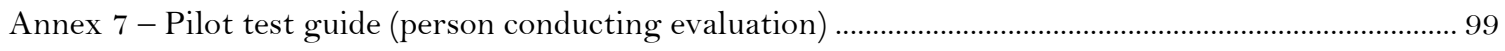

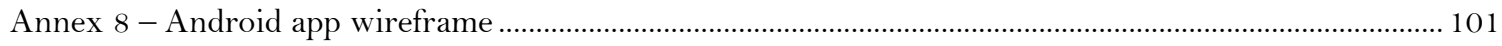

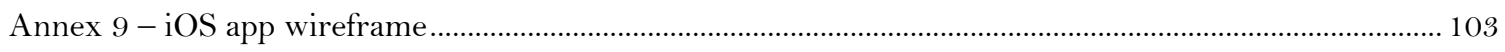




\section{LIST OF FIGURES}

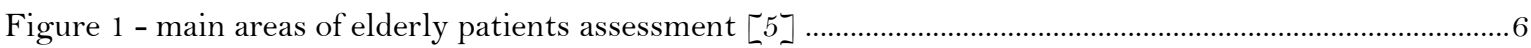

Figure 2 - Start criteria for the musculoskeletal system [6] ……….............................................................

Figure 3 - Stopp criteria for the endocrine system [6] ……….....................................................................

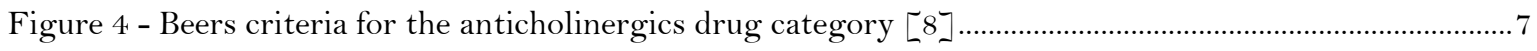

Figure 5 - typical architecture of an mHealth service (taken from $[11]$ ) ........................................................

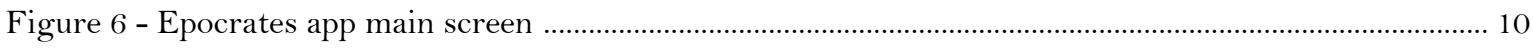

Figure 7 - Sanford Guide to Antimicrobial Therapy - information about a disease ....................................... 10

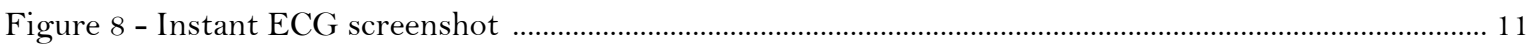

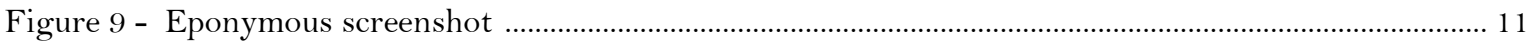

Figure 10 - Architecture of the eCAALYX Mobile Platform (taken from [16]) ….................................... 12

Figure 11 - Proposed ViCare framework (taken from [2 1]) ............................................................................ 14

Figure 12 - overview of the architecture of the centralized mobile system to conduct elderly frailty assessments by J. Fontecha et al. (taken from [22]) ....................................................................................... 14

Figure 13 - Indicators of Dependence main screen ...................................................................................... 16

Figure 14 - OncoScale screenshot depicting clinical scales grouped by CGA area ........................................ 16

Figure 15 - iGeriatrics screenshot depicting Beers criteria for Alprazolam .................................................. 17

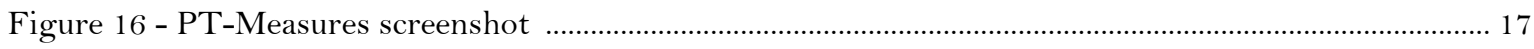

Figure 17 - Plus65 Med screenshot with Stopp Criteria for Musculoskeletal System .................................. 17

Figure 18 - example of the iterative design and development approach followed during this work, integrating User-Centered Design, and multiple cycles of requirement elicitation, prototype development and evaluation.

Figure 19 - GeriatricHelper use cases diagram .............................................................................................. 29

Figure 20 - image shown to the patient during the Mini-Mental State Examination [2] ............................ 31

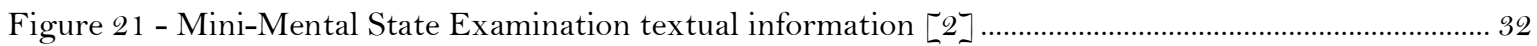

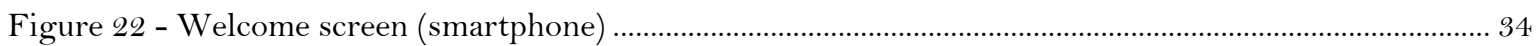

Figure 23 - Screenshot of the app's initial screen where too much text is displayed (smartphone) ................ 36

Figure 24 - Screenshot of Beers criteria, where the concepts of QE and SR are not explained to the user

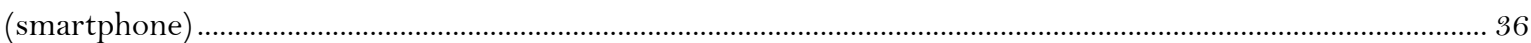

Figure 25 - Screenshot of a popup with scale's information where too much text is present (tablet) ............ 37

Figure 26 - Screenshot of the Clock Drawing scale where the black back arrow is shown in a blue background

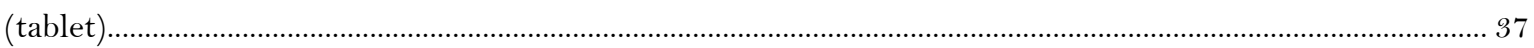

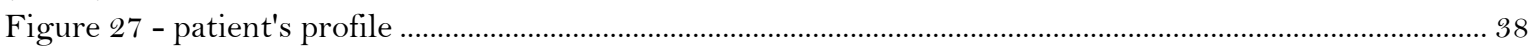

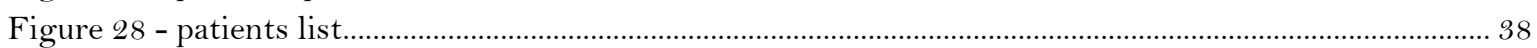

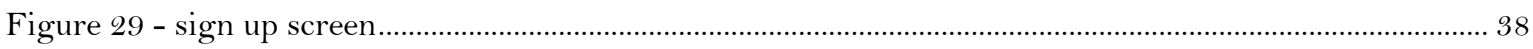

Figure 30 - characterization of participants in P2's evaluation (college degree) ………….............................. 43

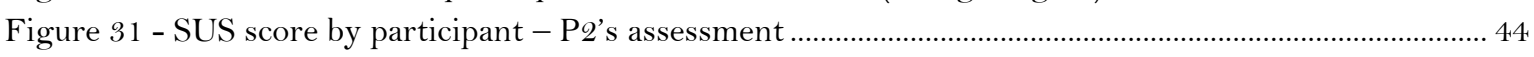

Figure 32 - task completion rate for P2's assessment (both platforms) ………………………........................ 44

Figure 33 - task completion rate for P2's assessment (smartphone) …............................................................. 44

Figure 34 - task completion rate for P2's evaluation (tablet) ….................................................................. 45

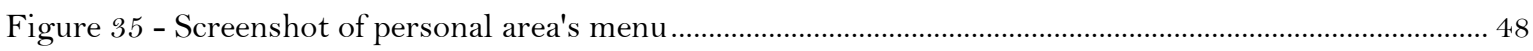

Figure 36 - possible arrangement of the app's modules in the settings menu ................................................. 52

Figure 37 - initial screen depicting the CGA's organization in areas …………………..................................... 52

Figure 38 - app tour guide depicting the different CGA areas ………............................................................. 52

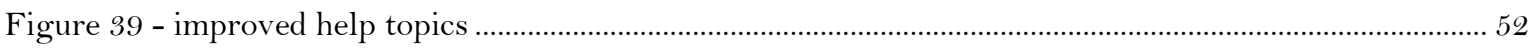

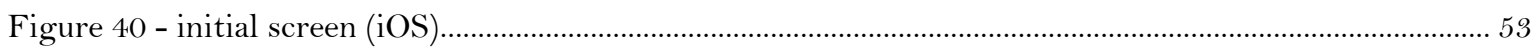

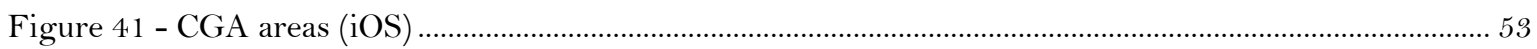

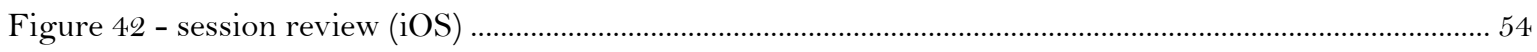

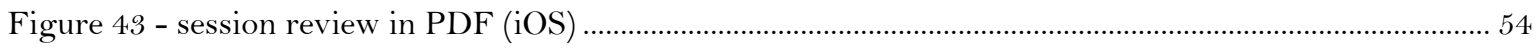


Figure 44 - CGA guide areas (iOS).

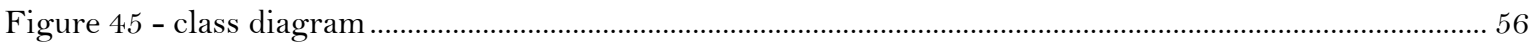

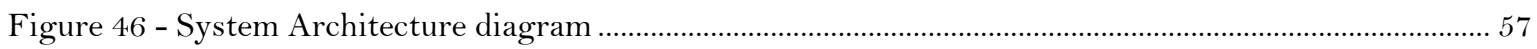

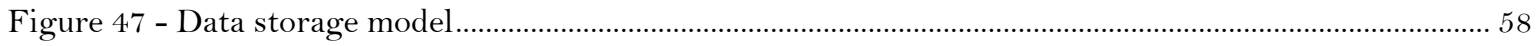

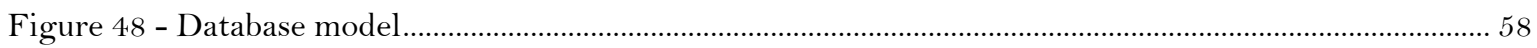

Figure 49 - Firebase JSON tree depicting how information is stored and organized on the backend .............58

Figure 50 - separation between clinical and demographical data on the backend ............................................. 59

Figure 51 - cipher process for patient's personal information ..........................................................................59

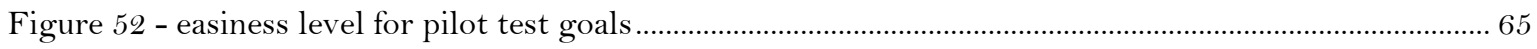

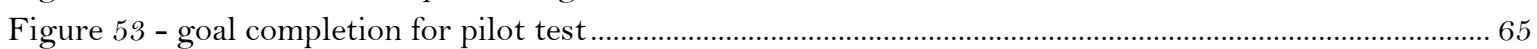

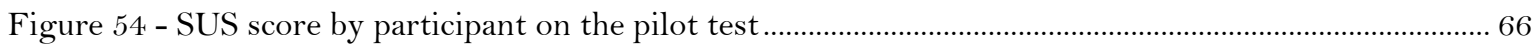




\section{LIST OF TABLES}

Table 1 - overview of CGA mobile solutions and their functionalities ................................................................ 16

Table 2 - Nielsen's heuristics for system usability [25] …............................................................................. 19

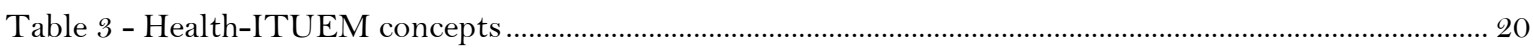

Table 4 - mobile-specific heuristics (with sample sub heuristics) ……..........................................................2 21

Table 5 - questions made to participants during the PSSUQ …….................................................................22

Table 6 - questions made to participants during SUS evaluation ……............................................................23

Table 7 - pros and cons of native mobile development [32] ……....................................................................23

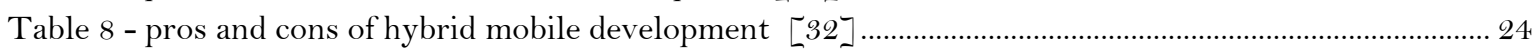

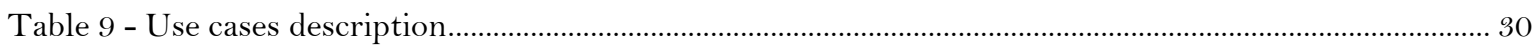

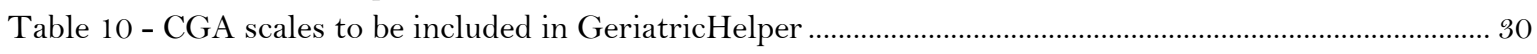

Table 11 - GeriatricHelper prototypes. their focus, evaluation strategy and assessment tool..........................33

Table 12 - Smartphone results for P1's usability evaluation grouped by Nielsen's heuristics ....................... 35

Table 13 - Tablet results for P1's usability evaluation grouped by Nielsen's heuristics................................. 36

Table 14 - comments made by testers during P 1's assessment ............................................................................ 37

Table 15 - Changes made in $\mathrm{P} 2$ based on physician’s feedback …….................................................................. 39

Table 16 - added functionalities and corrections made in $\mathrm{P} 2$.......................................................................... 39

Table 17 - Tasks considered to drive P2's think aloud session with the double goal of presenting GeriatricHelper features to testers and obtaining feedback on first impressions regarding the application 42

Table 18 - average, min and max time taken to reach each goal in P2's assessment .........................................43

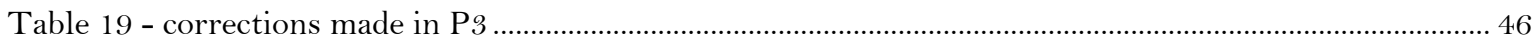

Table 20 - Changes made for $\mathrm{P} 3$ based on assessment by single physician ..................................................... 49

Table 21 - Changes made in P4 based on assessment by GERMI ................................................................... 51

Table 22 - functional requirements implemented on the iOS version of GeriatricHelper ..............................5 53

Table 23 - devices and API levels used for functional testing with Espresso................................................... 60

Table 24 - Tasks for the initial think aloud session with the double goal of presenting GeriatricHelper features to physicians and obtaining feedback on first impressions on the application ...................................... 64 .

Table 25 - average goal time and goal time by participant (in seconds) ...............................................................6.

Table 26 - comparison between the current approach followed by physicians to perform different steps needed for the CGA and how GeriatricHelper supports those tasks. 


\section{LIST OF ABBREVIATIONS AND ACRONYMS}

$\begin{array}{ll}\text { AES } & \text { Advanced Encryption Standard } \\ \text { CGA } & \text { Comprehensive Geriatric Assessment } \\ \text { CNPD } & \text { cerebrovascular accident } \\ \text { EHR } & \text { Comissão Nacional de Proteção de Dados } \\ \text { GERMI } & \text { Electronic Health Record } \\ \text { Health-ITUEM } & \text { Health IT Usability Evaluation Model } \\ \text { HCP } & \text { Healthcare professional } \\ \text { ICT } & \text { Information and communications technology } \\ \text { PSSUQ } & \text { Post-Study System Usability Questionnaire } \\ \text { QoS } & \text { Quality of Service } \\ \text { SPMI } & \text { Sociedade Portuguesa da Medicina Interna } \\ \text { SUS } & \text { System Usability Scale } \\ \text { UCD } & \text { User Centred Design } \\ \text { uHealth } & \text { Ubiquitous Healthcare } \\ \text { WHO } & \text { World Health Organization }\end{array}$




\section{1 - INTRODUCTION}

The world population is ageing at a much faster pace than in the past 50 years. By 2020, the number of people aged 60 years and older will outnumber children younger than 5 years [1].

Worldwide healthcare systems must be apt to treat the elderly. The so-called geriatric syndromes (presence of several complex health states and that do not fall into discrete disease categories) may lead to frailty, urinary incontinence, falls, delirium and pressure ulcers. These seem to be better predictors of death than the presence or number of specific diseases but tend to be overlooked in countries that have not developed geriatric medicine as a specialty [1] .

Geriatrics is the healthcare branch responsible for the treatment of the elderly, thus it is expected to have an increased demand for the next years to come, both in healthcare professionals (HCPs) and in treatment facilities.

\section{1 - Motivation}

The Comprehensive Geriatric Assessment (CGA) is a multidimensional and interdisciplinary evaluation of the elderly. Its main objectives are to reach a precise and full diagnose, give a better quality of life to the patients and facilitate prevention and follow up [2]. CGA is applied to people over 75 years old or over 65 when in risk situations, such as lack of social support, multiple concurrent pathologies, chronic disease or institutionalization. Being a multidisciplinary evaluation, it is applied by physicians, nurses, social services technicians, gerontology physicians and physiotherapists. The CGA is composed of five areas of assessment, clinical, physical, mental, functional and social.

The classical evaluation process is based solely in biological alterations and in illnesses. It has the disadvantages of not improving the overall health condition (nutrition, mental state, etc.) and may lead to feelings of despair and inefficiency by the health professionals when chronical situations are perpetuated. The CGA, by making use of scales, allows for an objective and systematic evaluation approach, increase in the diagnosis accuracy, tracking the patient's evolution by comparing previous results and it is simple, reliable and cheap to apply [3].

The target population for this evaluation spans a wide range of patients with very heterogeneous profiles regarding their functional, cognitive, social and nutritional health. One common aspect of these patients is that they suffer from multiple pathologies, have an advanced age (usually over 75 years old), functional deterioration and presence of diverse geriatric syndromes (polypharmacy, for example). The patients envisaged by this evaluation are not the typical elderly that are totally dependent and remain most part of their time lying in their beds, but the ones who start presenting the mentioned symptoms and still have the chance of avoiding that outcome.

The goal of CGA is to enable and maintain a better quality of life for the patients. One of the requirements is that it is performed on a regular basis to better adjust to the vastly decaying health condition of some patients. 
In Portugal, there is no concept of a geriatric medical appointment. The inexistence of a specialty in Geriatrics makes it difficult to implement CGA in the medical routine of the Portuguese clinicians. Currently there are only three medical centres where the CGA is performed by multiple professionals (nutritionist, physician and pharmaceutical). In those situations, a CGA appointment may spawn a whole afternoon, in which the patient has a predefined set of steps to follow and places to go. Since those cases are a small percentage of the appointments, we can consider that this evaluation is always performed by a single physician, mainly internal medicine physicians and general practitioners.

Given the lack of specific professionals to cover the entire population, this kind of assessment needs to be applied by professionals such as general practitioners with no background on CGA. This, however, can enable a more systematic coverage of the older population with a potential positive impact in their quality of life.

The Núcleo de Estudos de Geriatria da Sociedade Portuguesa de Medicina Interna (GERMI) ' approached the University of Aveiro, seeking a collaboration to implement the CGA on a mobile platform. In the context of this collaboration a mobile application for applying the CGA, developed for the Android and iOS mobile operating systems, was implemented, called GeriatricHelper. This mobile application was developed in several iteration-evaluation-iteration cycles, under the principles of User-Centred Design (UCD), and is the objective of the present work.

\section{2 - Objectives}

Motivated by the need for an alternative implementation of the CGA assessment method and the general availability of smartphone devices in the context where the CGA is applied, the objectives for the current work were:

- Propose and implement a mobile application that supports medical doctors in applying the CGA in an easier, more systematic way

- Adopt a user-centred design and development approach to improve understanding of end-user motivations, needs and skills

- Validate the proposed solution in pilot usage

\section{3 - Contributions}

The present work originated two mobile applications, one for Android and another one for iOS, both named GeriatricHelper, which can be accessed from the Google Play Store and App Store respectively.

In addition, there were two presentations in scientific forums:

a) Rafael Felgueiras, Ilídio Oliveira, Samuel Silva "GeriatricHelper: iterative development of a mobile application to support geriatric assessment”, Proc. MobiHealth, Nov. 2017 [presented, to be published]

b) Rafael Felgueiras, Ilídio Oliveira, Samuel Silva, “Avaliação Geriátrica Global: Uma Aplicação para dispositivos móveis”, $2^{\text {a }}$ Reunião Nacional do Núcleo de Estudos Geriatria, Nov. $2017^{2}$

1 “.: sociedade portuguesa de medicina interna :.” [Online]. Available: http://www.spmi.pt/nucleos_estudo_conteudos.php?id_nucleo=17.

2 “2 $2^{\text {a }}$ Reunião do Núcleo de Estudos de Geriatria - SPMI.” [Online]. Available: http://www.spmi.pt/2areuniao-do-nucleo-estudos-geriatria/. [Accessed: 15-Sep-2017]. 


\section{4 - Structure}

This dissertation is organized in seven chapters:

Chapter 1 presents the motivation and objectives of the present work that lead to the development of a mobile-based approach to the CGA.

Chapter 2 describes the key concepts in geriatrics and related state of art containing an overview of the CGA, Start, Stopp and Beers criteria and mHealth. There is an overview of usability evaluation methods as well and a review of current mHealth applications in geriatrics.

Chapter 3 presents the users, personas, workflows, use cases and requirements for the system.

Chapter 4 is divided into four development iterations, each one concerned with a different version of the application prototypes, and contains an overview of the pilot test for the system, conducted by geriatric physicians.

Chapter 5 describes the system architecture, each key component and how they interact, along with more technical-related descriptions about implementation, security concerns, testing and quality assurance.

Chapter 6 describes the pilot test, on which the application was used in a real context, with physicians, to retrieve their feedback, which would serve for later instalments of GeriatricHelper.

Chapter 7 presents the conclusions and future work. 


\section{2 - BACKGROUND AND RELATED WORK}

Aging creates a general mental, physical and functional deficit which influences the elderly in every aspect of life. The CGA has the objective of assessing the elderly state and his/her problems, allowing for a more adequate response from the clinicians. The CGA protocol [2], proposed by GERMI, implies collecting a broad range of patient's parameters (clinical, physical, mental, functional and social evaluation) (Figure 1).

The impact of mobile apps is widespread. They can assist in our daily life activities and, in general, make our life easier. One of the areas of interest in mobile applications is the health domain, allowing clinicians to have a companion when assessing patients, facilitating diagnosis, preventing incorrect diagnosis, etc [4] . This type of applications deal with sensitive data and must have reliable and tested security provisions, preventing sensitive data to be accessed by third parties.

\section{1 - Key concepts in geriatrics}

The following sections provide a brief description of the main aspects involved in the Comprehensive Geriatric Assessment and associated clinical criteria.

\subsection{1 - Comprehensive Geriatric Assessment}

The main goal of the CGA [2] is enhancing the quality of diagnostics and the health for the elderly patients. It is usually applied once or twice a year, in situations such as severe diseases and institutionalization. Physicians, nurses, social security technicians and physical therapists should be able to apply it. It encompasses five main evaluation categories, (1) clinical (clinical exams, complementary diagnostic exams), (2) physical (physical capacity, march and balance, nutrition state), (3) mental (cognitive, affective), (4) functional (autonomy, independence) and (5) social (family, daily life, economical resources, social networks). Instruments used for the evaluations should be simple, trustful, of easy execution, quick to use and well accepted by the elderly. GERMI has translated and consolidated the CGA recommendations to be applied in the Portuguese context.

The tests conducted, designated by scales, are grouped by CGA area. These are based in a set of scales, or questionnaires, that are made by a physician to a patient. The HCP calculates the results for the scales by hand and then stores them in the information system, if needed. This approach can be quite cumbersome because the physician must compute the results as the questionnaire unfolds, before getting all the questions answered.

Sometimes it would be necessary to prescribe drugs for a patient; in the context of the CGA, it is possible to use guidelines that advice when to proceed (Start) or stop (Stopp) a medication, for the senior adults. These are named Start/Stopp and Beers criteria (see also 2.1.2 - Stopp/Start criteria and 2.1.3 - Beers criteria). 


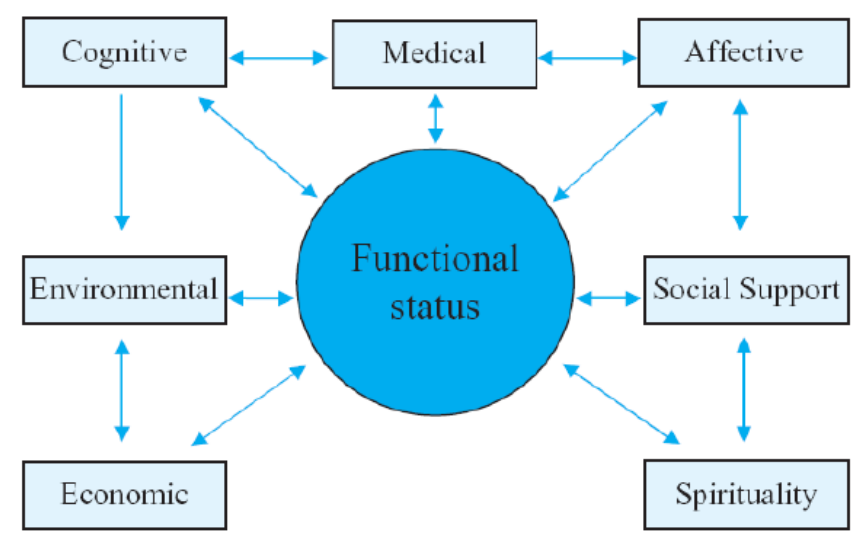

Figure 1 - main areas of elderly patients assessment $[5]$

When the results for a test indicate that the patient has become more dependent, the HCP has several courses of action:

- Search the major cause of dependency (new pathology, base pathology got worse)

- Assess the social sphere (who is the caregiver? What is their availability? Which social resources are needed? Needs evaluation by a social assistant?)

- Lifestyle/pharmacology intervention

- Shortening the reassessment period

\subsection{2 - Stopp/Start criteria}

The Stopp/Start criteria is "a medication review tool designed to identify medication where the risks outweigh the benefits in the elderly and vice versa " [6]; they "provide explicit, evidence based rules of avoidance of commonly encountered instances of potentially inappropriate prescribing and potential prescribing omissions" [7]. Their three main goals are to improve medication appropriateness, prevent adverse drug events and reduce drug costs. They are organized by system and for each one define criteria for drugs related to that system (Figure 2, Figure 3). 


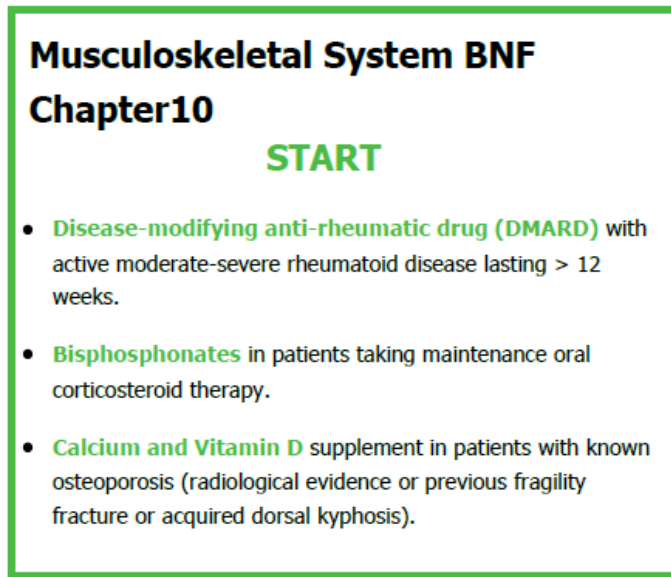

Figure 2 - Start criteria for the musculoskeletal system [6]

\author{
Endocrine System BNF Section 6 \\ STOPP \\ - Glibenclamide or chlorpropamide with type 2 diabetes \\ mellitus (risk of prolonged hypoglycaemia). \\ - Beta-blockers in those with diabetes mellitus and frequent \\ hypoglycaemic episodes i.e. > 1 episode per month (risk of \\ masking hypoglycaemic symptoms). \\ Oestrogens \\ - with a history of breast cancer or venous thromboembolism \\ (increased risk of recurrence) \\ - without progestogen in patients with intact uterus (risk of \\ endometrial cancer).
}

Figure 3 - Stopp criteria for the endocrine system [6]

When an HCP needs to prescribe drugs for a patient which contains Oestrogens, s/ he would consult the Endocrine System Stopp criteria section (Figure 3) and check if this drug is to be avoided for the patient in question. In case of any doubt regarding which is the best drug for the patient's condition, the HCP may consult the corresponding Start criteria (Figure 2).

\subsection{3 - Beers criteria}

Beers criteria, originally conceived in 1991 by Mark Beers, a geriatrician, is a catalogue of medications that cause adverse drug reactions in older adults. Each criteria is rated in terms of quality and strength of evidence using the American College of Physicians' Guideline Grading System [8]. They have a somewhat similar purpose to the Stopp criteria, since both state what should not be prescribed for older patients. Quality of evidence and strength of recommendation are used by the clinicians to support their clinical decisions; even though these criteria exist, it is still a human intervenient that chooses what to prescribe.

\begin{tabular}{|c|c|}
\hline $\begin{array}{l}\text { Organ System/ } \\
\text { Therapeutic Category/Drug(s) }\end{array}$ & $\begin{array}{l}\text { Recommendation, Rationale, } \\
\text { Quality of Evidence (QE) \& Strength of Recommendation (SR) }\end{array}$ \\
\hline \multicolumn{2}{|l|}{ Anticholinergics (excludes TCAs) } \\
\hline
\end{tabular}

Figure 4 - Beers criteria for the anticholinergics drug category [8]

Considering the case when an HCP may need to prescribe a drug which contains Hydroxyzine, a common component of First-generation antihistamines, s/he would consult the Beers criteria section relative 
to this type of drugs (Figure 4). The criterion informs that this drug is to be avoided since it may lead to an increased risk of confusion and constipation, for example. For the component in question the quality of evidence is high, and the strength of recommendation is strong, so the HCP should find a replacement drug.

\section{2 - State of the Art for mHealth}

mHealth encompasses a multitude of application areas. We can find three main areas of mobile applications in medicine regarding their end user: for healthcare professionals, students, and patients [4]. This categorization is appropriate since different users demand for different contents and functionalities.

\subsection{1 - mHealth}

To the World Health Organisation (WHO), mHealth includes medical and public health practice supported by mobile devices, such as mobile phones, patient monitoring devices, personal digital assistants (PDAs), and other wireless devices [9]. mHealth has the potential to achieve better health care services and has been growing exponentially, due to the rapid advances in mobile technologies and applications [9]. It can be viewed as a complement to traditional medicine, in the sense that allows to perform medicine directed to a technological sphere. mHealth solutions are not meant to replace doctors, since it may be necessary that doctors accompany patients in their use of these solutions [10]. mHealth is particularly important in lowincome contexts, where physicians may not be readily available.

Using the mobile devices' technologies, such as SMS, Wi-Fi, mobile data, sensors, etc, data can be collected and processed in different points, allowing for telemedicine, for example (see Figure 5 for an example of typical architecture of an mHealth service).

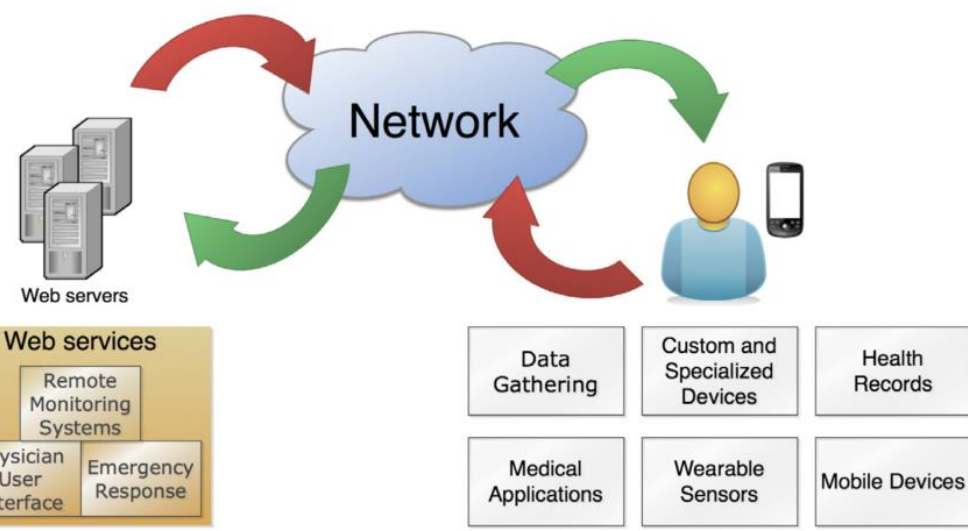

Figure 5 - typical architecture of an mHealth service (taken from [11]) 


\subsection{2 - Applications for healthcare professionals}

This application area includes the disease diagnosis, drug reference, medical calculators, literature search, clinical communication, Hospital Information System clients, and medical training categories [4]. Disease diagnosis applications focus on diagnosing and assessing a patient, including mobile versions of medical reference materials such as the Sanford Guide to Antimicrobial Therapy ${ }^{4}$ (Figure 7 contains a screenshot from this app), which provide information about pathogens and clinical criteria.

Drug reference applications include dosages, pharmacology, contraindications, cost, etc, acting as a pocket-guide, containing a wide array of information. Epocrates ${ }^{5}$ is one of the most popular drug-reference applications [4] (Figure 6). It includes drug information, diseases and clinical practice guidelines.

A medical calculator computes clinical scores such as body mass index (BMI) using input parameters and a standard formula, so the user does not need to know the formula by heart.

Literature search applications for HCPs facilitate searching biomedical literature databases such as PubMed/MEDLINE, Essie, etc. to find and display medical reference information, however they are seldom useful at the point of care or used by clinicians [4].

Clinical communication applications are used to simplify communication among HCPs. This area includes apps used in hospitals, for instance, for doctors to communicate with nurses; these improve communication and decrease disruptions, by spending less time trying to contact physicians [12]. They make use of typical smartphone technologies (voice and video calls, SMS, email, etc) to convey clinical information $[4]$.

Client applications for Hospital Information Systems (HISs) allow accessing patient information securely outside the medical environment. These include electronic health records (EHR), electronic medical records (EHR), and picture archiving and communication systems (PACS) [4].

As for the last category, medical training, it includes applications employed by physicians to continuously improve their medical practice by providing the most up-do-date medical techniques and knowledge. As examples we have apps about HIV/AIDS and cardiopulmonary resuscitation (CPR) [4].

mHealth may be employed in medical research as well, to improve data collection during trials; in a study of falls risk in the elderly, the accelerometer was used to help detect those at higher risk [12].

4. "The Sanford Guide to Antimicrobial Therapy on the App Store." [Online]. Available: https://itunes.apple.com/us/app/the-sanford-guide-to-antimicrobial-therapy/id863196620? $\mathrm{mt}=8$.

[Accessed: 08-Oct-2017].

5 "Point of Care Medical Applications | Epocrates." [Online]. Available: http://www.epocrates.com/. [Accessed: 26-Sep-2017]. 


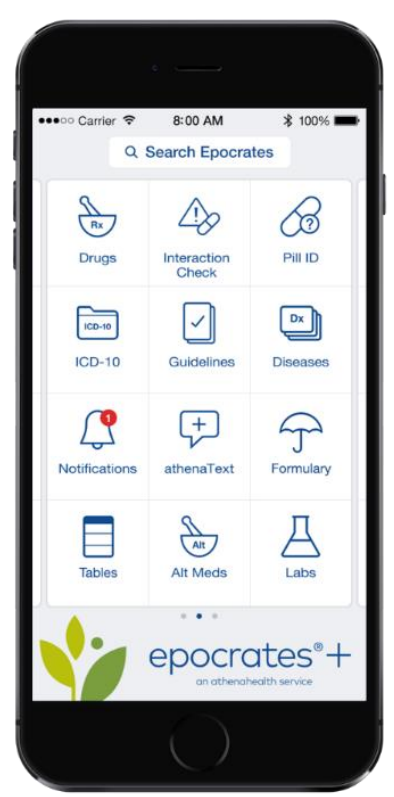

Figure 6 - Epocrates app main screen ${ }^{6}$

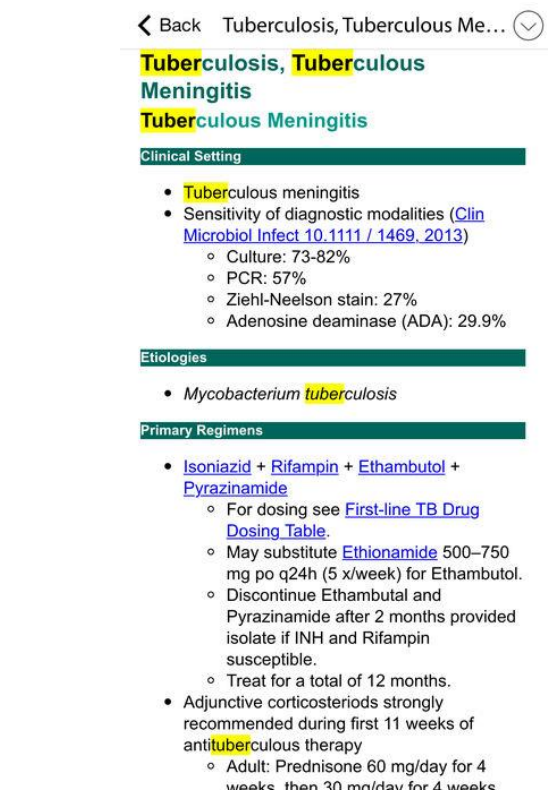

Figure 7 - Sanford Guide to Antimicrobial Therapy - information about a disease ${ }^{7}$

\subsection{3 - Applications for medical and nursing students}

Apps in this domain are targeted at HCPs in their education stage, i.e., are used to teach important materials to students. Popular tools in this domain include interactive anatomy tools and electronic versions of medical books [4].

As example applications we have Instant $\mathrm{ECG}^{8}$ (Figure 8), an ECG / EKG / Electrocardiogram guide, and Eponyms ${ }^{9}$ (Figure 9), comprising a guide of eponymous signs and diseases. A survey among medical residents in Botswana showed how a smartphone preinstalled with medical apps can be an effective way to obtain information in a resource-poor region [12].

6 "Point of Care Medical Applications | Epocrates." [Online]. Available: http://www.epocrates.com/. [Accessed: 26-Sep-2017].

7 "The Sanford Guide to Antimicrobial Therapy on the App Store." [Online]. Available: https://itunes.apple.com/us/app/the-sanford-guide-to-antimicrobial-therapy/id863196620? $\mathrm{mt}=8$.

[Accessed: 08-Oct-2017].

8 "Instant ECG: An Electrocardiogram Rhythms Guide on the App Store." [Online]. Available: https://itunes.apple.com/us/app/instant-ecg-an-electrocardiogram-rhythms-guide/id301270080? mt=8. [Accessed: 02-Oct-2017].

9 "Eponyms (for students) on the App Store." [Online]. Available: https://itunes.apple.com/us/app/eponyms-for-students/id286025430?mt=8. [Accessed: 08-Oct-2017]. 


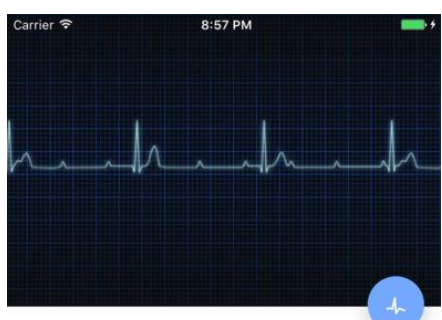

ECG BASICS

Learn the basics of electrocardiogram interpretation.

RHYTHMS

All healthcare providers should be able to recognize and
understand all these riyythms for patient safety

EXAMS

Prove your understanding of the electrocardiogram, thythm
recognition and test essential knowledge

REFERENCES

Quick reference of key values, axis, lead arrangement and

SETTINGS

Review App, Remove Ads, Purchase Movies/Quize:

Figure 8 - Instant ECG screenshot ${ }^{10}$

Carrier ₹ Eponyms
All Eponyms
Starred Eponyms
Recent Eponyms
CATEGoRIES
Anatomy
Biochemistry
Cardiovascular
Dermatology
Ear, nose, and throat
Endocrine
Gastrointestinal
Geographic eponyms
Gynecology

Figure 9 - Eponymous screenshot ${ }^{11}$

\subsection{4 - Applications for patients}

Applications used by patients include chronic disease management (diabetes, cardiac disease, pulmonary rehabilitation), monitoring risk of wandering in patients with Alzheimer [12], ENT (ears, nose and throat) and fall detection. Apps have been used in the context of rehab as well: e.g. using a smartphone connected by Bluetooth to an ECG device, patients who suffered a stroke may be monitored outside of a clinical environment [12].

This type of mobile applications provides medical information to patients, in some cases without the direct participation of a physician. iFall [15] uses the accelerometer, processes the data locally, and prompts the user in cases of possible falls. If the user fails to respond to the prompt, iFall makes an emergency call [12].

10 "Instant ECG: An Electrocardiogram Rhythms Guide on the App Store." [Online]. Available: https://itunes.apple.com/us/app/instant-ecg-an-electrocardiogram-rhythms-guide/id301270080?mt=8. [Accessed: 02-Oct-2017].

11 "Eponyms (for students) on the App Store." [Online]. Available: https://itunes.apple.com/us/app/eponyms-for-students/id286025430?mt=8. [Accessed: 08-Oct-2017]. 


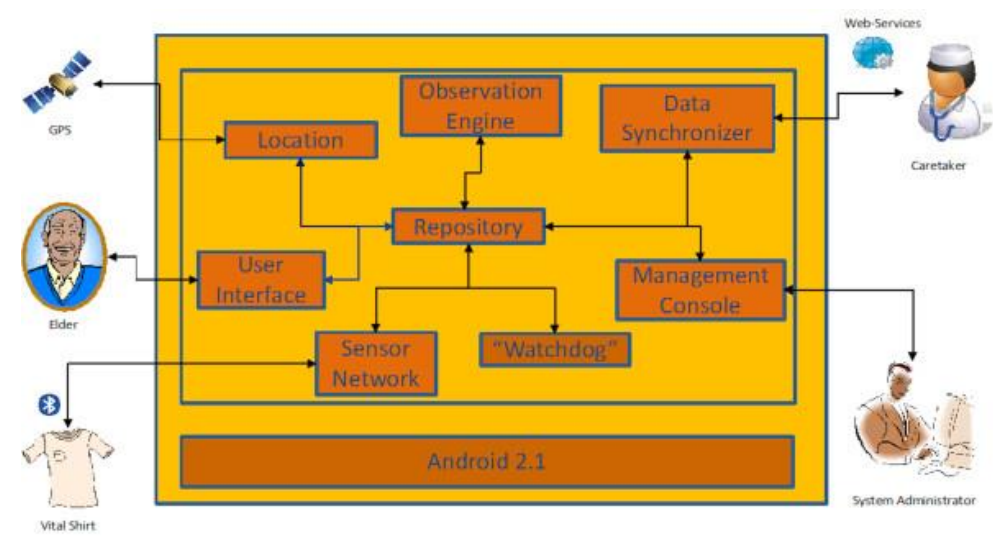

Figure 10 - Architecture of the eCAALYX Mobile Platform (taken from [16])

The eCAALYX Android app [16], developed for the Enhanced Complete Ambient Assisted Living Experiment (2009-2012), an EU-funded project for older people with multiple chronic conditions, implements a remote monitoring and management of older patients with multiple chronic conditions. It combines input from a smartphone's GPS and health sensors inside a wearable, communicating with a remote server accessible by HCPs (Figure 10).

This type of applications is built on top of the devices sensors, such as GPS, accelerometer, gyroscope, heart rate, pedometer, etc. The use of external monitoring devices can extend the possibilities.

Weight loss and fitness apps, which track the amount of exercise, as well as wellness apps (teaching yoga and tracking women periods, for instance), also fit into this category [12]. Fitness apps are being increasingly adopted by athletes, as well as common people. Apps may provide a way to track consumed calories for better control of weight loss goals.

However, it is questionable whether most of the wellness apps do more than just provide information, so there is a need to invest more in research and innovation to ensure a high degree of efficacy and reliability [10]. They may not provide information on who developed them or whether they have been properly reviewed or followed established medical guidelines during their development [10].

\subsection{5 - Risks in mHealth}

The most common issues when implementing mHealth systems are privacy and data security, funding, a lack of good examples of the efficacy and cost effectiveness of mHealth in practice, and the need for more high-quality research [17]. The cost of mHealth services to the public is relevant, particularly to those working with socioeconomically disadvantaged populations, being linked to the wider issue of the implementation of mHealth initiatives in underprivileged populations. [17]

Many mHealth applications may lack in usability and effectiveness, failing to meet the needs of users [17]. mHealth research needs more high-quality research, in terms of defining a standardized approach to designing these apps [17].

A study about research in mHealth concluded that users overlooking system rules, because they underestimate or fail to understand the costs of their actions, may lead to breaches in security and data protection [18]. Typical breaches include sharing passwords or leave them written, leaving mobile devices unsecured, or losing a mobile device [18].

In mHealth, information is often transmitted over Wi-Fi networks, which can be more susceptible to monitoring and interception than broadband networks, so security protocols which aim to protect identity and make it impossible to link data with a person or with other data are necessary in preventing against data breaches [18]. 
Some solutions do not work as expected, lack proper testing or may even put users life in danger [10]. This can be overcome by employing user safety standards, specific quality labels or certification schemes [10].

There is an absence of standards that mandate interoperability between mHealth solutions and devices which prevents mHealth investments from being utilised well and limits the scalability of such solutions [10]. The slow uptake of international interoperability standards is even more problematic for the app market as it is dominated by small and medium-sized enterprises and app developers (these may favour short-term strategies for quick market access) [10].

There are numerous actors involved in developing and supporting an mHealth solution, such as the manufacturer and HCPs involved in treatments, so it is complex to assume liability when a patient's health suffers damaged (this may be due to wrong diagnosis based on inaccurate data or health devices used incorrectly by the patient, for example) [10].

\subsection{6 - eHealth and mHealth in the Portuguese context}

In the 1990's, the Portuguese Ministry of Health (MOH) designed a basic information system to support the management and control of the flow of patients, the standardization of clinical and administrative data, and the enabling of automatic billing and improvement in the communication between health providers [19]. In Portugal, according to the National Statistics Institute, $93 \%$ of the public hospitals and $73 \%$ of the private hospitals have an EHR [19].

The Portuguese healthcare system is facing the same issues as other countries, mainly increasing costs, population aging, incidence of chronic diseases and shortage of HCPs. To counteract, several types of ICT were incorporated, giving more access to information to patients, which in turn makes possible to make better informed decisions. The Portuguese government follows a top down approach to ICT, which facilitates system interoperability since all providers use a similar system, while a bottom up approach is devised independently by each provider, undermining interoperability [19]

On 2017, an inquiry regarding mHealth in Portugal was conducted, envisaging groups, associations, entities and individuals linked to the area [20]. This study concludes that mHealth is a relatively recent concept and people are not still familiarized with it, although there are solid mHealth initiatives, established since the end of the nineties. Mobile apps are the most used technological solutions, with patient monitoring and vigilance, and communication between care giver and receiver as the most frequent categories of applications. As a general note, usability was considered during development stage and the majority are newly created systems, with no concern for interoperability.

Portugal compares well with other developed countries in the use of digital eHealth. There is a wide penetration of mobile devices and a national platform for health data sharing that already allows mobile apps to contribute to its repository (Plataforma de Dados da Saúde ${ }^{12}$ ).

${ }^{12}$ E. SERVIÇOS PARTILHADOS DO MINISTÉRIO DA SAÚDE, "PDS - Plataforma de Dados da Saúde - SPMS,” 2016. [Online]. Available: http://spms.min-saude.pt/2013/11/pds-plataforma-de-dados-dasaude/. [Accessed: 23-Oct-2017]. 


\subsection{7 - Geriatric assessment applications}

Focusing on applications mHealth, several solutions were proposed and are currently implemented.

Virtual Caregiver (ViCare) [21] is a framework that enables a human caregiver to monitor the elderly. It uses sensors to understand the activities made by the patient and to decide what service to provide them, assuring the well-being of the elderly on their environment. ViCare is a response to the high demand for caregivers' assistance for patients on their homes, which need assistance in their daily life activities. Figure 11 presents the ViCare framework and how each component interacts.

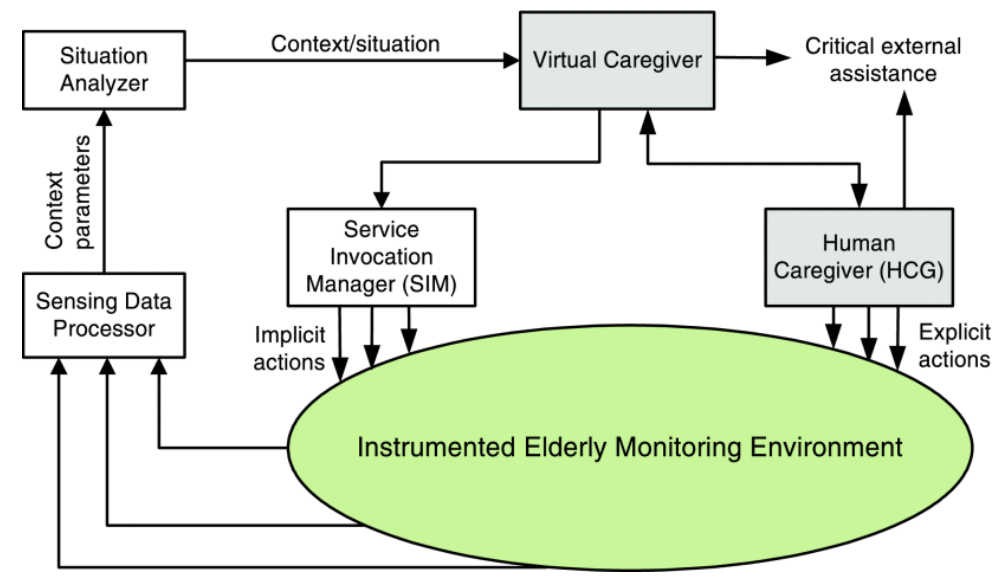

Figure 11 - Proposed ViCare framework (taken from [ $[21]$ )

J. Fontecha et al. developed a centralized mobile system to conduct elderly frailty assessments in an accurate and objective way using mobile phone capabilities [22]. It assesses the frailty state of elders by using tools found on mobile devices (accelerometer, wireless networking, local processing on the device, etc). It is a new method that achieves an objective assessment of frailty based on similarity results for an elderly population, providing an essential support for physicians. Figure 12 contains an overview of its architecture.

First, gait information from accelerometer sensors is collected and processed; then, all frailty risk factors found in the patient record are studied, providing valid results, which are interpreted by physicians on their mobile devices.

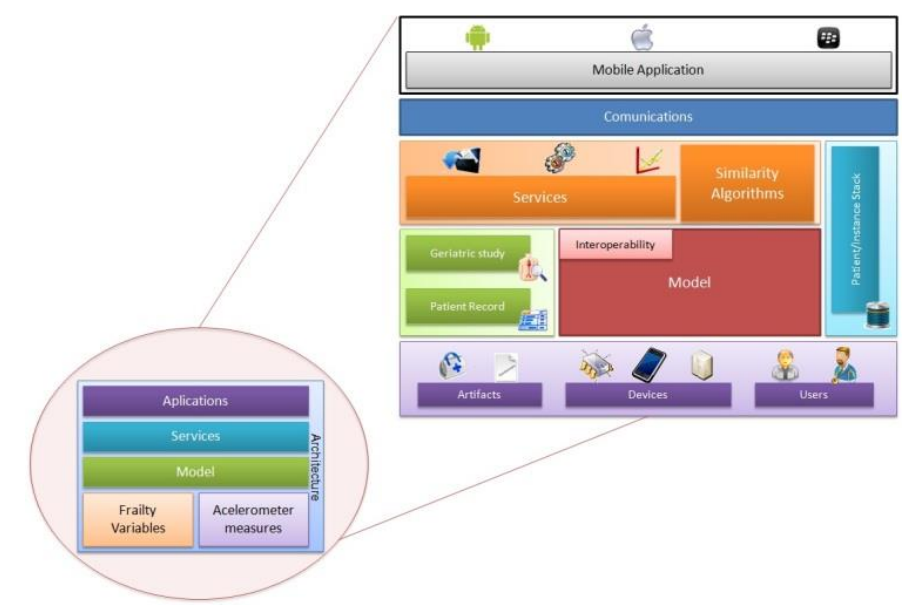

Figure 12 - overview of the architecture of the centralized mobile system to conduct elderly frailty assessments by J. Fontecha et al. (taken from [22])

A search for CGA mobile solutions was conducted on the app stores of the two main mobile platforms, Android and iOS, using the keywords "CGA", "geriatrics", "geriatric assessment", "comprehensive 
geriatric assessment", "start criteria”, "stopp criteria” and "beers criteria”. App selection was based on the app features, i.e., apps that implemented part of the envisaged functionalities for this system (patient follow-up, conducting CGA scales, consulting clinical criteria and information related to scales). Table 1 contains an overview of the selected apps.

iGeriatrics ${ }^{13}$ (Figure 15) was developed by the American Geriatrics Society, does not include information on how to perform CGA, but instead covers a wide range of topics related to older adults, such as vaccinations and prevention of falls. It does not allow to perform scales, but contains the Beers criteria.

Indicators of dependence ${ }^{14}$ (Figure 13) contains eleven scales, from mental, functional and social areas, but scales are not grouped into areas; there is detailed information on how to perform each scale, their scoring outcomes and associated bibliography; scales cannot be associated to a patient, only saved with a keyword.

OncoScale ${ }^{15}$ (Figure 14) includes mental, functional and nutritive scales, grouped into areas; there is info about a scale's bibliography and how to perform it. As a side-note, none of these apps allows tracking patient's medication.

Plus65 Med ${ }^{16}$ (Figure 17) is a pocket guide for the Start and Stopp criteria. Criteria can be consulted one by one or searched for a certain medication, medication class or disease, containing references for each criterion.

PT-Measures ${ }^{17}$ (Figure 16) includes one scale from the mental area and five from the functional area, which are grouped by their respective area; each scale includes some associated textual info; there is no list of patients, so when a scale is saved the physician has to insert the patient's personal data to be able to conduct a later follow-up appointment; this application does not include any clinical criteria.

Only PT-Measures is available in Portuguese. It is important to stress out that the CGA can assess multiple areas and contain multiple scales or tests, while these apps only allow to perform one at a time.

13 "iGeriatrics - Android Apps on Google Play." [Online ]. Available: https://play.google.com/store/apps/details?id=com.usbmis.reader.dwtf1. [Accessed: 30-Apr-2017]. 14. "Indicators of dependence - Android Apps on Google Play." [Online]. Available: https://play.google.com/store/apps/details?id=gt.app.dep. [Accessed: 30-Apr-2017].

15 "OncoScale - Android Apps on Google Play." [Online]. Available: https://play.google.com/store/apps/details?id=com.agmmultimedia.oncoscale. [Accessed: 30-Apr-2017]. 16 "Plus65 Med - Android Apps on Google Play." [Online]. Available: https://play.google.com/store/apps/details?id=com.mam.plus65. [Accessed 23 Nov. 2017].

17 "PT-Measures - Android Apps on Google Play." [Online]. Available: https://play.google.com/store/apps/details?id=com.sensingfuture.ptmeasures. [Accessed: 30-Apr-2017]. 


\begin{tabular}{|c|c|c|c|c|c|}
\hline & PT-Measures & $\begin{array}{l}\text { Indicators of } \\
\text { dependence }\end{array}$ & iGeriatrics & OncoScale & $\begin{array}{c}\text { Plus65 } \\
\text { Med }\end{array}$ \\
\hline Scales & $\begin{array}{l}\text { one scale } \\
\text { (mental) and five } \\
\text { (functional) area; } \\
\text { grouped by area }\end{array}$ & $\begin{array}{l}\text { eleven } \\
\text { (mental, } \\
\text { functional and } \\
\text { social); } \\
\text { grouped by }\end{array}$ & - & $\begin{array}{l}\text { mental, } \\
\text { functional and } \\
\text { nutritive } \\
\text { scales; grouped } \\
\text { by areas }\end{array}$ & - \\
\hline $\begin{array}{l}\text { Textual info } \\
\text { about scales }\end{array}$ & + & ++ & - & ++ & - \\
\hline $\begin{array}{l}\text { Patient } \\
\text { follow-up }\end{array}$ & - & - & - & - & - \\
\hline $\begin{array}{l}\text { Clinical } \\
\text { criteria }\end{array}$ & - & - & Beers & - & $\begin{array}{l}\text { Start and } \\
\text { Stopp }\end{array}$ \\
\hline Language & Portuguese & English & English & French & English \\
\hline $\begin{array}{l}\text { Scientific } \\
\text { promotor }\end{array}$ & sensingfuture & GrupoTrevenque & $\begin{array}{l}\text { American } \\
\text { Geriatrics } \\
\text { Society }\end{array}$ & $\begin{array}{l}\text { F. Hoffmann- } \\
\text { La Roche }\end{array}$ & - \\
\hline
\end{tabular}

Table 1 - overview of CGA mobile solutions and their functionalities

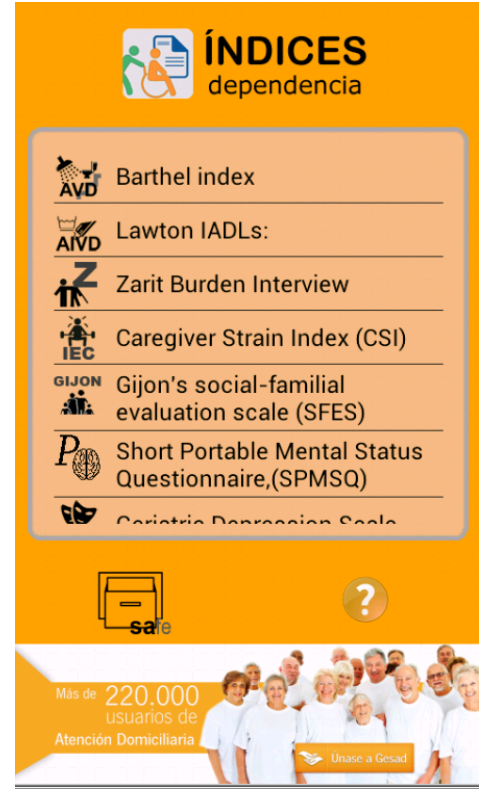

Figure 13 - Indicators of Dependence main screen

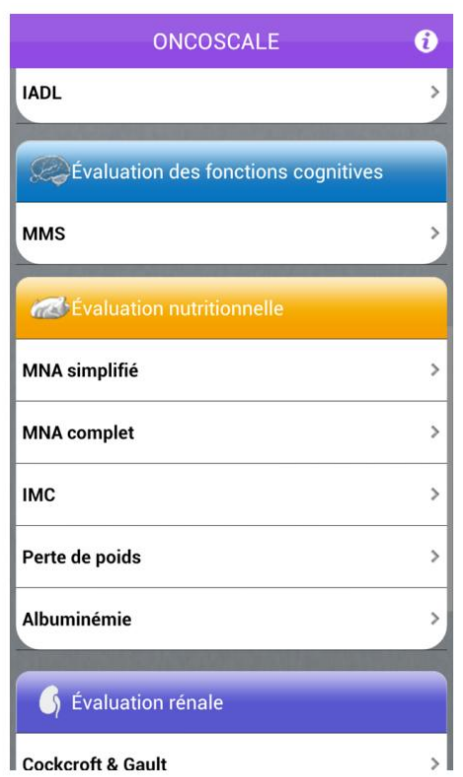

Figure 14-OncoScale screenshot depicting clinical scales grouped by CGA area 


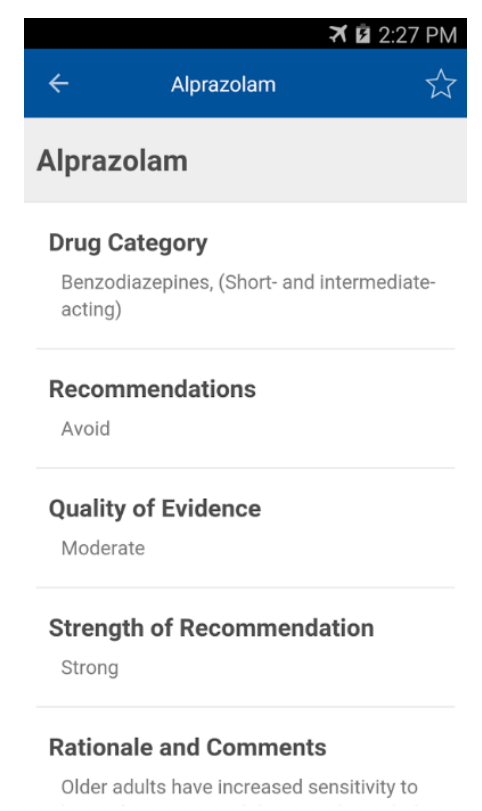

Figure 15 - iGeriatrics screenshot depicting Beers criteria for Alprazolam ${ }^{18}$

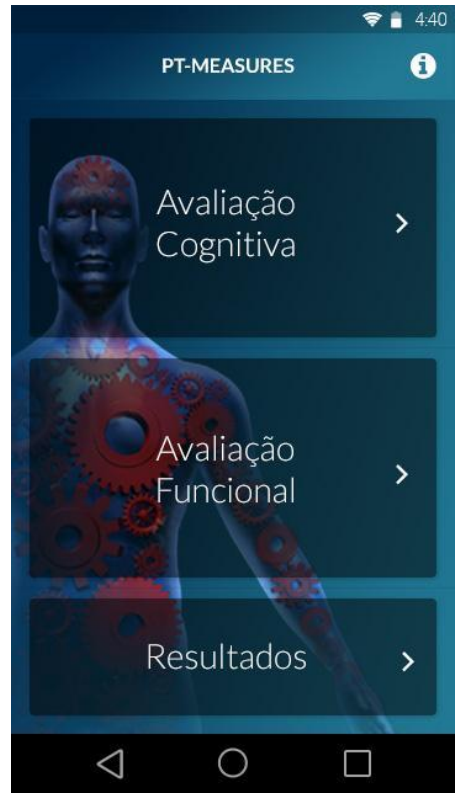

Figure 16 - PT-Measures screenshot ${ }^{19}$

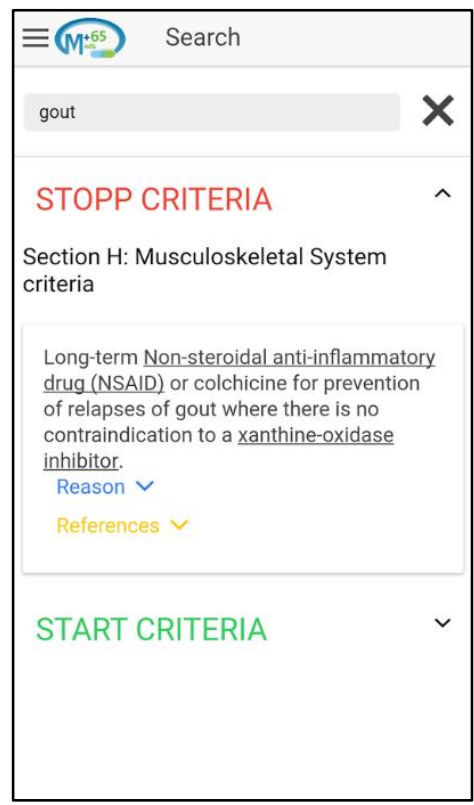

Figure 17 - Plus65 Med screenshot with Stopp Criteria for Musculoskeletal System ${ }^{20}$

18 "iGeriatrics - Android Apps on Google Play." [Online]. Available: https://play.google.com/store/apps/details?id=com.usbmis.reader.dwtf1. [Accessed: 30-Apr-2017].

19 "PT-Measures - Android Apps on Google Play." [Online]. Available: https://play.google.com/store/apps/details?id=com.sensingfuture.ptmeasures. [Accessed: 30-Apr-2017]. 20 "Plus65 Med - Android Apps on Google Play." [Online]. Available: https://play.google.com/store/apps/details?id=com.mam.plus65. [Accessed 23 Nov. 2017]. 


\section{3 - User-centred Design and Development}

When designing ICT solutions, part of the system is kept hidden and only accessed by system admins or other entities, while the user takes only knowledge of the visible part of the system, i.e., the system entries with interfaces available to the user. When designing for the end-user, one of the main goals is to reach a usable system which is pleasant and easy to use. User-Centred Design (UCD) [23] consists of designing a product around the end-user characterization and necessities.

This section provides a brief description of an iterative design and development method aligned with UCD and describes a set of methods that can be considered, in this context, for performing usability evaluations. It is not intended as a comprehensive overview of UCD methods, but the content deemed relevant to support and understand the work carried out.

\subsection{1 - Iterative User-Centred Design}

On interface design, the software design process can be iterative or incremental. In the former, one of the techniques is UCD, which is based on the end-user characterization, example workflows and requirements, with the objective of obtaining a final product with high usability standards. Figure 18 presents an example of an iterative UCD approach applied on a system.

For requirements elicitation, the first step is to define Personas and build scenarios for the context of interest. Personas provide examples of representative users for better capturing not only the roles, but also the motivations of users in using the technology in their daily activities. Personas include a description of demographic characteristics, competences, expectations, and other user profiling information, to humanize actors.

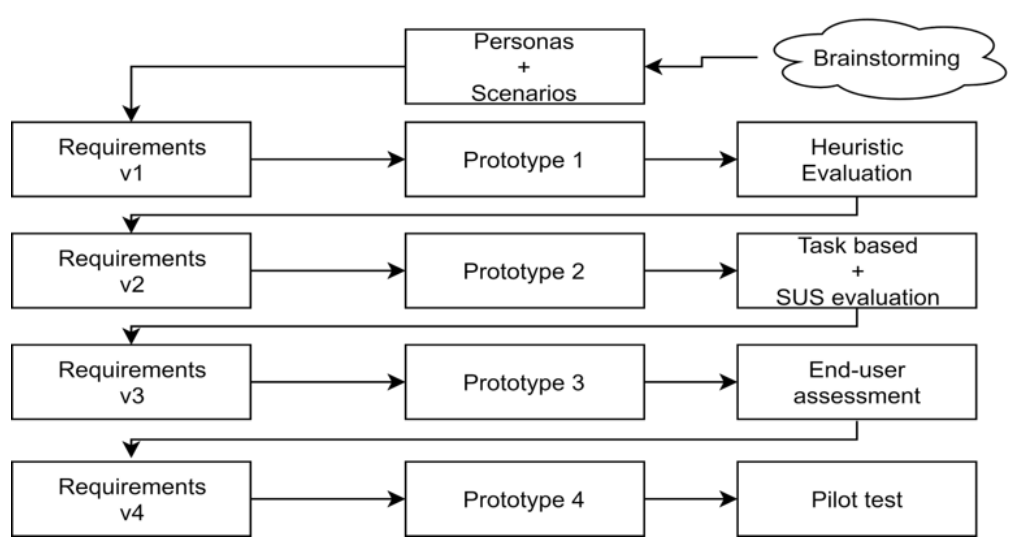

Figure 18 - example of the iterative design and development approach followed during this work, integrating User-Centered Design, and multiple cycles of requirement elicitation, prototype development and evaluation.

Being an iterative process, there are short prototyping cycles followed by an evaluation adjusted to the current stage of development. This evaluation can be, for instance, a heuristic evaluation, as well as a task based assessment. After this stage of assessment, new requirements are created, and a new prototype implemented, thus continuing the cycle. This iterative process meets an end when the user requirements are satisfied. 


\subsection{2 -Usability Evaluation}

Usability [24] is a quality attribute that assesses how easy user interfaces are to use. Ultimately, it is what defines if a software will succeed or not, if the users will continue to use it or abandon it. Usability is of the utmost importance when designing a mobile application, so it needs to be tested to assure its compliance. It is relevant to choose a usability evaluation method that suits the development stage and the type of feedback a developer needs.

This section provides a description of methods used for evaluating usability in mobile applications, some are more general while others have a special focus in mHealth apps.

\section{Nielsen heuristics}

Nielsen defined a set of ten heuristics for interaction design [25]. They are called heuristics since they are broad rules and not specific usability guidelines (see Table 2 for the Nielsen's heuristics list).

\begin{tabular}{|c|c|}
\hline 1. Visibility of system status & $\begin{array}{l}\text { The system should always keep users informed about what is going on, } \\
\text { through appropriate feedback within reasonable time }\end{array}$ \\
\hline $\begin{array}{l}\text { 2. Match between system and } \\
\text { the real world }\end{array}$ & $\begin{array}{l}\text { The system should speak the users' language, with words, phrases and } \\
\text { concepts familiar to the user, rather than system-oriented terms } \\
\text { Follow real-world conventions, making information appear in a natural } \\
\text { and logical order. }\end{array}$ \\
\hline 3. User control and freedom & $\begin{array}{l}\text { Users often choose system functions by mistake and will need a clearly } \\
\text { marked "emergency exit" to leave the unwanted state without having } \\
\text { to go through an extended dialogue }\end{array}$ \\
\hline 4. $\quad$ Consistency and standards & $\begin{array}{l}\text { Users should not have to wonder whether different words, situations, } \\
\text { or actions mean the same thing }\end{array}$ \\
\hline 5. Error prevention & $\begin{array}{l}\text { Even better than good error messages is a careful design which } \\
\text { prevents a problem from occurring in the first place. Either eliminate } \\
\text { error-prone conditions or check for them and present users with a } \\
\text { confirmation option before they commit to the action }\end{array}$ \\
\hline $\begin{array}{l}\text { 6. Recognition rather than } \\
\text { recall }\end{array}$ & $\begin{array}{l}\text { Minimize the user's memory load by making objects, actions, and } \\
\text { options visible. The user should not have to remember information } \\
\text { from one part of the dialogue to another }\end{array}$ \\
\hline $\begin{array}{l}\text { 7. Flexibility and efficiency of } \\
\text { use }\end{array}$ & $\begin{array}{l}\text { Accelerators -- unseen by the novice user -- may often speed up the } \\
\text { interaction for the expert user such that the system can cater to both } \\
\text { inexperienced and experienced users. Allow users to tailor frequent } \\
\text { actions. }\end{array}$ \\
\hline $\begin{array}{l}\text { 8. Aesthetic and minimalist } \\
\text { design }\end{array}$ & $\begin{array}{l}\text { Dialogues should not contain information which is irrelevant or rarely } \\
\text { needed. Every extra unit of information in a dialogue competes with } \\
\text { the relevant units of information and diminishes their relative visibility }\end{array}$ \\
\hline $\begin{array}{l}\text { 9. Help users recognize, } \\
\text { diagnose, and recover from } \\
\text { errors }\end{array}$ & $\begin{array}{l}\text { Error messages should be expressed in plain language (no codes), } \\
\text { precisely indicate the problem, and constructively suggest a solution. }\end{array}$ \\
\hline 10. Help and documentation & $\begin{array}{l}\text { Even though it is better if the system can be used without } \\
\text { documentation, it may be necessary to provide help and documentation. } \\
\text { Any such information should be easy to search, focused on the user's } \\
\text { task, list concrete steps to be carried out, and not be too large }\end{array}$ \\
\hline
\end{tabular}

Table 2 - Nielsen's heuristics for system usability [25] 
One of the disadvantages for this method is that it works best with usability experts since they have the required skills and train to correctly identify the heuristics. The results can also be prone to the evaluator personal view on usability.

\section{Health IT Usability Evaluation Model}

Health IT Usability Evaluation Model (Health-ITUEM) [26] was developed in response to the gaps in the existing usability models. It tries to identify new heuristics, focused on mHealth applications, that would allow to better assess the usability of this type of software (Table 3 ).

\begin{tabular}{|l|l|}
\hline Concept & Description \\
\hline Error prevention & $\begin{array}{l}\text { System offers error management, such as error messages as feedback, error } \\
\text { correction through undo function, or error prevention, such as instructions } \\
\text { or reminders, to assist users performing tasks }\end{array}$ \\
\hline Completeness & $\begin{array}{l}\text { System can assist users to successfully complete tasks. This is usually } \\
\text { measured objectively by system log files for completion rate. }\end{array}$ \\
\hline Memorability & Users can remember easily how to perform tasks through the system. \\
\hline Information needs & $\begin{array}{l}\text { The information content offered by the system for basic task performance, } \\
\text { or to improve task performance }\end{array}$ \\
\hline Flexibility/Customizability & $\begin{array}{l}\text { System provides more than one way to accomplish tasks, which allows users } \\
\text { to operate system as preferred }\end{array}$ \\
\hline Learnability & Users can easily learn how to operate the system \\
\hline Performance speed & Users can use the system efficiently \\
\hline Competency & Users are confident in their ability to perform tasks using the system \\
\hline Other outcomes & $\begin{array}{l}\text { Other system-specific expected outcomes representing higher level of } \\
\text { expectations. }\end{array}$ \\
\hline
\end{tabular}

\section{Table 3 - Health-ITUEM concepts}

For each concept, there is a plus or minus classification, in case the application applies the concept positively or negatively. To apply this test, the evaluator is asked some questions and the responses are coded into the categories.

Health-ITUEM contains concepts not included in Nielsen's heuristics, mainly Completeness, Information needs, Competency and Other outcomes.

\section{Think Aloud protocol}

In a think aloud test [27], the participants are asked to use the system while verbalizing their thoughts. Users are given a set of tasks or higher order goals to execute and their thoughts are recorded while they execute them. It is one of the easiest tests to apply and it is general enough to fit any stage in the development process. As downside, users sometimes filter what they say, fearing embarrassment, so the feedback should also be complemented with observer notes of detected difficulties and procedures.

This kind of test is easier for a tester to apply since the evaluator does not need a previous knowledge about any usability aspects, relevant for heuristic evaluation. 


\section{Heuristic Evaluation on Mobile Interfaces: A New Checklist}

A new set of mobile-specific heuristics and sub heuristics was proposed, having in mind mobile platforms and usability evaluations [28]. This set was heavily influenced by Nielsen's heuristics, which make up ten of the thirteen total heuristics. There was a proposed rearrange of the traditional heuristics, based in literature reviews, and from this rearranged set sub heuristics were compiled. These include heuristics from the literature (excluding the ones that did not fit well with mobile constraints) and the ones added by the authors which were related to mobile platforms (Table 4 ).

\begin{tabular}{|c|c|}
\hline Heuristic & Sample sub heuristics \\
\hline Skills & $\begin{array}{l}\text { - If system supports both novice and expert users, are multiple levels of error message } \\
\text { detail available? } \\
\text { - If the system supports both novice and expert users, are multiple levels of detail } \\
\text { available? } \\
\text { - Are users the initiators of actions rather than the responders? } \\
\text { - Do the selected input device(s) match user capabilities? } \\
\text { - Does the system correctly anticipate and prompt for the user's probable next activity? }\end{array}$ \\
\hline $\begin{array}{l}\text { Pleasurable } \\
\text { and } \\
\text { respectful } \\
\text { interaction }\end{array}$ & $\begin{array}{l}\text { - For data entry screens with many fields or in which source documents may be } \\
\text { incomplete, can users save a partially filled screen? } \\
\text { - } \quad \text { Do the selected input device(s) match environmental constraints? } \\
\text { - } \quad \text { Are typing requirements minimal for question and answer interfaces? } \\
\text { - Minimize the number of submissions (and clicks) that the user needs to go through } \\
\text { - } \quad \text { to input information on your site } \\
\text { - } \quad \text { get around typing } \\
\text { - } \quad \text { Skipping registration should be the default option } \\
\text { - When logging in must be done, have an option that allows the user to see the } \\
\text { password clearly }\end{array}$ \\
\hline Privacy & $\begin{array}{l}\text { - For multi user devices, avoid being permanently signed in on an application } \\
\text { - If the application does store credit card information, it should allow users to decide if } \\
\text { they want to remain logged in. Ideally, when the user opts to be kept logged in, he/she } \\
\text { should get a message informing of the possible risks } \\
\text { - Are protected areas completely inaccessible? } \\
\text { - Can protected or confidential areas be accessed with certain passwords? }\end{array}$ \\
\hline
\end{tabular}

Table 4- mobile-specific heuristics (with sample sub heuristics) 


\section{Post-Study System Usability Questionnaire}

The Post-Study System Usability Questionnaire (PSSUQ) [29] is a 19-item questionnaire (Table 5) that measures users' perceived satisfaction. The PSSUQ is highly reliable and is entirely free. All questions are positively worded, which may lead to acquiesce bias (people are more likely to agree with a statement than to disagree with it) [30], therefore, considering this issue, this method is often replaced by other questionnaires that mix positive and negative worded question such as the System Usability Scale.

\begin{tabular}{|ll|}
\hline 1. & Overall, I am satisfied with how easy it is to use this system \\
\hline 2. & It was simple to use this system \\
\hline 3. & I could effectively complete the tasks and scenarios using this system \\
\hline 4. & I was able to complete the tasks and scenarios quickly using this system \\
\hline 5. & I was able to efficiently complete the tasks and scenarios using this system \\
\hline 6. & I felt comfortable using this system \\
\hline 7. & It was easy to learn to use this system \\
\hline 8. & I believe I could become productive quickly using this system \\
\hline 9. & The system gave error messages that clearly told me how to fix problems \\
\hline 10. & Whenever I made a mistake using the system, I could recover easily and quickly \\
\hline 11. & The information (such as on-line help, on-screen messages, and other documentation) provided with \\
\hline this system was clear \\
\hline 13. & It was easy to find the information I needed \\
\hline 14. & The information was effective in helping me complete the tasks and scenarios \\
\hline 15. & The organization of information on the system screens was clear \\
\hline 16. & The interface of this system was pleasant \\
\hline 17. & I liked using the interface of this system \\
\hline 18. & This system has all the functions and capabilities I expect it to have \\
\hline 19. & Overall, I am satisfied with this system \\
\hline
\end{tabular}

Table 5 - questions made to participants during the PSSUQ

\section{System Usability Scale}

The System Usability Scale (SUS) [31] consists of a ten-item questionnaire (Table 6) with five response options, from Strongly agree to Strongly disagree, and was designed to measure the users perceived usability of a product or system. It allows to evaluate a wide range of products, from mobile apps to hardware. It can be applied on a small number of users with reliable results but, as drawback, the scoring system is not straightforward. 


\begin{tabular}{|ll|}
\hline 1. & I think that I would like to use this system frequently. \\
\hline 2. & I found the system unnecessarily complex. \\
\hline 3. & I thought the system was easy to use. \\
\hline 4. & I think that I would need the support of a technical person to be able to use this system. \\
\hline 5. & I found the various functions in this system were well integrated. \\
\hline 6. & I thought there was too much inconsistency in this system. \\
\hline 7. & I would imagine that most people would learn to use this system very quickly. \\
\hline 8. & I found the system very cumbersome to use. \\
\hline 9. & I felt very confident using the system. \\
\hline 10. & I needed to learn a lot of things before I could get going with this system. \\
\hline
\end{tabular}

Table 6 - questions made to participants during SUS evaluation

\section{4-Mobile applications development}

In what follows, we present an overview of native and hybrid mobile apps, stating the pros and cons of each approach to mobile apps development.

\subsection{1 - Native apps}

A native app is developed specifically for a mobile operating system (Table 7 contains an overview of pros and cons of native mobile development). Since the app is developed following the technical and user experience guidelines of the OS, it has a look and feel consistent with the majority of native apps for that operating system.

A critical advantage when developing natively is being able to easily access the built-in capabilities of a device (e.g., camera, GPS, accelerometer, Bluetooth, etc) [32]. When new technologies and APIs are developed for an OS, they are instantly available to the programmer, while when using hybrid development tools these tend to take longer to be available since ports needs to be created to access those functionalities.

\begin{tabular}{|c|c|}
\hline Pros & Cons \\
\hline $\begin{array}{l}\text { - Native apps can work with a device's built-in } \\
\text { features, often making them faster and easier to } \\
\text { use } \\
\text { - } \text { Better user experience overall } \\
\text { - When there is a platform update they get access } \\
\text { to it sooner than hybrid apps, which rely on } \\
\text { plugins to be developed to account for new } \\
\text { functionalities } \\
\text { - Native UI allows users to quickly learn the app }\end{array}$ & $\begin{array}{l}\text { - Native apps tend to be more expensive to } \\
\text { develop, maintain and update } \\
\text { Programmer must learn the programming } \\
\text { language specific to a certain platform, instead } \\
\text { of just having a single language for several } \\
\text { different platforms } \\
\text { - Approving an app on the app store can be } \\
\text { arduous and success is not guaranteed }\end{array}$ \\
\hline
\end{tabular}

Table 7 - pros and cons of native mobile development [32]

Vulnerabilities are present in any mobile platform. For example, an Android app might be storing sensitive data in an SQLite database and an attacker can access it by getting a shell on the device. The same attack may happen on an iOS application by logging into the device if it is jail broken [33]. Common attacks in native apps include insecure local data storage, weak SSL implementation, unintended data leaks, reverse engineering and code injection [34]. 
Apart from the platform specific security controls and guidelines, there are third party libraries which enforce security; as example, there is an SQL cipher library available for Android and iOS ${ }^{23}$ and a library for securing data stored in Shared Preferences ${ }^{24}$.

\subsection{2 - Hybrid apps}

A hybrid app is built using HTML5, JavaScript and related web technologies, wrapped in a native container which loads most of the information on the page as the user navigates through the application [32] (Table 8 contains an overview of pros and cons of hybrid mobile development). Native apps, on the contrary, download the base of their content when they are installed. One big disadvantage of this approach for mobile development is that, general rule, hybrid apps perform worse in terms of speed when compared to native apps [32].

Example platforms or frameworks for developing hybrid mobile apps are Xamarin ${ }^{25}$, Phonegap ${ }^{26}$, and Ionic ${ }^{27}$. Xamarin has the peculiarity of using $\mathrm{CH}$, a proprietary programming language from Microsoft, for building hybrid apps.

\begin{tabular}{|l|l|}
\hline \multicolumn{1}{|c|}{ Pros } & \multicolumn{1}{c|}{ Cons } \\
\hline - $\begin{array}{l}\text { Many developers prefer hybrid applications } \\
\text { over native applications because the } \\
\text { development process is very similar to that of } \\
\text { building a website }\end{array}$ & $\begin{array}{l}\text { Many developers make the mistake of simply } \\
\text { copying their web applications to mobile } \\
\text { without any kind of redesign; this can result in } \\
\text { many problems, such as non-optimized } \\
\text { components that are not made for mobile. }\end{array}$ \\
$\begin{array}{l}\text { Hybrid applications are typically multi- } \\
\text { platform and portable, with a single code base } \\
\text { for multiple devices and OSs }\end{array}$ & $\begin{array}{l}\text { Performance is usually slower because the app } \\
\text { is based on a WebView }\end{array}$ \\
$\begin{array}{l}\text { Faster speed of development } \\
\text { When there is a bug in the code, instead of } \\
\text { having to correct it using multiple } \\
\text { programming languages for several platforms, } \\
\text { the programmer has only to make a single } \\
\text { change }\end{array}$ & $\begin{array}{l}\text { APIs tend to take longer to be available since } \\
\text { ports or plugins needs to be created to access } \\
\text { them }\end{array}$ \\
\end{tabular}

Table 8 - pros and cons of hybrid mobile development [32]

Hybrid apps are not exempt to vulnerabilities. Since they rely on HTML5 and JavaScript, attacks that focus on these technologies may happen. One way to minimize incidence of attacks is to use a framework that contains built-in security controls. Common attacks in hybrid apps include JavaScript injection, weak SSL implementation and caching issues [35].

${ }^{23}$ https://github.com/sqlcipher/android-database-sqlcipher

${ }^{24}$ https://github.com/scottyab/secure-preferences

25 “Mobile App Development \&amp; App Creation Software - Xamarin." [Online]. Available: https://www.xamarin.com/.

26 “PhoneGap." [Online]. Available: http://phonegap.com/.

27 "Build Amazing Native Apps and Progressive Web Apps with Ionic Framework and Angular.” [Online]. Available: https://ionicframework.com/. 


\section{Chapter 3}

\section{3 - REQUIREMENTS FOR MOBILE-AIDED GERIATRIC ASSESSMENT}

The current chapter presents personas, workflows for the current and proposed CGA methods, use cases and non-functional requirements for the envisaged system.

\section{1 - Description of the users and their motivations}

Personas provide examples of representative users for better capturing the motivations of users when using a system.

The following sections present four personas that, considering the information gathered for the CGA context, depict the overall setting targeted by the work carried out in this dissertation. Even though our aim, at this stage, was not to include any feature for patients nor address, with detail, specific features for general practitioners, their personas have been included to enable a more complete understanding of the application scope. They cover two distinct kinds of physicians, with different experiences, working at an Hospital and a Healthcare Centre, and two older adults with different problems.

\section{Persona 1 - Internal Medicine Physician (Francisco)}

Francisco is a 30 years old Internal Medicine Physician who obtained his degree one and a half years ago. During the courses he took he never had specific education about geriatric patients and how to diagnose them regarding the CGA. The first contact he had with CGA happened about one year ago, when he started his work in Aveiro's Hospital. Besides his studies, he enjoys jogging at least twice a week and going to the movies with his girlfriend.

His patients usually are people with multiple pathologies that tend to display multiple geriatric syndromes and have autonomy problems in daily life activities, such as cleaning up their homes, doing laundry, using electronical equipment, and so forth. He starts seeing them when the patient begins to lose his/her abilities or presents symptoms of acute diseases.

Francisco is willing to replace the current standard procedure of assessing the geriatrics patients. He thinks that the current procedure, using paper and pen, is slow and a digital approach would be more useful, since it would be easier to store, recall and share information.

He believes that a system that allows to directly send the tests results to the medical information system and act as a tool to access up-to-date information on geriatric practice for physicians would speed up his work. During the first year exercising his professional activity he would be faced daily with the struggle of prescribing the correct drug to a patient, since there are additional criteria that establish the drugs or active components included in those drugs that should or should not be prescribed for patients in certain situations.

Motivation: Francisco would like to improve the way he performs CGA during his practice and be more certain that his prescriptions consider all the applicable criteria. 


\section{Persona 2 - General practitioner (Alberto)}

Alberto is a 55-year-old general practitioner that has been working in Aveiro Health Care Centre for the past ten years. He is a very patient and caring person and often does volunteering where he lives. For two years, he was associated to an NGO that distributed food for Asian countries with prevalent poverty rates. Besides his daily work, sometimes he reunites with his old college colleagues and does some jamsessions in a local pub, playing the bass and singing the main vocals.

Being a general practitioner, he has contact with the same patient many times throughout the years, developing a more personal relation with them. With an increasing elderly population, most his patients fit in that category, so he performs the CGA weekly. To view a patient's evolution, he must consult the previous paper records about the patient and that can be somewhat cumbersome. Sometimes he uses his tablet to store notes about his patients.

Motivation: Alberto would like to have an easier way to visually assess the patient evolution.

\section{Persona 3 - Geriatric Patient that goes to the hospital (Lurdes)}

Eighty-two-year-old Lurdes is the mother of one child and the grandmother of two. She lives together with her son, his wife and their two children, who are young adults and go to college. She used to live in her own home twenty-something years ago but when her son got married she moved in with her husband to their new home. She is a widower, her husband died one year ago from health complications related to smoking.

Two and a half years ago she had a cerebrovascular accident (CVA) which led to problems in locomotion and right-side dexterity, mainly loss of strength, coordination of movements and decrease in reflexes.

She uses to wake up around ten and have breakfast in bed, made by their grandsons when they are at home or by herself when she is alone. At about midday she starts to cook launch for everyone and is frequently in need of help for doing certain chores such as opening or closing jars, reaching cooking utensils on higher cabinets, etc. After lunch, she stays in the living room and watches some soap operas or other shows, eventually falling asleep after some time. Typically, her everyday life is very based in routine. Before the CVA, she used to make dresses in her free time but after that she had to stop.

Following the death of her husband and the health issues related to the CVA, very often she experiences some level of depression which can range from mild to severe. She has already taken some medication to help, but very frequently she finds herself questioning her daily life and feeling alone. She lacks the motivation to keep engaged in other activities that escape her routine.

Motivation: Lurdes would like to stop feeling down and depressed by overcoming the death of her husband. She would also like to have a more active role in her community and maybe start making dresses to later sell them. After having dealt with depression she will be able to have a more full and rich life experience in the last stage of her life. 


\section{Persona 4 - Gerontology Patient that goes to the health care centre (Martins)}

Martins is a 68 years old unwed man who recently retired from a law firm where we had been working for the past thirty years. He enjoys morning hikes, the movies, meeting with old friends from his college years and occasionally traveling abroad.

Recently he has been experiencing a certain discomfort in both his knees and has been taking hydrotherapy sessions to soothe some pain he may feel. Usually this does not affect him very much but, as his friends and his older brother told him, it is better to have those sessions before the problem gets more serious and he must undertake surgery. He has also been experiencing problems in taking his medication since he usually scrambles, usually resorting to another person to organize it for him.

He likes to consider himself a positive person, of course he had ups and downs in his life but that did not stop him from remaining focus in his job and delivering a quality service to the firm and their clients. Till now, he has only stopped completely for two months when ten years ago, he had a bike accident and fractured his left arm, having to wear a cast that felt somewhat uncomfortable.

Martins still thinks he has many things to try in life, and being retired does not mean that he should now stay at home and watch TV all day as some of his former colleagues at the law firm do.

Motivation: Martins would like to overcome the knee pain he feels and problems in taking his medication. He still wants to have new experiences in his life.

\section{2 - Workflows in geriatric assessment and monitoring}

The following sections presents a description of how the current CGA method is applied and scenarios that capture the intended workflows to be supported, based on typical actions performed by the personas.

\subsection{1 - Current practice for Comprehensive Geriatric Assessment}

During a typical day of work, a HCP sees multiple patients that fit in the geriatric category. Those appointments usually follow the same structure, having a protocol of scales that comprise CGA. The functional scales are always applied and, according to the patient, other tests are conducted. Due to time constraints, not all areas are evaluated in all the patients. These are done through a questionnaire to the patient using paper and pen that is later transposed to the informatics system. Sometimes the HCP has the need of taking notes about a patient for a follow-up appointment and uses his/her personal smartphone to do so, even though it is not the safest approach regarding medical data confidentiality.

\subsection{2 - Proposed practice for Comprehensive Geriatric Assessment}

\section{Physician Francisco uses the app for the first time}

The first time Francisco opens the app, he sees a welcome message which informs him about the key features of the app. He is informed the app currently has the standard features activated, and he can proceed to the settings menu to activate new functionalities.

Since he needs to consult medication-related criteria, which is not included in the default set of modules, he heads to the settings menu. He browses a list of the modules that can be activated and deactivated. He then proceeds to activate the Clinical Criteria module. 


\section{Martins attends his first appointment}

1. Martins checks-in for the first appointment

Physician Francisco starts his appointments around 9am every day. The first patient is Martins, it is the first time he goes to this kind of appointment and he does not know what to expect. Being his first appointment, Francisco needs to register this patient in the application.

2. Evaluate Martins' health status

Francisco informs Martins about the tests that will be performed, and since it is his first appointment the CGA comprises all assessments. Francisco starts the new evaluation session with the Lawton \& Brody Scale. He explains that the test is a simple questionnaire and there is nothing to be worried about.

Francisco reads aloud every question and for each one tries to match the patient's response. Every time there is a doubt from Martins' side, Francisco is pleased to answer it. The physician enters the given answers in the app. After finishing all the questions from that test set, they proceed to the next one.

Having completed the assessment protocol, Francisco checks the results in the overview section for the session, and concludes the only issue is that Martins has some difficulties deciding which medicine to take. Francisco informs Martins about the results.

Martins is expected to return after a couple of months to follow-up. Francisco chooses to save the assessment data in the app and associate it with Martins' record.

\section{Martins' second appointment}

1. Reassess Martins health condition

Today is Martins' second appointment with Francisco and his problems with daily life activities have been increasing since he needs help from another person when handling with money and personal finances. His knee pain has also gotten worse and after brief walking periods he starts feeling pain. As soon as the appointment starts, Martins informs Francisco of that.

\section{Re-evaluate Martins using the CGA}

To re-evaluate Martins, the physician decides it is best to run some tests, mainly the Lawton \& Brody, for evaluating daily life activities autonomy, and the Holden test, to see the difficulties a patient may have in locomotion. The results indicate that the patient has a mild dependency in daily life activities and should thus be accompanied by the physician. Francisco chooses to create a report of the session, to print and archive it in Martins' process.

\section{Lurdes' monthly appointment}

It is time for Lurdes' monthly appointment. Her son is usually the one who drives her to the hospital. When she feels worse, a physician/health technician goes to her house and re-evaluates her there, but since recently her health has stabilized, she manages to go to the hospital.

When the two arrive, they spend some time at the waiting room before being called by the nurse to Francisco's office. Lurdes has been evaluated by him sometimes in the last few months/years, so she already knows the standard procedures and routines while in his office.

To re-evaluate her, Francisco decides it is better to redo every test of the CGA. Lurdes does not oppose, so Francisco opens her patient profile in the app and creates a new evaluation for her.

1. Track Lurdes's health state evolution

Before starting the assessment, they have a brief chat where they talk about how she felt in the last month. The physician thinks that Lurdes has been sadder recently since this month marks the first anniversary of her husband's death. He then conducts the Yesavage test for tracking depression states in elderly patients. He checks her temporal evolution for the test and sees that the results have worsen since the last appointment, pointing to a and indicate a state of mild depression. He opts to prescribe some drugs. 


\section{Prescribing drugs for Lurdes}

The physician needs to be careful since Lourdes already takes medication for other health issues and the drug he is going to prescribe must not interfere, causing new health complications. Francisco consults the app and inserts the name of the medicine he has in mind. The app tells him that medicine should be avoided for a health issue Lourdes already has, so it must be avoided. Francisco searches another drug by using the Start criteria that inform which drugs are best for certain conditions.

\section{3 - System Requirements}

The current section makes a description of the use cases that make up the system and non-functional requirements.

\subsection{1 - Use cases description for an assessment assistant application}

The proposed application, named GeriatricHelper, will act as a pocket assistant to conducting the CGA. The target users are the physicians that need to apply the CGA. Figure 19 presents the use cases diagram, where use cases marked in white can be enabled or disabled by confirmation (more details on this point in section 5.3 - Security ). A brief description of each one can be found in Table 9.

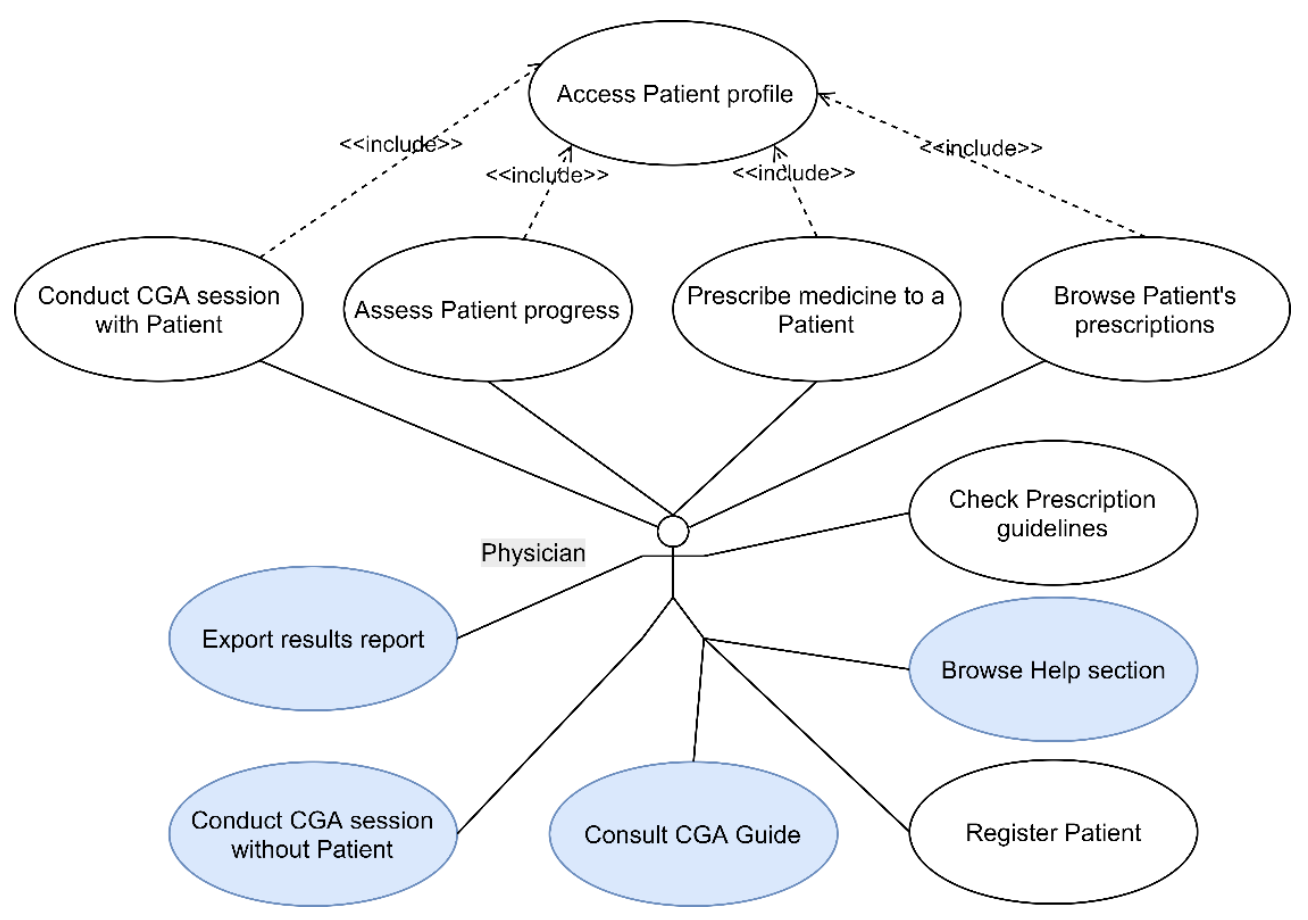

Figure 19 - GeriatricHelper use cases diagram 


\begin{tabular}{|l|l|}
\hline \multicolumn{1}{|c|}{ Use Case } & \multicolumn{1}{|c|}{ Description } \\
\hline Conduct CGA session with Patient & $\begin{array}{l}\text { Physician creates a new CGA session for a Patient that is already } \\
\text { registered in the system. }\end{array}$ \\
\hline Register patient & $\begin{array}{l}\text { Physician registers a new patient in the system } \\
\text { progress in the application's dashboard. }\end{array}$ \\
\hline Assess patient progress & Physician checks the guidelines regarding a certain drug. \\
\hline Check prescription guidelines & $\begin{array}{l}\text { Physician prescribes medicine for a Patient that is already } \\
\text { registered in the system. }\end{array}$ \\
\hline Prescribe medicine to a Patient & $\begin{array}{l}\text { Physician consults the CGA guide section, browsing information } \\
\text { about a certain scale. }\end{array}$ \\
\hline Consult CGA guide & $\begin{array}{l}\text { Physician generates a report containing the outcomes for a CGA } \\
\text { session. }\end{array}$ \\
\hline Export results report & $\begin{array}{l}\text { Physician checks the prescriptions currently associated with a } \\
\text { patient }\end{array}$ \\
\hline $\begin{array}{l}\text { Conduct CGA session without } \\
\text { Patient }\end{array}$ & \begin{tabular}{l} 
Physician creates a new evaluation without associating a Patient. \\
\hline Browse Help section
\end{tabular} \\
\hline
\end{tabular}

Table 9 - Use cases description

\section{Conduct CGA session}

A geriatric evaluation consists of a set of tests or scales that are filled up by a physician considering the patient's feedback and answer to such questions (Table 10 presents the CGA scales included in GeriatricHelper). The physician opens the test to be performed, asks the questions included in it and uses the app to record the answer. New evaluations created inside the app may or may not be added to a patient's profile. Certain scales include images which are show to the patient (Figure 20), these can be shown directly from a mobile device.

\begin{tabular}{|l|l|}
\hline \multicolumn{1}{|c|}{ CGA Area } & \multicolumn{1}{c|}{ Scales } \\
\hline \multirow{5}{*}{ Functional state } & Katz scale \\
\cline { 2 - 2 } & Lawton \& Brody scale \\
\cline { 2 - 2 } & Barthel Index (-) \\
\cline { 2 - 2 } & Tinetti (-) \\
\hline Affective state & Yesavage depression scale \\
\hline March & Functional Classification of March \\
\hline Cognitive state & Mini-Mental State Examination \\
\cline { 2 - 2 } & Clock-Drawing Test (-) \\
\cline { 2 - 2 } & Holden (-) \\
\hline Nutritional state & Nutritional assessment - screening \\
\cline { 2 - 2 } & Nutritional assessment - global evaluation \\
\hline Social State & Valoración Socio-Familiar (-) \\
\hline
\end{tabular}

Table 10 - CGA scales to be included in GeriatricHelper ${ }^{28}$

${ }^{28}$ Scales signalled with (-) were included during the development process but were disabled in the final prototype. 


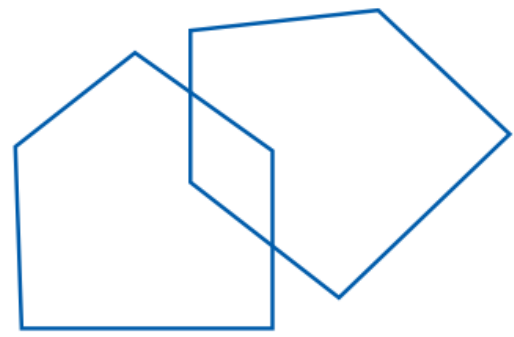

Figure 20 - image shown to the patient during the Mini-Mental State Examination [2]

It should be simple and straight-forward to add and remove scales to be included in the app. This management is to be made on the backend, with the mobile application fetching and updating the scales every time there is an updated version or a new scale.

\section{Register patient}

A physician may be consulting a patient for the first time. That patient must be added to the system, so the mobile application should provide that functionality. There should be a screen where the patient information is written down by the physician. The fields that characterize a patient are name, birthdate, gender, address, and process number. There is a personal area for each patient, in which the physician can see the results from previous appointments and prescriptions.

\section{Assess patient progress}

The physicians need to see how a patient is progressing along the time to take measures about how to treat the patient. One possibility is to present graphics and charts that make it easier to see how the patient progressed over time. These graphics will use the results from previous tests, both quantitative and qualitative.

\section{Check prescription guidelines}

There are situations in which a physician needs to prescribe a medicine for a patient and that patient may already be taking other medicine and/or suffer from more health issues. The Start, Stopp and Beers criteria aid the physician choosing the most well-fitted medicine for each situation, so they are accessible from inside the app. They can be consulted in the form of a list or by showing all the criteria associated to a given drug.

\section{Prescribe medicine to a patient}

The mobile application should store information about drugs or medicine prescribed to a patient. This will allow the physician to track and adjust a patient's medication on each new appointment.

\section{Consult CGA Guide}

Expertise level regarding CGA evaluation is different for each physician; while some may be familiar with the term and on how to conduct one, others may need some aid when conducting one. The app must have an area on which the CGA is presented, with explanations on how it is conducted, its objectives, etc. Each scale contains textual information relevant to the HCP which should be present (Figure 21).

\section{Export a session's result into a PDF file or send them via email}

Allow to create a PDF document with all the data associated to a CGA session; this PDF would then be printed or sent via email, and included in the patient's clinical record. 


\section{Mini-Mental State Examination (MMSE) de Folstein \\ Questionário que permite fazer uma avaliação sumária das funçōes cognitivas. \\ É constituído por várias questões, que avaliam a orientação, a memória imediata \\ e a recente, a capacidade de atenção e cálculo, a linguagem e a capacidade construtiva.}

A informação é obtida através do questionário directo ao idoso que pode ser aplicado por médicos, psicólogos, enfermeiros ou outros profissionais de saúde.

Figure 21 - Mini-Mental State Examination textual information [2]

\subsection{2 - Non-Functional requirements}

Non-functional requirements specify criteria that can be used to judge the operation of a system, rather than specific behaviours that are conveyed by functional requirements. Following is the list of nonfunctional requirements for GeriatricHelper:

\section{Design adapted for different screens}

As mentioned in the personas section, there are two types of physicians, internal medicine and general practitioners, which use smartphones and tablets. The application needs to be adapted to both types of displays. For example, when using a tablet, the screen size is much bigger, so more data items can be displayed at the same time, while in a smartphone the layout must be adapted to cope with a smaller display.

\section{Patients data must remain confidential}

When dealing with medical data, confidentiality is of paramount importance; only the physician that created a patient record may access it.

\section{Support multiple languages, mainly Portuguese, English and Spanish}

It should be possible to easily adapt this mobile application to different countries. To do so, contents must be presented in different languages; this translation should be managed in the backend, so for each new update a new app version would not need to be launched.

\section{Strong focus on tutorial contents}

GeriatricHelper acts as a pocket guide on how to conduct a CGA assessment; therefore, physicians must feel confident using the app. Several apps employ a guided initial tour, and almost everyone provides a help menu with most frequent help topics explained into detail, which present common strategies to aid the user.

\section{Work offline}

Internet access may not be available in certain healthcare facilities, so an application that relies on internet access to work would not be usable. Information about scales and clinical criteria is to be saved directly on the device and updated only when needed, and local changes to the database are replicated on the remote database when network is available.

\section{Device availability}

It is important to support the Android and iOS platform. The iOS version, not being the main platform for this system, should be considered as well, with the objective of developing a simplified version of the Android version, containing only the main functionalities needed to conduct a CGA evaluation. 


\section{4 - DEVELOPMENT OF GERIATRICHELPER}

The development of GeriatricHelper was based in UCD, in a sequence of prototypes.

This chapter is divided into four parts, each corresponding to one iteration of the application prototype (Table 11). The main purpose is to put into evidence the different stages of the work carried out, the methods considered at each stage, and their value for the outcome. When referring to a prototype version, the notation used is PX, where $\mathrm{X}$ is the prototype number.

\begin{tabular}{|c|c|c|c|}
\hline Prototypes & Focus & $\begin{array}{l}\text { Evaluation } \\
\text { strategy }\end{array}$ & Tool \\
\hline $\mathrm{P} 1$ & $\begin{array}{l}\text { Initial version of the application, minimal viable } \\
\text { product, general usability guidelines assessment }\end{array}$ & Heuristics & $\begin{array}{l}\text { Nielsen } \\
\text { heuristics, } \\
\text { concepts from } \\
\text { other sets }\end{array}$ \\
\hline $\mathrm{P}_{2}$ & $\begin{array}{l}\text { Correct P1 issues, add more functionalities (like } \\
\text { improvements to patients and sessions } \\
\text { management), thinking aloud assessment based on } \\
\text { the achievement of goals }\end{array}$ & Think aloud & $\begin{array}{l}\text { Accomplishment } \\
\text { of tasks }\end{array}$ \\
\hline $\mathrm{P} 3$ & $\begin{array}{l}\text { Further develop the concept of patients and session } \\
\text { management, explore multiple workflows for the } \\
\text { same action, improve the CGA guide; assessment } \\
\text { by geriatric physicians, to reach a functional } \\
\text { validation of the app }\end{array}$ & $\begin{array}{l}\text { Assessment } \\
\text { with end- } \\
\text { users }\end{array}$ & $\begin{array}{l}\text { Free interaction } \\
\text { with the } \\
\text { application }\end{array}$ \\
\hline $\mathrm{P} 4$ & $\begin{array}{l}\text { Meet particular details identified by the end-users } \\
\text { in P3 assessment, development of the iOS version }\end{array}$ & Pilot test & $\begin{array}{l}\text { Accomplishment } \\
\text { of tasks, pilot } \\
\text { stage, and SUS }\end{array}$ \\
\hline
\end{tabular}

Table 11 - GeriatricHelper prototypes. their focus, evaluation strategy and assessment tool

\section{1 - First Prototype}

This section presents the details for the first prototype of GeriatricHelper and its assessment.

\subsection{1 - Setting the context}

At the beginning of the dissertation we had to choose on which platform to develop, either native or hybrid. After some research regarding the functionalities of the latter we concluded that this type of approach has major disadvantages, mainly not allowing for finely tuning certain aspects of the app, such as complex security measures and sending information to an external server or backend. There is also lack of documentation regarding security, they are dependent on the success of the mobile frameworks and new hardware capabilities take longer time to be adapted to the framework. 
Thus, we chose to develop this mobile application using a native mobile development approach. As for the platform itself, the options were targeting Android or iOS. Since we had more programming experience with the Android ecosystem, which is more open than the iOS counterpart, and the process of creating and distributing an Android application comprises less costs than on the iOS counterpart, we chose this platform.

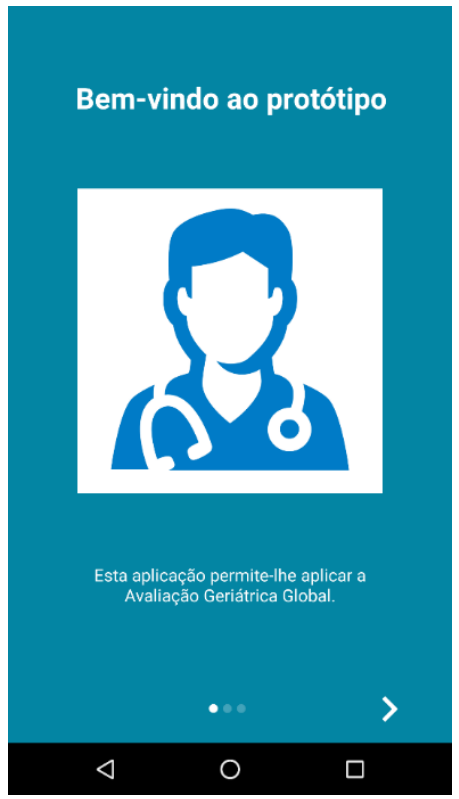

Figure 22 - Welcome screen (smartphone)

The first prototype was created based on the first version of the system requirements (Figure 22 presents the welcome screen): it supported conducting CGA evaluations, creating and managing patients, tracking the patient's progress in a graphical way, and it included general help topics about CGA and means to browse clinical criteria (Start/Stopp and Beers). The first stage of evaluation was not focused on the functionalities themselves, but general usability issues that could arise; evaluations based on functionality were made in further stages of the development, when the app was to be tested with end-users. This evaluation was meant to detect high-level usability issues concerning the app.

The objective of conducting an evaluation by users external to the project team was to learn how a user reacted to the app without having previously used it. Another objective was to expose the issues concerning general usability guidelines, focusing on platform and context specific methods in later stages of the usability evaluation process.

The users that participated in the evaluation were students from the master's degree in Computer and Telematics Engineering from the University of Aveiro. They were chosen because they had already attended a course in which they studied and applied Nielsen's heuristics to evaluate an interface and it was easy to motivate them to collaborate in a peer's work.

\subsection{2 - Methodology for usability evaluation}

The method to assess this first prototype was heuristic evaluation. The advantage of heuristics is that they can be evaluated by people other than the end-users.

The main goal in selecting the heuristics was to reach a sufficiently rich set that would cover most relevant aspects of the application while not burdening the participant with too many heuristics to consider. Therefore, only the set of Nielsen's heuristics [25] was considered in full complemented with some extra key points covered by heuristics extracted from different sets. In this line of thought, we also considered the Competency concept from Health-ITUEM [36] and "Pleasurable and respectful interaction" and "Privacy" heuristics from the heuristics proposed for mobile interfaces [28].

The evaluation consisted of a brief introduction to the app's purpose and what it could achieve, as well as the ten usability heuristics for user interface design defined by Nielsen, with the extra explanation about the other topics we deemed important. The evaluator would then have an entire day to handle the app. After having interacted with it, $\mathrm{s} / \mathrm{he}$ would fill out a questionnaire to indicate the violations made to each of the heuristics.

\subsection{3 - Usability evaluation results}

According to Nielsen [37], five is the number of testers needed to identify the majority of usability issues; thus, the prototype was assessed by five users, three tested the smartphone version and the other two tested the tablet version. 
The results for those tests are presented in two tables, one for each platform (Table 12 and Table 13). The violation severity rating used is as defined by Nielsen [38], ranging between 0 ("I don't agree that this is a usability problem at all”) and 4 ("Usability catastrophe: imperative to fix this before product can be released.").

\begin{tabular}{|c|c|c|}
\hline Heuristic & Heuristic Violation & $\begin{array}{l}\text { Violation } \\
\text { Severity }\end{array}$ \\
\hline \multirow{3}{*}{$\begin{array}{l}\text { Visibility of system } \\
\text { status }\end{array}$} & No feedback when Session is discarded & 2 \\
\hline & No indicator if user is already logged in & 3 \\
\hline & Not every scale appears in scales list & 3 \\
\hline $\begin{array}{l}\text { User control and } \\
\text { freedom }\end{array}$ & $\begin{array}{l}\text { There is no support for undo/redo when session } \\
\text { is cancelled }\end{array}$ & 2 \\
\hline \multirow[t]{2}{*}{$\begin{array}{l}\text { Recognition rather } \\
\text { than recall }\end{array}$} & $\begin{array}{l}\text { Meaning of } \mathrm{QE} \text { and } \mathrm{SR} \text { is not mentioned } \\
\text { (context of Prescription) - Figure } 24\end{array}$ & 2 \\
\hline & $\begin{array}{l}\text { The first time creating a session user did not } \\
\text { know if all the tests were to be filled or not }\end{array}$ & 3 \\
\hline \multirow{4}{*}{$\begin{array}{l}\text { Aesthetic and } \\
\text { minimalist design }\end{array}$} & Text is chopped up & 3 \\
\hline & $\begin{array}{l}\text { Texts in Prescription section are not organized } \\
\text { properly }\end{array}$ & 2 \\
\hline & $\begin{array}{l}\text { Help text refers wrong name of criteria (Start } \\
\text { instead of Beers/Stopp) }\end{array}$ & 2 \\
\hline & $\begin{array}{l}\text { Too much textual information (e.g. information } \\
\text { about some scales and screen from where CGA } \\
\text { session is started - Figure } 23 \text { ) }\end{array}$ & 2 \\
\hline $\begin{array}{l}\text { Consistency and } \\
\text { standards }\end{array}$ & $\begin{array}{l}\text { "Discard" and "Cancel" are used for the same } \\
\text { action }\end{array}$ & 2 \\
\hline \multirow[t]{2}{*}{ Error prevention } & $\begin{array}{l}\text { Clicking on an already selected item in the } \\
\text { navigation drawer should not reload the current } \\
\text { fragment (this may lead to loss of info/having to } \\
\text { retype info) }\end{array}$ & o \\
\hline & Menu items do not work & 3 \\
\hline $\begin{array}{l}\text { Help and } \\
\text { documentation }\end{array}$ & $\begin{array}{l}\text { There should be documentation about a sample } \\
\text { workflow for using the app }\end{array}$ & 3 \\
\hline
\end{tabular}

Table 12 - Smartphone results for P1's usability evaluation grouped by Nielsen's heuristics 


\begin{tabular}{|c|c|c|}
\hline Heuristic & Heuristic Violation & $\begin{array}{l}\text { Violation } \\
\text { Severity }\end{array}$ \\
\hline \multirow[t]{2}{*}{$\begin{array}{l}\text { Visibility of system } \\
\text { status }\end{array}$} & $\begin{array}{l}\text { It is unclear if the user is on the private/public } \\
\text { area, only indicator is Log in or Log out buttons }\end{array}$ & 3 \\
\hline & $\begin{array}{l}\text { When reviewing a session, the title shows the } \\
\text { full date, could be better contextualized }\end{array}$ & 2 \\
\hline \multirow[t]{2}{*}{$\begin{array}{l}\text { Consistency and } \\
\text { standards }\end{array}$} & $\begin{array}{l}\text { "Evaluation" and "Session" mention the same } \\
\text { concept }\end{array}$ & 3 \\
\hline & Button icon is not always the same & 2 \\
\hline \multirow[t]{4}{*}{$\begin{array}{l}\text { Aesthetic and } \\
\text { minimalist design }\end{array}$} & $\begin{array}{l}\text { Favourite icon appears in front of the list of } \\
\text { patient's sessions }\end{array}$ & 3 \\
\hline & $\begin{array}{l}\text { Black icons in blue background, which are } \\
\text { sometimes difficult to see - Figure } 26\end{array}$ & 3 \\
\hline & Text sometimes too small & 3 \\
\hline & Too much text - Figure 25 & 3 \\
\hline $\begin{array}{l}\text { Help and } \\
\text { documentation }\end{array}$ & Documentation could be more self-explanatory & 2 \\
\hline
\end{tabular}

Table 13 - Tablet results for P1's usability evaluation grouped by Nielsen's heuristics

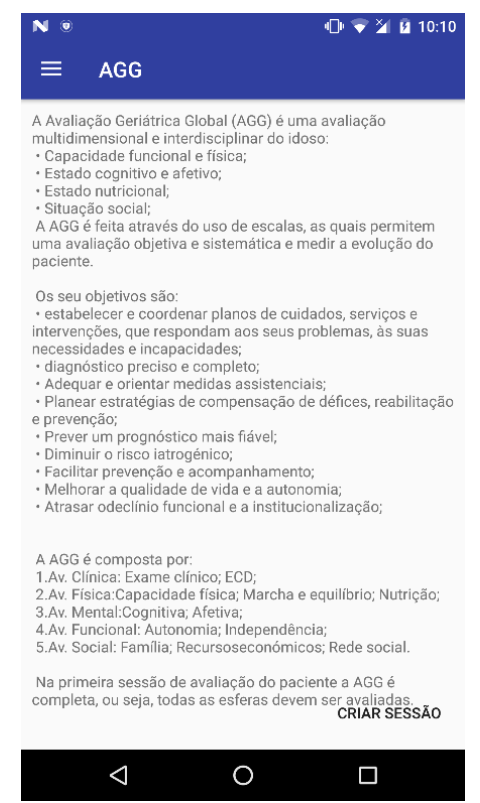

Figure 23 - Screenshot of the app's initial screen where too much text is displayed (smartphone)

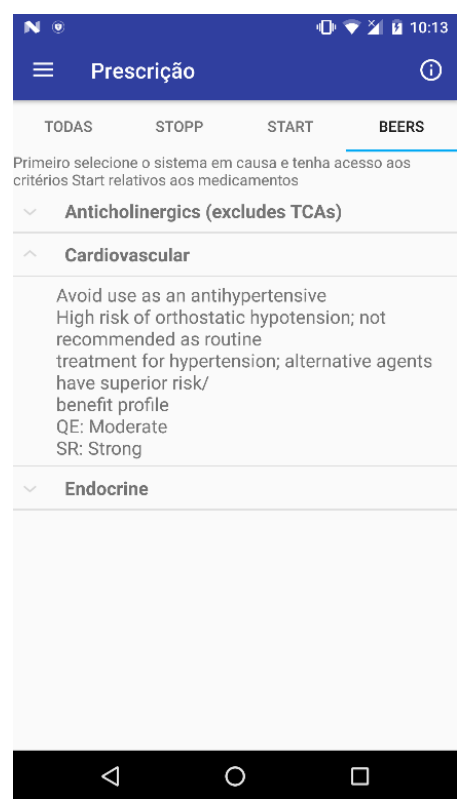

Figure 24 - Screenshot of Beers criteria, where the concepts of $Q E$ and $S R$ are not explained to the user (smartphone) 


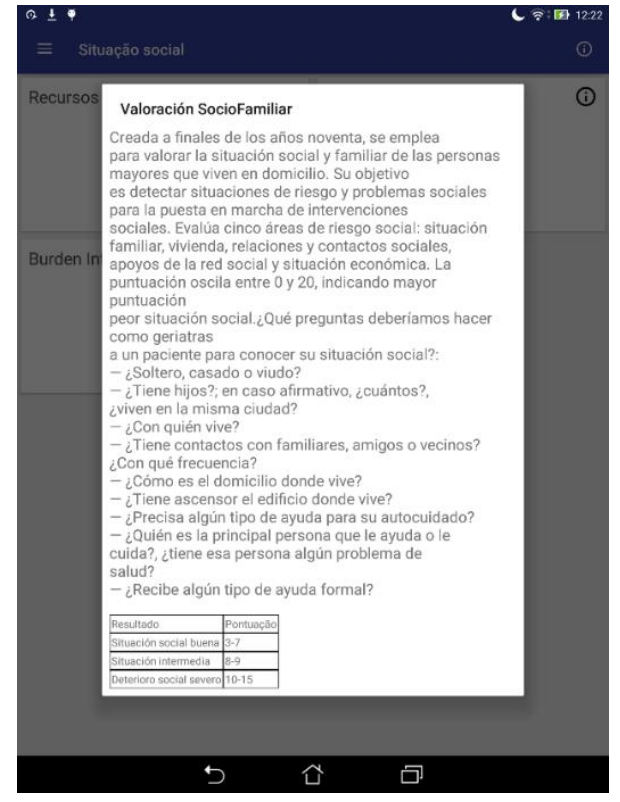

Figure 25 - Screenshot of a popup with scale's information where too much text is present (tablet)

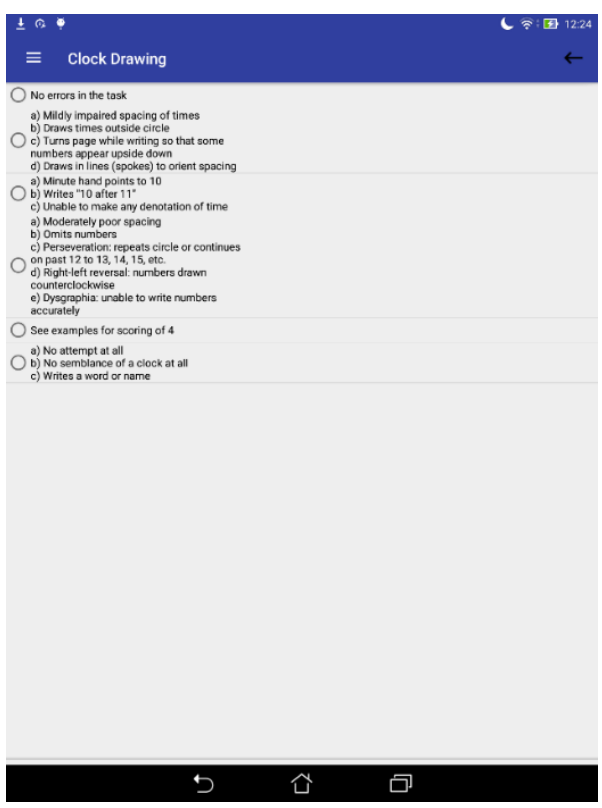

Figure 26 - Screenshot of the Clock Drawing scale where the black back arrow is shown in a blue background (tablet)

Besides the heuristic evaluation, the users could comment on other aspects of the app that did not fit into a heuristic but deemed necessary for the improvement of the app's usability (Table 14).

\begin{tabular}{|c|c|}
\hline Platform & Comments \\
\hline Smartphone & $\begin{array}{l}\text { - "Images are too big, take too long to load, should be scaled down" } \\
\text { - "Signal already filled in categories, otherwise I do not know which ones I have } \\
\text { already filled in" } \\
\text { - "When filling up a big questionnaire, going back and resuming it the user's } \\
\text { - "Interactive area of button does not occupy all of its area" }\end{array}$ \\
\hline Tablet & "When changing screen orientation, the current page is lost" \\
\hline
\end{tabular}

Table 14 - comments made by testers during P1's assessment

\subsection{4 - Discussion}

Most of the usability problems would not make it completely impossible to use the application. The heuristic category that had more flaws was Aesthetic and minimalist design, in both versions of the app. Regarding the comments made by the testers, the most serious concerned the tablet version, when the screen orientation changes and the current page is lost (an implementation flaw)

When comparing the results obtained using the two versions of the app, we can see that several problems are common to both versions, such as the user not knowing if he/she is already logged in and too much textual information, while there are issues that only occur in one of the versions, mainly the text being too small on the tablet. 


\section{2 - Second Prototype}

This section presents the details for the second prototype of GeriatricHelper and its assessment.

\subsection{1 - New development iteration}

After analysing the results from the first evaluation and considering the severity of each reported violation, the priority was to solve as many problems as possible, within a reasonable time frame, starting from the more severe. Every issue identified in the assessment of P1 was solved. Some users commented that the orientation change in the screen could induce errors, so we chose to lock the screen orientation, avoiding this issue.

Besides the users' feedback, there was a discussion with the physician collaborating in this work, regarding the clinical evaluation, mainly with respect to the information to be saved, and which scales to include (some of them may not be used in Portugal). The changes based on the physician's feedback are presented in Table 15.

Although it is not a usability problem per se, some texts in the app regarding the help menus for the scales and their questionnaires were in Portuguese, Spanish and English, depending on their origin. Simple translation to Portuguese would not solve the problem since clinical validation of the scales is required. The solution would be to check if there were versions of those scales validated for the Portuguese language, which can be done in a future iteration since the physicians are still capable of understanding the scales although they are not in Portuguese. This same idea applies to the prescription criteria, available in English.

Besides making changes to the application based on the usability tests and the physician feedback, we also added new functionalities, such as signing up (Figure 29), and made some corrections that we thought would increase the overall usability or made sense in the context of the app; some of the changes also resulted from internal feedback from the teachers that were helping in this dissertation (Table 16), such as adding textual notes to a patient (Figure 27) and creating a tab for displaying the last patients ordered by day (Figure 28).

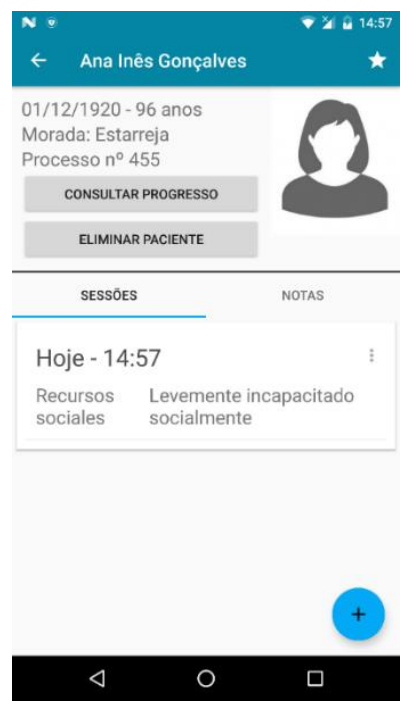

Figure 27 - patient's profile

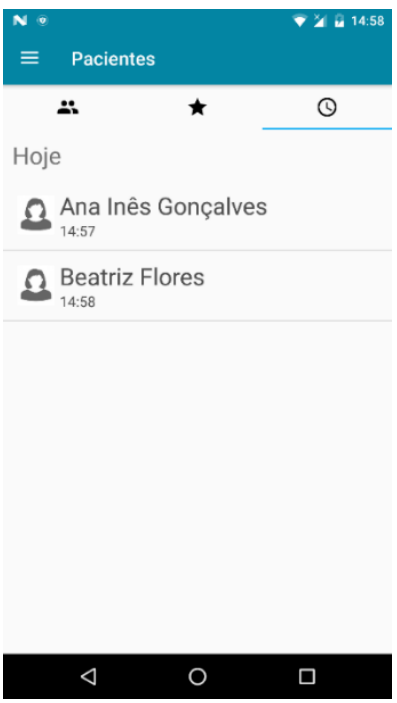

Figure 28 - patients list

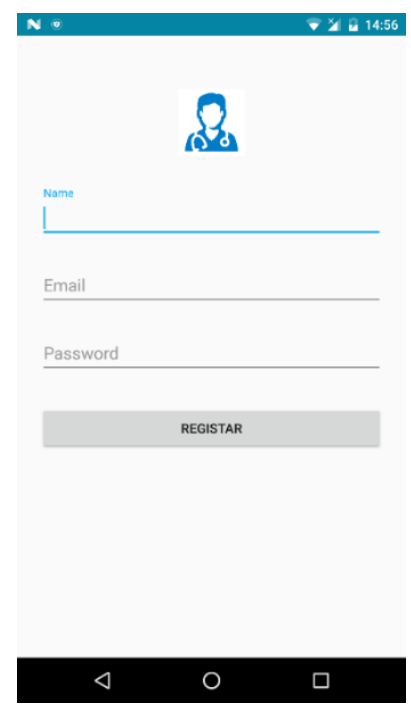

Figure 29 - sign up screen 


\begin{tabular}{|l|}
\hline Changes proposed by physician \\
\hline $\begin{array}{l}\text { Remove the Short Portable Mental Status, Set Test, Hamilton Depression Scale and Burden Interview, } \\
\text { the first does not add anything new to the other scales, the second is more applied by neurophysiologists, } \\
\text { so is out of scope for this app, and the last ones are not used in Portugal }\end{array}$ \\
\hline Add Tinetti scale since it was validated in Portugal in 2001 \\
\hline Scales are divided in four spheres instead of the five in which they were organized \\
\hline $\begin{array}{l}\text { The clinical evaluation is to be included in the app but on another iteration, since it is not part of the CGA, } \\
\text { although there is some recommendation about aspects to consider when applying it to geriatric patients }\end{array}$ \\
\hline Add patient record number to patient and age is displayed in patient's profile \\
\hline
\end{tabular}

\section{Table 15 - Changes made in P2 based on physician's feedback}

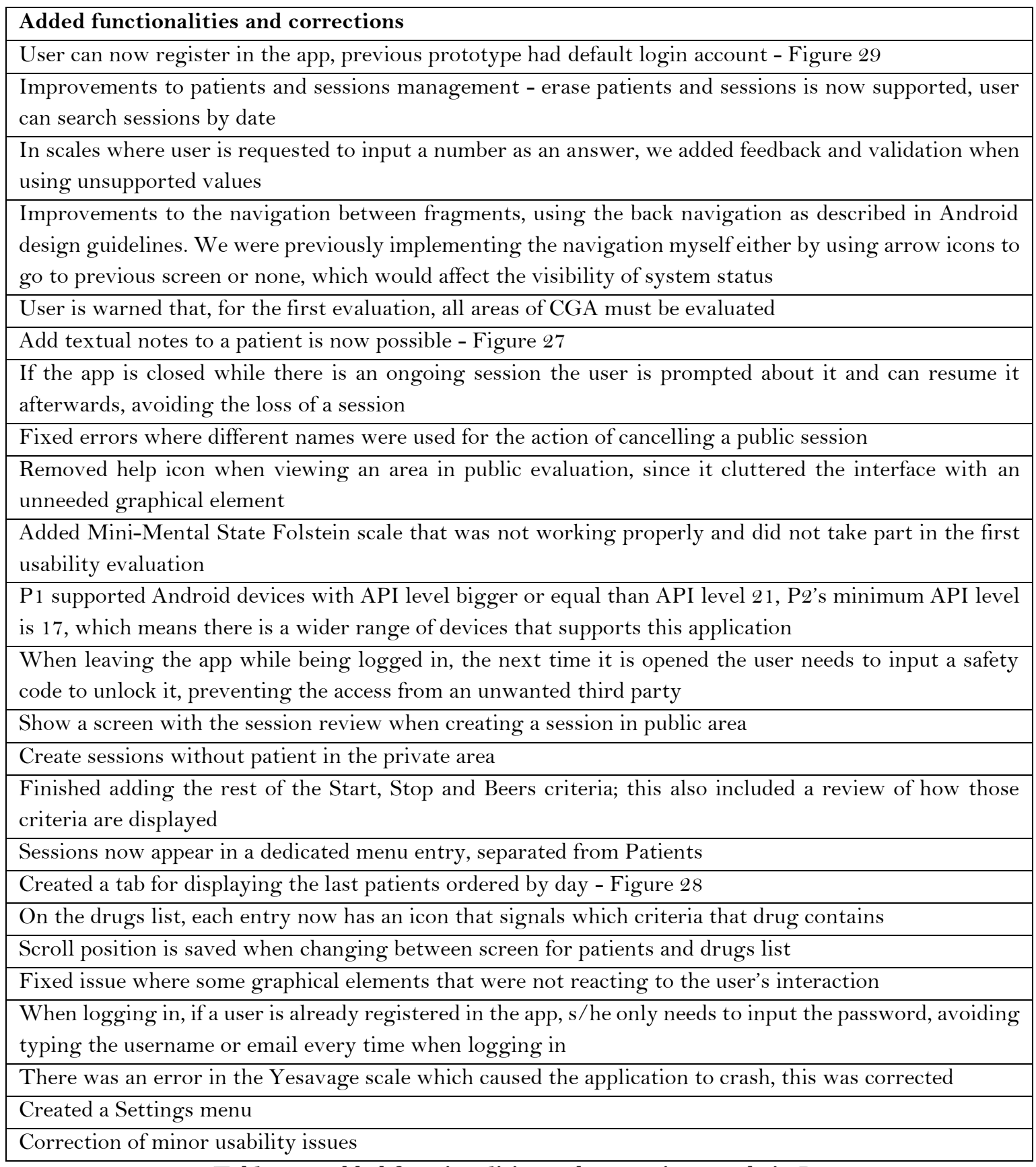

Table 16 - added functionalities and corrections made in P2 


\subsection{2 - Updated requirements}

The feedback obtained from usability tests and the exploratory use by domain experts of $\mathrm{P} 2$ allowed us to define a new set of requirements:

\section{Personal area}

The application must have two areas, one of public domain and the other one, more secure, that can only be accessed through logging credentials and registering in the application.

\section{Patients and CGA sessions management}

A physician may be consulting a patient for the first time. That patient must be added to the system, so the mobile application should provide that functionality. There should be a screen where the patient's info is written down by the physician. The fields that characterize a patient to be used when creating the new profile are Full name, Date of birth, Gender, Address and patient record number.

Any patient profile may be erased. The same applies for the sessions, which can be created, reviewed and deleted. A session can be resumed in case the application is closed.

\section{View a patient's profile}

There is a personal area for each patient, in which the physician can see the results from previous appointments, erase the patient, add the patient to the favourites and consult the progress for each scale.

\section{Design adapted for both smartphones and tablets}

As mentioned in the personas section, we have two types of physicians, internal medicine and general practitioners, which use smartphones and tablets. The application needs to be adapted to both types of displays. For example, when using a tablet, the screen size is much bigger, so more data items can be displayed at the same, while in a smartphone the display must be adapted to cope with smaller amounts of data.

\section{Must allow to track the patient's progress}

The physicians need to see how a patient is progressing along the time to adjust therapeutics. The progress is presented in a graph, making it easier to see how values evolved over time. These graphics will use the results from previous tests, both quantitative and qualitative. From the graph, it should be possible to access each individual session.

\section{Create new evaluations}

A geriatric evaluation consists of a set of tests that is filled up by a physician considering the patient's feedback and answer to such questions. The physician opens the test to be performed, asks the questions included in it and uses the app to record the answer.

New evaluations created inside the app may or may not be added to a patient's profile. A new evaluation session can be created straight from the patient's profile, from the favourites list if is marked as favourite and from the sessions list; for the last case, the session can be created with or without a patient (patient can be created at the end of start of session).

\section{Act as a guide for choosing the best medicine for a given patient}

There are situations in which a physician must prescribe a medicine for a patient and that patient may already be taking other medicine and/or suffer from more health issues. The Start, Stopp and Beers criteria aid the physician choosing the most well-fitted medicine for each situation, so they are accessible from inside the app. They can be consulted in the form of a list or by showing all the criteria associated to a given drug. 


\section{Patients data must remain confidential}

Data confidentiality is assured by PIN or password mechanism for logging in, having to re-enter the pin after leaving the app for some time and app being idle for some minutes and ciphering contents in database

\section{Store information relative to patients and evaluations}

The mobile application stores information about the patients and their evaluations, i.e., everything a physician will need to assist him when tracking a patient's progress.

\section{Act as a guide on how to conduct a CGA evaluation}

There must be an area dedicated to explaining how a CGA evaluation is to be conducted; it acts as a pocket guide, displaying the CGA areas, scales and allowing to see the content of each scale.

\subsection{3 - Methodology for usability evaluation}

After the implementation of the set of functionalities described, a new moment of usability evaluation took place. The mobile application should be self-explanatory, i.e., should allow a user to handle it without any questions regarding how to achieve a goal. Two possible methods for conducting a task-based evaluation are the definition of unitary tasks that the evaluator should conduct and the other one is giving a goal to the user, which is divided into multiple tasks, without disclosing which tasks are involved so the evaluator must select the tasks needed to achieve the goal. The latter is more useful since we can conclude if the application is self-explanatory and the user can achieve a complex goal composed of multiple tasks without being told beforehand how to proceed.

This new evaluation aimed to detect additional usability issues that the heuristic evaluation might not have detected. At this stage, since it was the first evaluation of this kind, we chose to consider a general audience that still did not include medical doctors. The main purpose was that when the application reached MDs, their expertise and time would be used for domain specific issues.

The eleven evaluators were chosen among colleagues with knowledge of Human Computer Interaction (HCI) and/or mobile applications development, with ages ranging from 23-42. They were chosen since they had experience in usability evaluations and analysing/developing mobile applications, which would make them suitable to identify usability problems on the application (Figure 30 characterizes the testers according to their college degree).

Think aloud [27] was the chosen evaluation method, since it is based in tasks and goals. At the start of the evaluation we made a brief introduction to the application. This time the evaluators had a set of goals they had to perform. Besides this method, there was also a questionnaire regarding the perceived usability of the application. Popular questionnaires include Software Usability Measurement Inventory (SUMI), PostStudy System Usability Questionnaire (PSSUQ), and the System Usability Scale (SUS). The first one requires purchasing a license, so it was crossed out from the start.

The SUS method was chosen since, contrary to PSSUQ, avoids the "acquiesce bias", and is widely used for usability questionnaires. The original version is in English, but there is already a proposed translation to Portuguese which was used [39].

This section provides a definition of high level goals (Table 17). Goals consist of activities which the user should perform based in the workflows and the three main sections of the app, Evaluations, Drug Prescription and Patients. Each goal has a maximum duration, when a participant exceeds that time the goals are not reached.

In the beginning of the evaluation the users received a brief introduction to the purposes of the study and were informed that they could leave the evaluation at any time. Afterwards, they were informed about the main purposes and features of the application and received a list of goals where they could also grade the difficulty felt when trying to achieve them using a Likert-like scale (Annex 2). In case there was any doubt 
regarding what each goal envisaged, all questions could be answered before proceeding. Participants were free to comment on any aspect of the app.

An observer was present during the complete evaluation session and registered the time taken to achieve each goal and any other aspect considered relevant. After performing all the tasks, the participant filled up the Portuguese version for the SUS (Annex 2), concluding the evaluation.

1 - Create a new CGA session, fill out two scales from the Functional State area with random values and finish session

2 - Register as user in the application

3 - Create a new patient called Manuel (use random values in for other fields)

4 - Create new session without associating a patient, fill out Valoración Socio-Familiar scale with random values, finish the session and associate it to patient Manuel

5 - Access session created in previous task, state the qualitative result regarding Valoración Socio-Familiar scale

6 - Create a new session for patient Manuel and then cancel it before filling out any scale

7 - Create a new session for patient Manuel and fill out again the Valoración Socio-Familiar scale (with random values)

8 - Verify patient's progress relatively to the Valoración Socio-Familiar scale (has he got better, worse or there is no change)

9 - Add patient Manuel to the favourites

10 - Consult favourite patients list and remove Manuel from the favourites

11 - Eliminate the most recent session from Manuel

12 - Eliminate Manuel's profile from the application

13 - Consult the Start criteria associated to Metformin

14 - Indicate for which medical conditions Bladder antimuscarinic drugs are to be avoided

15 - Log Out from the application

Table 17 - Tasks considered to drive P2's think aloud session with the double goal of presenting GeriatricHelper features to testers and obtaining feedback on first impressions regarding the application 


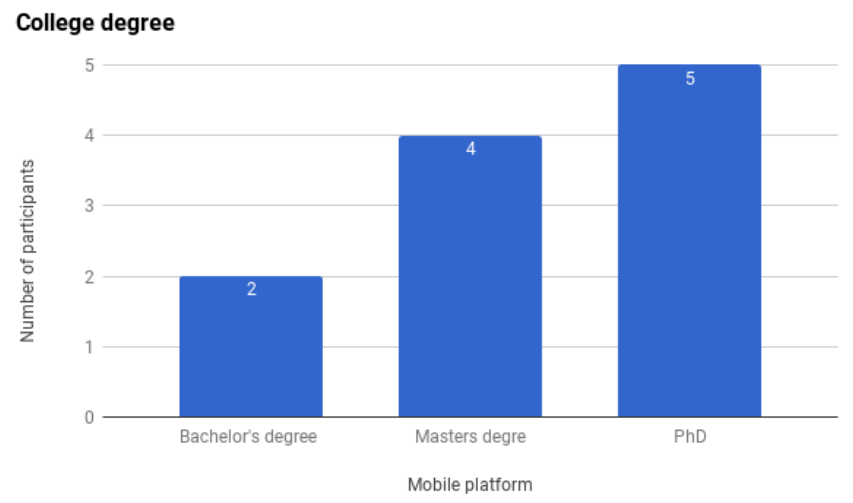

Figure 30 - characterization of participants in P2's evaluation (college degree)

\subsection{4 - Usability evaluation results}

The results produced were of two kinds, quantitative (time to achieve goal - Table 18, goal completion rate - Figure 32, Figure 33 and Figure 34-, difficulty at achieving goals and SUS results - Figure 31) and qualitative (comments made during think aloud). For the sake of brevity, the comments made during the evaluation are included in Annex 3.

\begin{tabular}{|c|c|c|c|}
\hline Goal & Average & Min & Max \\
\hline Task 1 & $2 \mathrm{~m} 38 \mathrm{~s}$ & $1 \mathrm{~m} 3 \mathrm{~s}$ & $4 \mathrm{~m} 30 \mathrm{~s}$ \\
\hline Task 2 & $57 \mathrm{~s}$ & $30 \mathrm{~s}$ & $1 \mathrm{~m} 4 \mathrm{Os}$ \\
\hline Task 3 & $40 s$ & $21 \mathrm{~s}$ & $1 \mathrm{~m}$ \\
\hline Task 4 & $1 \mathrm{~m} 37 \mathrm{~s}$ & $1 \mathrm{~m} 6 \mathrm{~s}$ & $3 \mathrm{~m} 30 \mathrm{~s}$ \\
\hline Task 5 & $23 \mathrm{~s}$ & $5 \mathrm{~s}$ & $49 s$ \\
\hline Task 6 & $35 \mathrm{~s}$ & $12 \mathrm{~s}$ & $2 \mathrm{~m}$ \\
\hline Task 7 & $33 \mathrm{~s}$ & $19 \mathrm{~s}$ & $55 \mathrm{~s}$ \\
\hline Task 8 & $19 \mathrm{~s}$ & $3 \mathrm{~s}$ & $1 \mathrm{~m} 5 \mathrm{~s}$ \\
\hline Task 9 & $4 s$ & $2 \mathrm{~s}$ & $9 \mathrm{~s}$ \\
\hline Task 10 & $10 \mathrm{~s}$ & $3 \mathrm{~s}$ & $26 \mathrm{~s}$ \\
\hline Task 11 & $21 \mathrm{~s}$ & $4 s$ & $1 \mathrm{~m}$ \\
\hline Task 12 & $6 \mathrm{~s}$ & $1 \mathrm{~s}$ & $23 \mathrm{~s}$ \\
\hline Task 13 & $30 s$ & $15 \mathrm{~s}$ & $46 s$ \\
\hline Task 14 & $30 \mathrm{~s}$ & $7 \mathrm{~s}$ & $1 \mathrm{~m}$ \\
\hline Task 15 & $7 \mathrm{~s}$ & $3 \mathrm{~s}$ & $28 \mathrm{~s}$ \\
\hline
\end{tabular}

Table 18 - average, min and max time taken to reach each goal in P2's assessment 


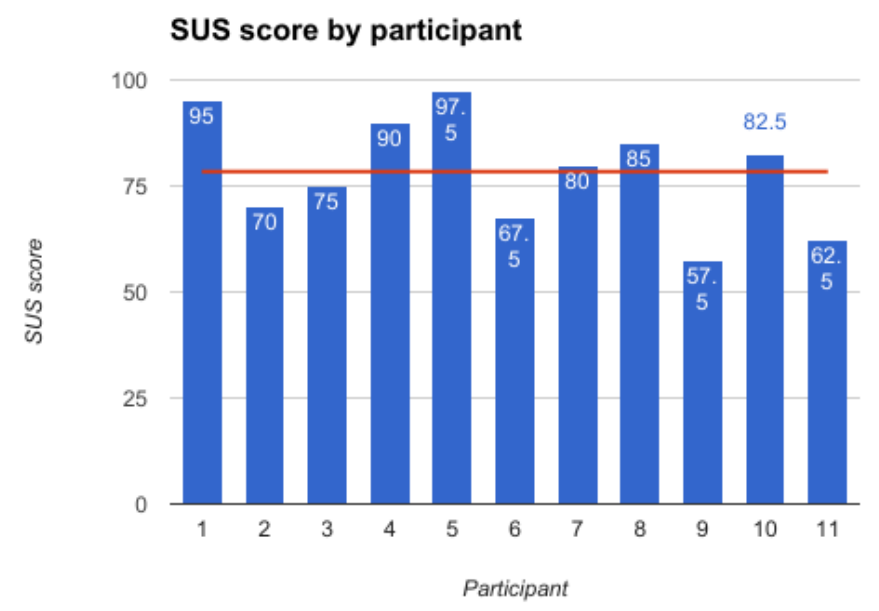

Figure 31 - SUS score by participant - Pa's assessment

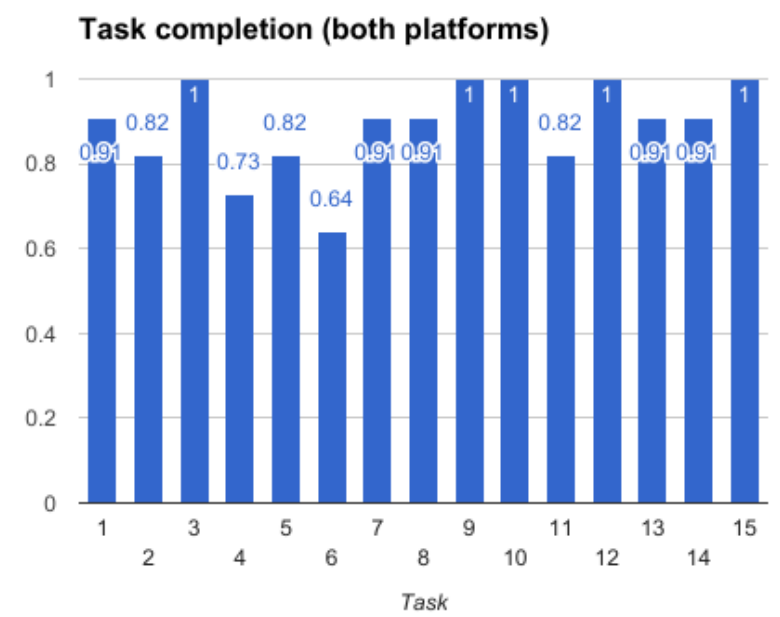

Figure 32 - task completion rate for P2's assessment (both platforms)

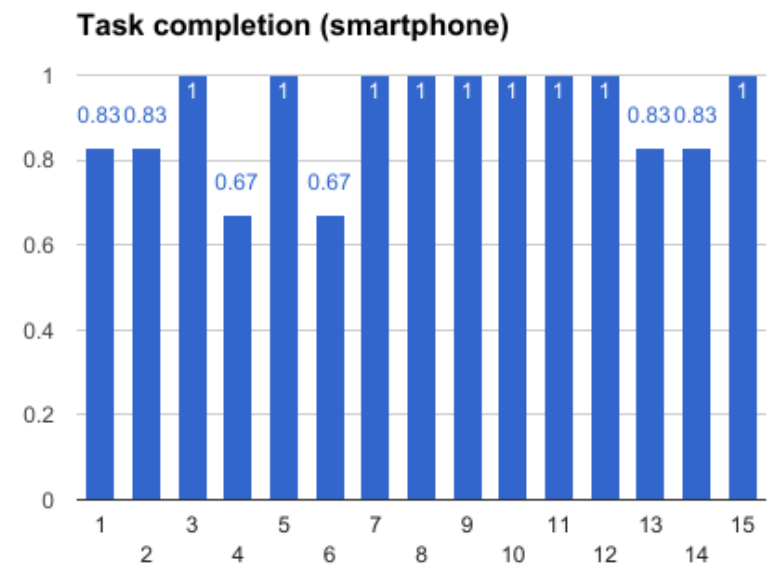

Figure 33 - task completion rate for P2's assessment (smartphone) 


\section{Task completion (tablet)}

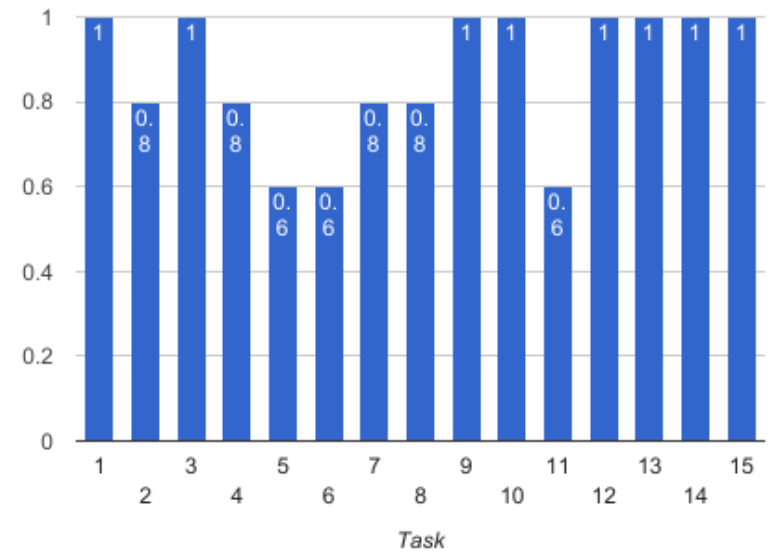

Figure 34 - task completion rate for P2's evaluation (tablet)

\subsection{5 - Discussion}

Regarding the comments made and notes taken during the usability evaluation, we could identify some problems that arose because of the participants lack knowledge in the area and not knowing how to perform the CGA, such as identifying the qualitative result for a scale and not knowing all the questions were to be answered when filling out a scale with multiple questions. This made the goals take more time than expected or led to not being completed. Mainly, for goal number 8, several participants found it difficult to state the progress a patient had with respect to a geriatric scale, due to that lack of technical knowledge of the CGA.

For goal 6, the participant was asked to create a new CGA session for a patient; the expected workflow was the participant selecting the patient from the list and from the patient's profile create the session. Some users followed another approach, first going to the Sessions screen and from there creating a session. Since we did not account for that workflow and only assumed that sessions initially without patient would be created from that screen, the participant did not have the option to select a patient from that screen. Another example of this alternative workflow happened when having to check the progress for a patient.

Regarding the tablet version, the bigger screen size was not being used to its full potentials, which could make the step of choosing a question from a scale more difficult than expected since the selection area is small. Another aspect mentioned by several users was the idea that, went filling out a scale and going back to the list of scales for an area, they thought this interaction meant that the scale was not being saved. Some participants suggested that, when creating a new session from the Sessions screen, there should be the possibility of choosing a patient right from the start, without having to associate it only in the end.

Based on the analysis of data about goal difficulty, the most difficult was goal 1 since it was the first contact with the app's logic. Other tasks that were difficult include goal number 4, since it has several steps, goal 6 , because several users failed it since they did not go to the patient's profile and created a session from there, goal 8 (tablet) and goal 11 (tablet).

The goals that took the longest to complete were 1 and 4; this result was expected, since goal 1 involved creating a CGA session, the first one to be created by the participant, while goal 4 was the one with more tasks involved.

Analysing the SUS results, the average was 78.4, the lowest 57.5 and the highest 97.5. These are not considered as percentages of usability. Considering that a SUS score of 68 is indicative of a good usability and satisfaction level, the obtained score indicates that the application's usability was above average. 
Overall, the results were positive and the comments made by the participants in this usability evaluation were very useful.

\section{3 - Third Prototype}

This section presents the details for the third prototype of GeriatricHelper and its assessment.

\subsection{1 - New development iteration}

The goal for P3 was to correct most of the usability issues encountered, with focus on the ones which seemed more relevant (Table 19 presents corrections made in P3).

\begin{tabular}{|c|c|}
\hline Area & Changes and improvements \\
\hline \multirow[t]{7}{*}{ Usability } & Increase in font size for some screens \\
\hline & Done button replaced back arrow \\
\hline & $\begin{array}{l}\text { Added feedback to actions that were lacking it and increased feedback time for key } \\
\text { actions }\end{array}$ \\
\hline & The area of some elements in the UI was not totally responsive, fixed that issue \\
\hline & $\begin{array}{l}\text { User must introduce the same password twice when registering to avoid using a } \\
\text { wrong one and not be able to retype it }\end{array}$ \\
\hline & $\begin{array}{l}\text { Replaced Login entry on menu with Personal Area, from which the user can log in or } \\
\text { register }\end{array}$ \\
\hline & $\begin{array}{l}\text { When on the login screen, if the user is not registered there is a message saying the } \\
\text { person can register and the person clicks it and is redirected to the register screen }\end{array}$ \\
\hline \multirow{9}{*}{$\begin{array}{l}\text { CGA } \\
\text { sessions } \\
\text { application } \\
\text { and } \\
\text { management }\end{array}$} & User is warned when trying to leave a scale without having answered every question \\
\hline & $\begin{array}{l}\text { The size of the card representing the scale is maintained throughout the creation of a } \\
\text { new CGA session }\end{array}$ \\
\hline & $\begin{array}{l}\text { For the tablet version, by default all answer options appear for a scale with multiple } \\
\text { questions }\end{array}$ \\
\hline & Added a button to close the popup with information about a scale or a CGA area \\
\hline & $\begin{array}{l}\text { When choosing patient to be associated with a session, the user must validate if the } \\
\text { chosen patient is indeed the one intended for the session }\end{array}$ \\
\hline & $\begin{array}{l}\text { When creating a new session for a patient the title is "New CGA session - Patient } \\
\text { name", signalling an ongoing session }\end{array}$ \\
\hline & $\begin{array}{l}\text { There is a message like "do you wish to save or not?" when clicking the button to save } \\
\text { a session }\end{array}$ \\
\hline & Used icon for the action of deleting a session \\
\hline & There is a review screen of each CGA area when conducting a Session \\
\hline \multirow[t]{4}{*}{ Patients } & $\begin{array}{l}\text { Button to save new patient's profile moved from the top of the screen to the bottom } \\
\text { (buttons used to create new patient and save the new patient's profile were in different } \\
\text { places of the screen) }\end{array}$ \\
\hline & Favourite icon in patient's profile was in reverse, now is fixed \\
\hline & Eliminate patient button went to the top bar \\
\hline & Added month, day and year validation when registering a new patient \\
\hline
\end{tabular}

Table 19 - corrections made in P3

There were suggestions made during the evaluation that needed the end user's opinion, since they depend on the way they will use the app and which functionalities should be supported. These include:

- Separate list of all drugs from drugs criteria 
- Going back should not close the application, instead, should prompt the user if wants to logout or not

- Hamburger icon to open menu is not very intuitive for users lacking smartphone experience

- Go back automatically to the scales list when current scale is completed

- All answer options should appear in the list and not just after clicking

- Instead of displaying qualitative result, use quantitative result in session card

- Create new patient right from the navigation drawer

The new functionalities included:

- Patient can be removed right from the favourites list

- Session can be eliminated when reviewing it

- Session can be saved or cancelled when filling out a scale or viewing the list of scales for an area

- Patient can be created when engaging in a new session

- When in Sessions view and creating a new Session, the user can now add a patient to the Session

- Bottom navigation replaced tab navigation

- Further improvements to the CGA guide

- Personal area has now an initial screen (Figure 35)

\subsection{2 - Updated requirements}

Following is the updated version of the application's requirements that are a follow-up to the changes stated beforehand:

\section{Possibility to create new patients}

A physician may be consulting a patient for the first time. That patient must be added to the system, so the mobile application should provide that functionality. There should be a screen where the patient's info is written down by the physician. The fields that characterize a patient and therefore must be used when creating the new profile are full name, date of birth, gender, address and patient record number

\section{View a patient's profile}

There is a personal area for each patient, in which the physician can see the results from previous appointments, erase the patient, add the patient to the favourites and consult the progress for each scale.

\section{Must allow to track the patient's progress}

The physicians need to see how a patient is progressing along the time to take measures about how to treat the patient. The progress is presented in a graph, making it easier to see how the patient progressed over time. These graphics will use the results from previous tests, both quantitative and qualitative. From the graph, it should be possible to access each individual session.

\section{Create new evaluations}

A geriatric evaluation consists of a set of tests that is filled up by a physician considering the patient's feedback and answer to such questions. The physician opens the test to be performed, asks the questions included in it and uses the app to record the answer.

New evaluations created inside the app may or may not be added to a patient's profile. A new evaluation session can be created straight from the patient's profile, from the favourites list if is marked as 
favourite and from the list of session; for the last case, the session can be created with or without a patient (patient can be created at the end of start of session).

\section{Act as a guide for choosing the best medicine for a given patient}

There are situations in which a physician must prescribe a medicine for a patient and that patient may already be taking other medicine and/or suffer from more health issues. The Start, Stopp and Beers criteria aid the physician choosing the most well-fitted medicine for each situation, so they are accessible from inside the app.

They can be consulted in the form of a list or by showing all the criteria associated to a given drug.

\section{Store information relative to patients and evaluations}

The mobile application stores information about the patients and their evaluations, i.e., everything a physician will need to assist him when tracking a patient's progress.

\section{Act as a guide on how to conduct a CGA evaluation}

There must be an area dedicated to explaining how a CGA evaluation is to be conducted; it acts as a pocket guide, displaying the CGA areas, scales and allowing to see the content of each scale.

\section{Design adapted for both smartphones and tablets}

As mentioned in the personas section, we have two types of physicians, internal medicine and general practitioners, which use smartphones and tablets. The application needs to be adapted to both types of displays. For example, when using a tablet, the screen size is much bigger, so more data items can be displayed at the same, while in a smartphone the display must be adapted to cope with smaller amounts of data.

\section{Patients data must remain confidential at all times}

Data confidentiality is assured by PIN or password mechanism for logging in, having to re-enter the pin after leaving the app for some time and app being idle for some minutes and ciphering contents in database
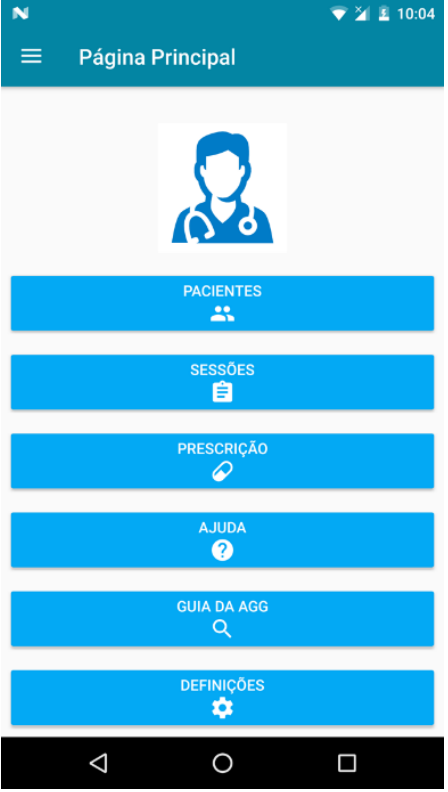

Figure 35 - Screenshot of personal area's menu

\subsection{3 - First evaluation by end-users}

The third stage of evaluation consisted of assessments made by the end-users of the application. It was time to test with them since the main usability issues were solved on the first two stages of assessment, being time to focus on the functionalities. This evaluation started with a preliminary stage, with just one physician, evaluating the third prototype. It was intended as a preparatory test, to detect any serious issues. Once again, the purpose was to obtain an application that would reach the group of end-users in the best possible state to profit from their time and expertise.

Having made further changes based on its outcomes, the new version of the application would then be tested by a broader group of physicians, in this case, eight physicians from GERMI. These used the application without any goals or tasks to perform, simply simulating their day-to-day activities, trying out every function of the app. 


\subsection{4 - Preliminary assessment by health professionals}

The first assessment was performed with the physician that acted as a consultant to this work, with whom we had an initial brainstorming to define the overall requirements for this application. In the assessment meeting, there was a brief presentation of the prototype, a guided walkthrough and space for discussion.

\section{Results and discussion}

For the third prototype, several changes were proposed, the major one was to implement data synchronization with a backend server. This backend would need to handle authentication and authorization, data and file storage. Other proposed changes were to add the possibility to generate a PDF document with the session results, store a patient's medication and save photos and videos for certain scales in which that type of content may be valuable to physicians. Table 20 presents the changes made to the app based on the physician's assessment.

\begin{tabular}{|c|c|}
\hline Area & Changes and improvements \\
\hline \multirow[t]{5}{*}{$\begin{array}{l}\text { CGA } \\
\text { application }\end{array}$} & $\begin{array}{l}\text { Allow to create a PDF document with all the data associated to a patient; this PDF would } \\
\text { then be printed and included in the patient's physical record }\end{array}$ \\
\hline & $\begin{array}{l}\text { For the Clock drawing test, a patient must draw a clock on a sheet of paper and from the } \\
\text { quality and accuracy of the clock's representation, a score is obtained. Besides taking note } \\
\text { of the score, it should be possible to save the photo of the clock drawn by the patient }\end{array}$ \\
\hline & Include video captures from the patient performing the Tinetti and March test \\
\hline & $\begin{array}{l}\text { Functional area scales are subdivided into three distinct categories, daily life basic } \\
\text { activities, daily life instrumental activities and march; this subdivision must be present } \\
\text { on the application }\end{array}$ \\
\hline & Include scoring for Tinetti scale \\
\hline \multirow[t]{2}{*}{$\begin{array}{l}\text { Backend } \\
\text { server }\end{array}$} & $\begin{array}{l}\text { Backup and synchronize data collected using the app to an external backend, that would } \\
\text { manage authentication and data storage; when a physician loses his/her phone or wants } \\
\text { to switch mobile devices, the data would be kept and logging in on the application with } \\
\text { the same account would display the existing info }\end{array}$ \\
\hline & Fetch scales and criteria at run time from a backend server \\
\hline \multirow[t]{3}{*}{ Usability } & Support multiple languages, mainly Portuguese, English and Spanish \\
\hline & Help screen about CGA has too much text and should be more concise \\
\hline & $\begin{array}{l}\text { Some tests consist of showing images to a patient and make questions afterwards related } \\
\text { to the image; it would be easier if the images were shown in full screen }\end{array}$ \\
\hline \multirow[t]{3}{*}{$\begin{array}{l}\text { Prescription } \\
\text { support }\end{array}$} & $\begin{array}{l}\text { Differentiate between drugs categories and active substance; when prescribing a drug, } \\
\text { first, the physician searches for the category and then accesses the active substance }\end{array}$ \\
\hline & Include Beers criteria in Portuguese \\
\hline & $\begin{array}{l}\text { Save drugs prescribed to a patient; the physician must have a list of currently prescribed } \\
\text { drugs, each entry displays the associated Stopp and Beers criteria, and can define alerts, } \\
\text { for example, add a note saying that this drug must only be taken for a period }\end{array}$ \\
\hline CGA guide & $\begin{array}{l}\text { On the CGA guide, there should be a listing with the bibliography of sources used for a } \\
\text { scale }\end{array}$ \\
\hline
\end{tabular}

Table 20 - Changes made for P3 based on assessment by single physician

The main corrections and improvements included: displaying a summary of each CGA area when conducting a Session, an increase in font size for some screens, warning the user when trying to leave a scale 
without having answered every question, better feedback to user actions, more contextualization for the user, and better use of the bigger screen on the tablet. The added functionalities were the possibility to generate a PDF for a Session, which later could be archived on the patient's physical record, and the ability to keep a list of drugs prescribed for each patient.

The key development for P3 was the addition of the backend and data synchronization. For the backend, we chose to use Firebase [40], given the tight integration available with the Android platform. Firebase provides mobile backend services, such as Authentication, Realtime Database, Cloud Storage and Remote Config. Another alternative was to implement a backend solution from scratch, which would take more time and since the focus for this dissertation was a mobile application and not the backend itself, we opted for an already available backend.

\subsection{5 - Assessment by GERMI physicians}

After implementing the proposed changes, the app was evaluated by GERMI physicians. One of the main aspects worth mentioning is that during the application assessment by the physicians, the considerable number of features made it more complicated for them to use the application. The main suggestion was that, at this stage, the key use case should be to conduct CGA tests. In addition, the group chose to keep only the GERMI validated scales, omitting others.

Patient's data confidentiality was mentioned as well. In Portugal, any application that makes use of personal medical data must be registered and authorized by the CNPD ${ }^{29}$. Thus, GeriatricHelper needed to be registered before being available to the public.

During this assessment, several doctors proposed the development of an iOS version of GeriatricHelper, since a considerable number of them only had iOS devices.

\subsection{6 - Discussion}

The main outcomes were the recommendation for a simpler version of the application, add more help contents and encapsulate more advanced features into modules which could be managed by the user.

The reason why physicians proposed a simpler version with less features (somewhat contrary to the physician that assessed the third prototype) was that these physicians had never had previous contact with GeriatricHelper, so maybe they felt a little overwhelmed with seeing an app with a lot of features. It was suggested that the app's features should be divided into modules, which the user could activate or deactivate.

Some physicians that took part in this session were of a more advanced age and did not have day to day contact with smartphone technologies, so they must be represented through the means of a persona. This led to the inclusion of a new persona which portrayed one of those physicians (general practitioner Alberto).

To make the app more intuitive and ease to use, more "tutorial" functionalities could be included, such as videos explaining how the app works and creating an interactive guide accompanying the user stepby-step when conducting the first CGA session.

Regarding clinical criteria, the Start and Stopp criteria were to be removed from the app, because GERMI is officially using only the Beers criteria. The current version of the Beers criteria, in English, was to be replaced by the Portuguese version to be launched by GERMI, so these criteria were removed for the moment while the new validated version was not launched.

The GERMI team chose to supress the parts in the application that capture and store personal data, since the formal authorization process with CNPD had not been started yet.

An initial iOS version was started as well, parallel to the development of an updated Android version prototype.

29 “Página Principal - CNPD.” [Online]. Available: https://www.cnpd.pt/. [Accessed: 16-Sep-2017] 


\section{4 - Final Prototype}

This section presents the details for the final prototype of GeriatricHelper, its assessment and the introduction of an iOS version.

\subsection{1 - New development iteration}

Most of the changes made in $\mathrm{P} 4$ (Table 21) were aimed at helping users on how to handle the app.

Some users prefer a simpler app, with less features and "clutter" (Alberto), while others may want to have access to everything the app allows to achieve (Francisco). The progressive activation of advanced functionalities will simplify the initial state of the application, which will allow for a more intuitive first use of the app and a more sustained learning curve.

The key modules include creating a CGA session to assess a patient and consult the CGA guide while outside of an appointment. The extra modules, as defined by the physician, were Prescription (browse clinical criteria), Personal Area (including patients' management) and Other Scales (certain scales can be activated and deactivated). The modules management is available through the settings menu (Figure 36).

\begin{tabular}{|c|c|}
\hline Area & Changes and improvements \\
\hline \multirow[t]{3}{*}{$\begin{array}{l}\text { CGA } \\
\text { application }\end{array}$} & $\begin{array}{l}\text { Only the CGA scales provided and validated by GERMI were included, removing the } \\
\text { others }\end{array}$ \\
\hline & BMI calculator included in Nutritional state CGA area \\
\hline & $\begin{array}{l}\text { Refactoring of the CGA scales into } 5 \text { different CGA categories (functional, affective, } \\
\text { march, cognitive and nutritional) }\end{array}$ \\
\hline Personal data & Video recording in different scales was removed, related to the use of personal data \\
\hline \multirow[t]{3}{*}{ Help contents } & There is a guided tour on how to create a CGA session - Figure 38 \\
\hline & Videos were included on the help section, which depict common app usages \\
\hline & $\begin{array}{l}\text { Help topics were reviewed, including the ones from the GERMI document about CGA } \\
\text { and a bibliography topic - Figure } 39\end{array}$ \\
\hline Backend server & More advanced features can be made available or hidden according to user preferences. \\
\hline \multirow[t]{4}{*}{ Usability } & $\begin{array}{l}\text { The initial screens presented to the user now include more precise information - Figure } \\
37\end{array}$ \\
\hline & $\begin{array}{l}\text { Simpler version was created, removing the personal area access and medical criteria } \\
\text { from the app }\end{array}$ \\
\hline & $\begin{array}{l}\text { In the scale screen, instead of saving and finishing the session which misled the users, } \\
\text { the scale is saved and user proceeds to another scale }\end{array}$ \\
\hline & Fixed minor grammatical errors \\
\hline
\end{tabular}

\subsection{2 - Updated requirements for the final prototype}

Following is the updated version of the application's requirements that are a follow-up to the changes stated beforehand:

1. Design adapted for both smartphones and tablets

2. Act as a guide on how to conduct a CGA evaluation

3. Export a session's result into a PDF file 
4. Support multiple languages, mainly Portuguese, English and Spanish

5. Capture photos for certain scales

6. Support modules integration

7. Strong focus on help contents, such as explaining how to use the app for the first time by means of a guided tour of a CGA scale

8. Available to the Android and iOS platforms (create a simplified iOS version)

At this stage of the development process, we had obtained a prototype which was already tested by the end-users and subscribed to their identified necessities. So, the fourth prototype was the final one developed in the context of this dissertation.

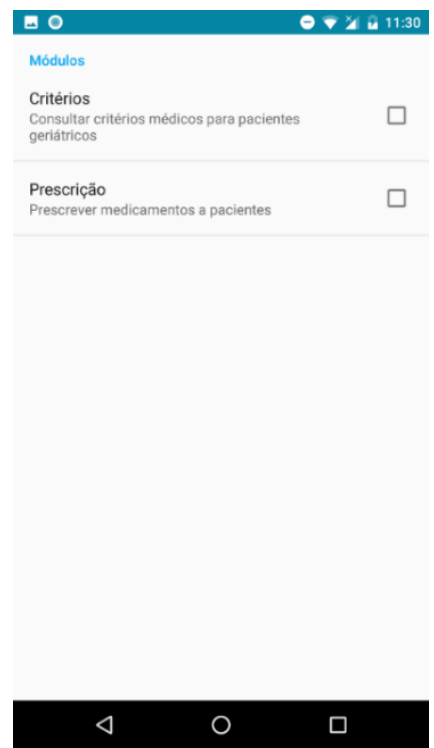

Figure 36 - possible arrangement of the app's modules in the settings menu

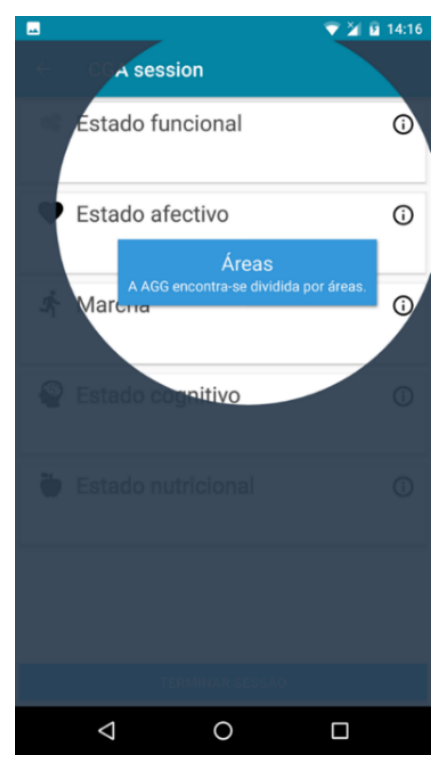

Figure 38 - app tour guide depicting the different CGA areas

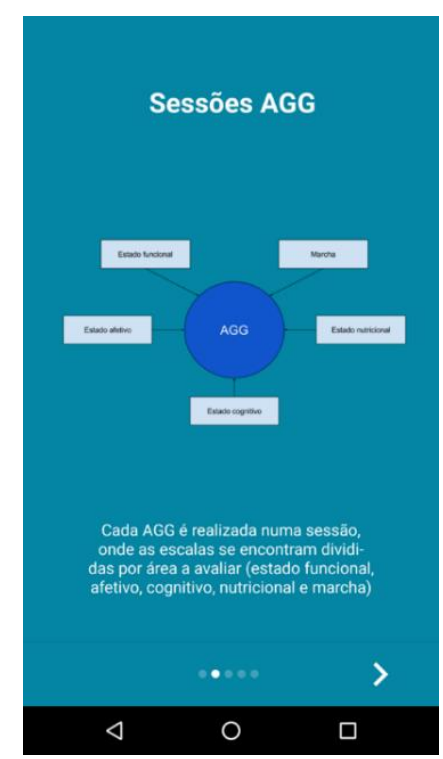

Figure 37 - initial screen depicting the CGA's organization in areas

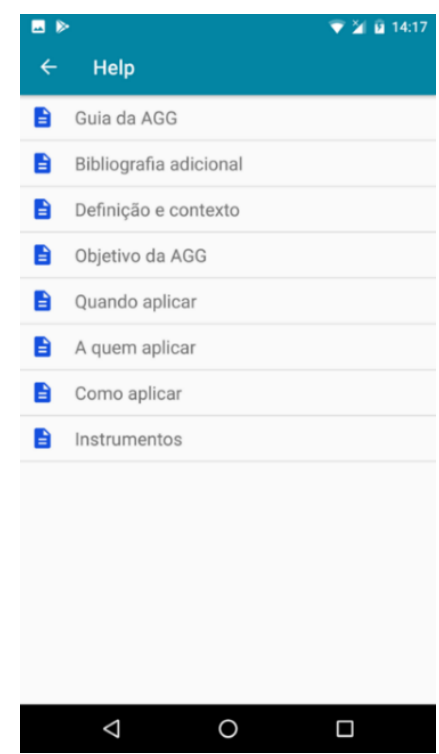

Figure 39 - improved help topics 


\subsection{3 - iOS version}

During the testing of the third prototype by physicians from GERMI, several of them wanted to test the application on their devices, but since they did not have an Android device, this was not possible. Moreover, one of the goals for this application was to replace the current CGA procedure for every physician, so the technological solution should be available for everyone that wishes to use it. This led to the decision of creating an iOS version, based on the Android final prototype. The requirements for the iOS version, which were already validated by the end-users, are present in Table 22.

\begin{tabular}{|l|}
\hline Conduct CGA evaluations - Figure 40 , Figure 41 and Figure 42 \\
\hline Act as a guide on how to conduct a CGA evaluation - Figure 44 \\
\hline Export a session's result into a PDF file or send them via email - Figure 43 \\
\hline Scales adaptability \\
\hline
\end{tabular}

Table 22 - functional requirements implemented on the iOS version of GeriatricHelper

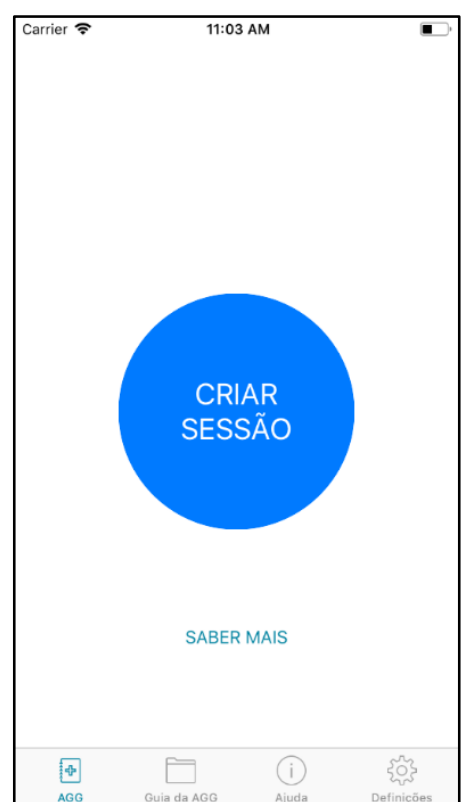

Figure 40 - initial screen (iOS)

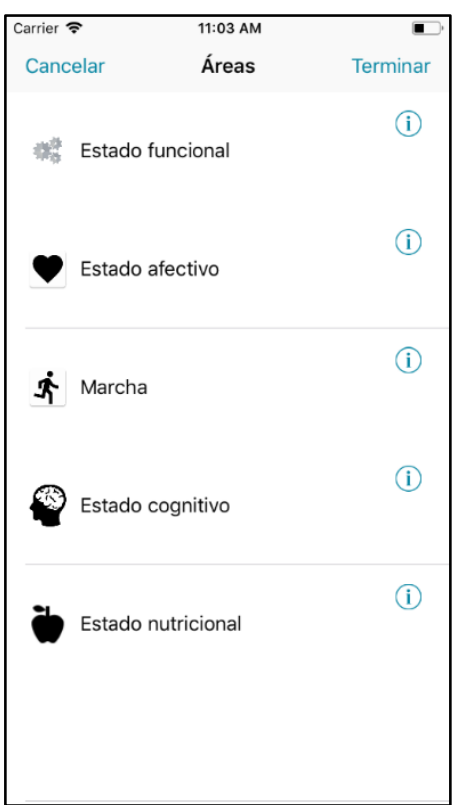

Figure 41 - CGA areas (iOS) 


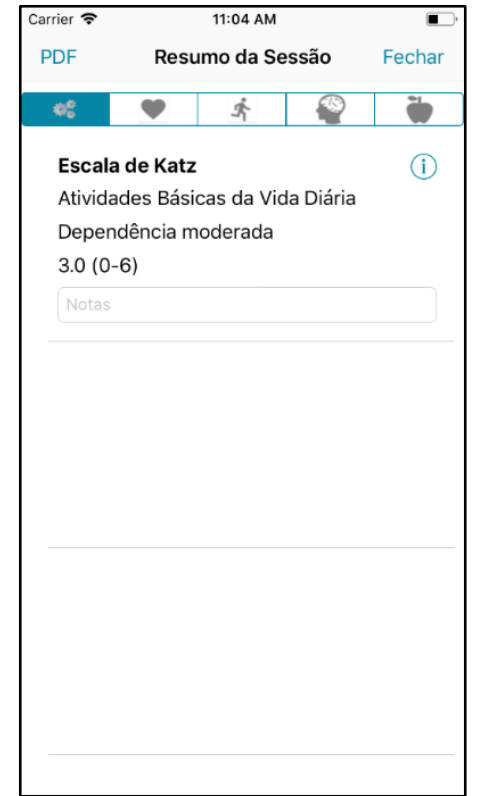

Figure 42 - session review (iOS)

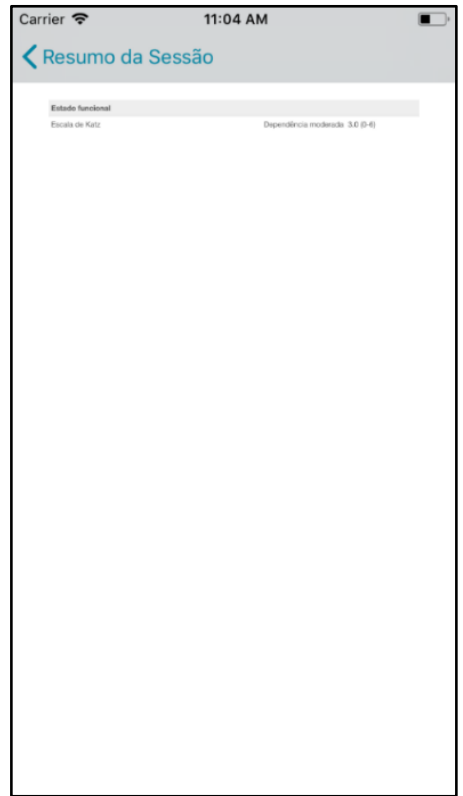

Figure 43 - session review in PDF (iOS)

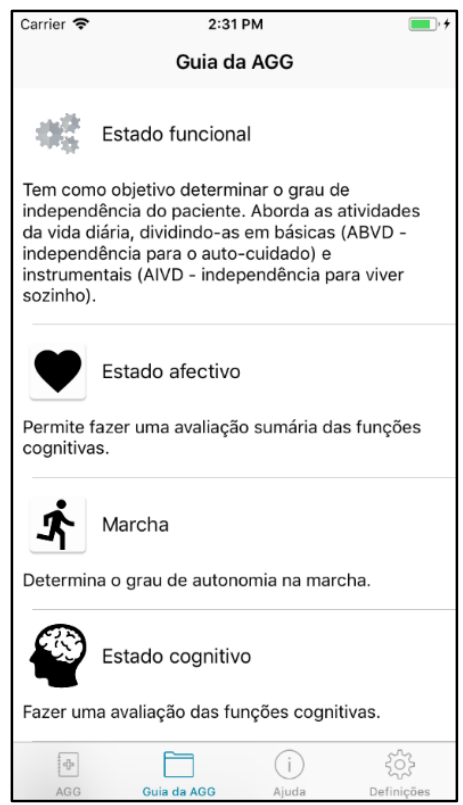

Figure 44 - CGA guide areas (iOS) 


\section{Chapter 5}

\section{5 - SYSTEM ARCHITECTURE AND IMPLEMENTATION}

The current chapter describes the system's architecture, each key component and how they interact, along with more technical-related descriptions about implementation, security concerns, testing and quality assurance. This chapter refers to the final stage of the system (intermediary options will not be addressed).

\section{1 - Data Model}

GeriatricHelper's data model (Figure 45) contains one entry-point, represented by the Physician. They create CGA sessions, in which a patient can participate. During that session, one or more scales are run, each one containing one or more questions. Scales can be of one of the following types: single questions, multiple choice, multiple category or right and wrong. The Physician also prescribes medicines to a patient; for that prescription, the name and the date are saved.

The data model contains eight entities:

- $\quad$ Physician -HCP who will be using the application during appointments

- Patient - geriatric patient who undergoes an appointment with the Physician

- Prescription - digital record of a prescription, containing date and drugs prescribed by a Physician to a Patient

- CGA Session - CGA appointment conducted by a Physician on the Patient; each Session contains one or more scales

- CGA Scale Info - each CGA scale is composed of one or more categories and belongs to an area

- $\quad$ CGA Scale Result - result for a CGA scale after its application

- Question Info - can be right or wrong, yes or no, or single choice

- Question Result - result for a question after its application 


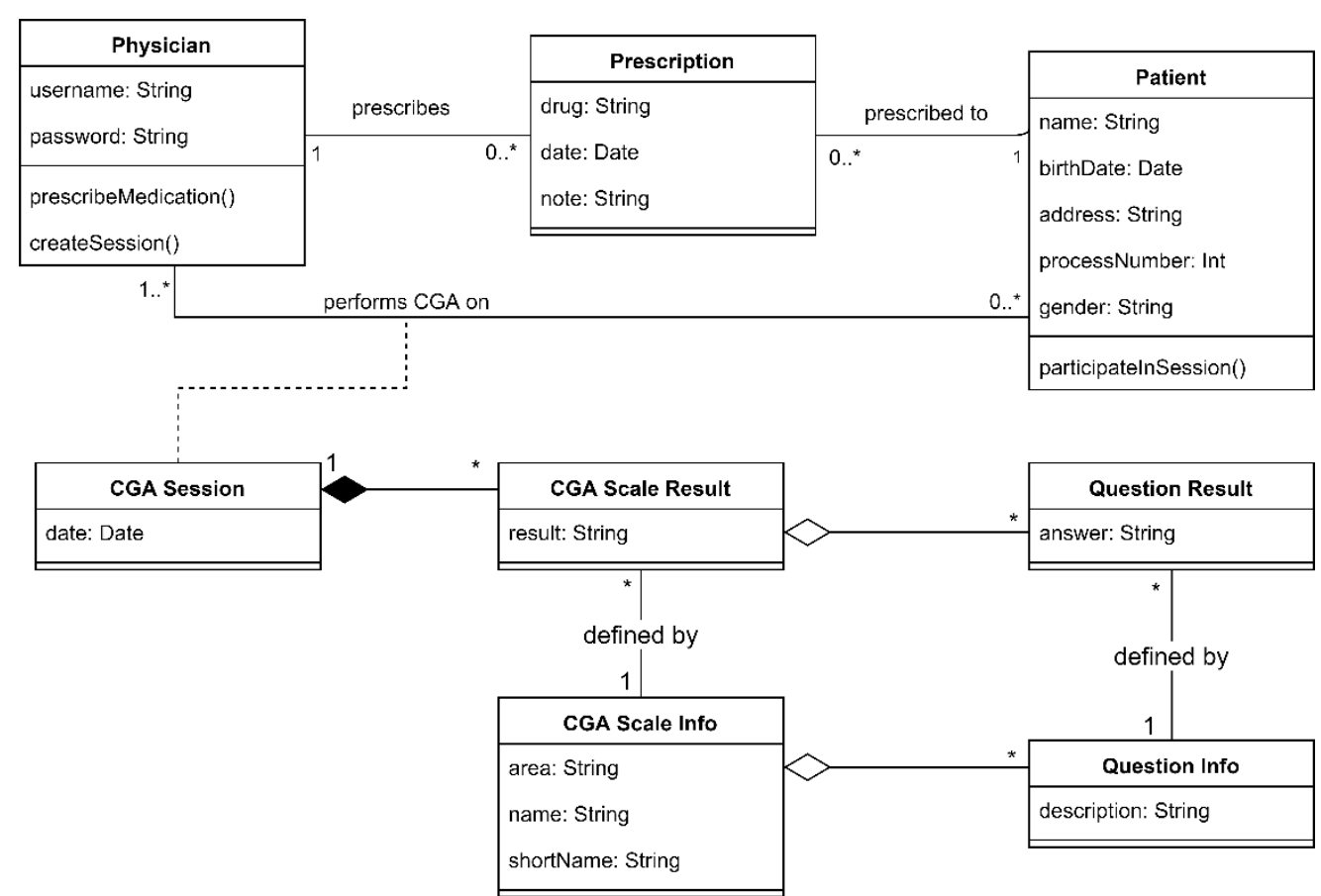

Figure 45 - class diagram

\section{2 - System Architecture components}

The developed solution is composed of two main components, the frontend and the backend (Figure 46). The frontend comprises the mobile applications and the backend all the necessary remote components that support the system, such as the database where scales are stored.

The iOS and Android applications are the user entry point in the system. All the user actions are made using the mobile application, which in turn communicates with the Backend, implemented on Firebase.

Firebase ${ }^{30}$ was used as the backend for this system because it provides a convenient and easy to use mobile-backend-as-a-service.

The current section presents each backend component in detail.

30 "Firebase | App success made simple." [Online]. Available: https://firebase.google.com/. [Accessed: 31Mar-2017]. 


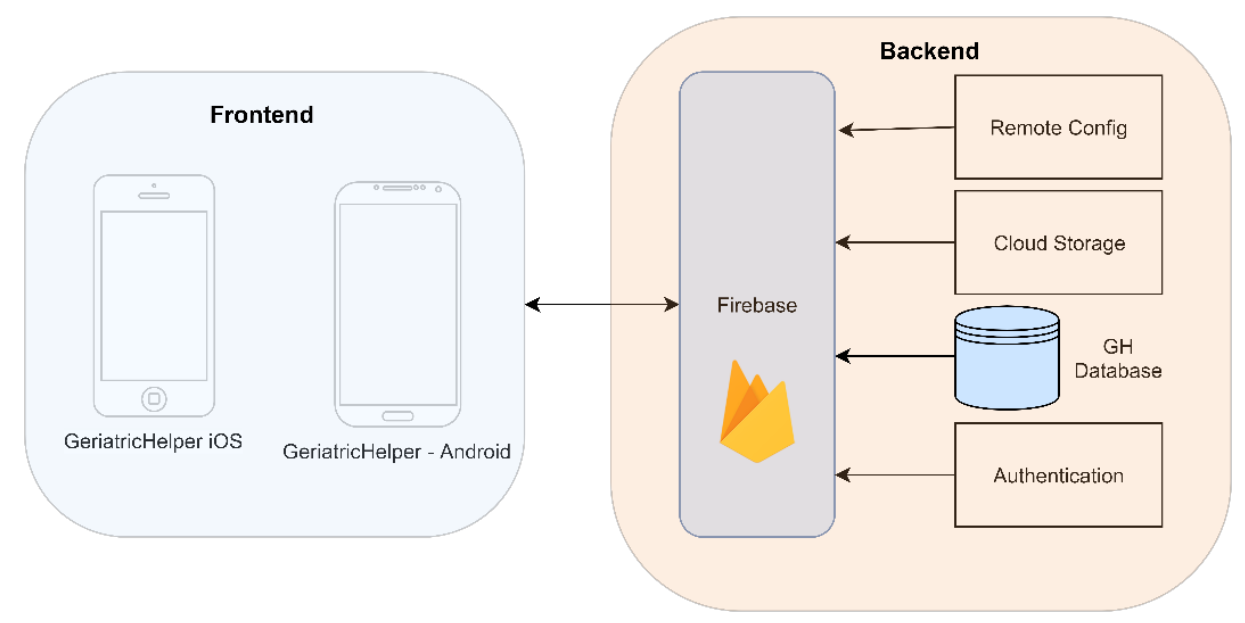

Figure 46 - System Architecture diagram

\section{Authentication}

Each user should register to obtain their own credentials, in this case, email address and password. Anyone can register as a user, just having to do it on the application. After registering and logging in, the data from that user is fetched from the Realtime Database, which keeps the data synched

\section{Database and Storage}

Some scales contained photos or videos taken with the device's camera, that are to be persisted. Besides, the different language versions for the scales needed to be accessed by the application, mainly when launching it for the first time or upon updating of the contents. To achieve this goal, Firebase's Cloud Storage functionality was used (Figure 47 presents the data storage model). The storage was divided into sections, scales (CGA scales and tests in different language versions), users (photos and videos recorded by the users while performing CGA), scales_other (scales that were not included in the current version of the application but were included in a certain point of the development process), images (photos used in scales) and criteria (clinical criteria - Start/Stopp and Beers - in a JSON format).

The scales content can be improved, such as correcting text typos or introducing a new language, so every time the scales were changed, they needed to be retrieved by the application to have the most recent updates. To achieve this functionality, every time the app starts, there is an access to the public area of the database, retrieving the scale's version, and every time it changes, the scales are retrieved as well.

The database model is composed of two principal areas, public and users, structured in a Firebase JSON tree (Figure 48 and Figure 49). The former refers to data that can be publicly accessed without authentication, and the latter is the personal data associated to each user. This personal data is subdivided into five tables, choices (answers to test questions), patients (patients this user is following up), prescriptions (drugs prescribed to patients), questions (questions associated to a test), scales (tests filled up during sessions), and, finally, sessions (every session saved by the user).

This database implementation is different than the native one available in Android devices, in the sense that it is a NoSQL database.

\section{Remote Config}

The Remote Config tool allows to push updates to an application without having to create a new release, such as updating text or differentiating an app's behaviour according to the user. Using this tool, it is possible to configure new languages for the application, without having to make a new release. The relevant fields are stored in a key-value mapping which, combined with a conditional mechanism, allows to set different languages for the same value, for example. 


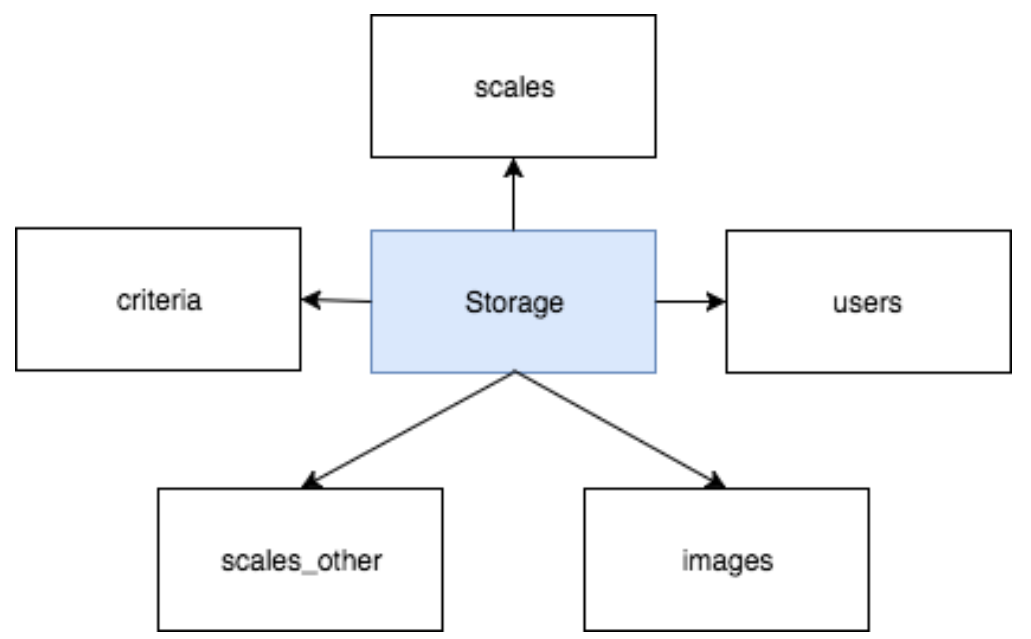

Figure 47 - Data storage model
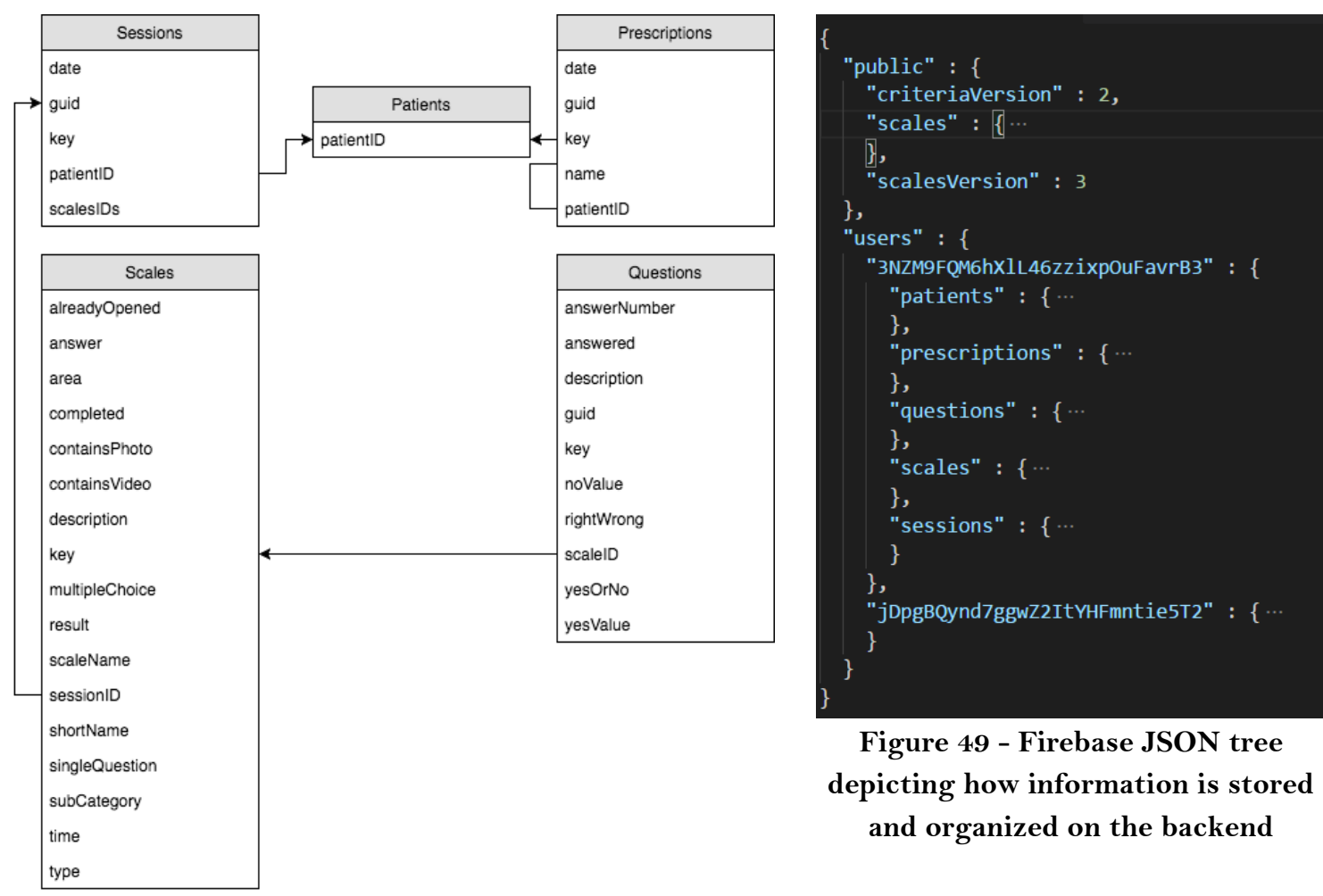

Figure 49 - Firebase JSON tree depicting how information is stored and organized on the backend

Figure 48 - Database model 


\section{3 - Security aspects}

There are two areas in the app, public and personal/private. The personal area provides access to patient data management. To access this area, physicians must login using their credentials (email and a password). If leaving the app while logged in, the next time the user opens it $\mathrm{s} /$ he needs to input a safety code to unlock it, preventing the access from an unwanted third party. GeriatricHelper deals with personal clinical data, which must remain confidential and inaccessible to third parties. Implementing this may not be straight-forward, which may explain why most of the apps currently available for this application area do not make it available. The security enforcement for this system is based on the separation of demographic and clinical data (Figure 50), i.e., data which may lead to identifying a person, such as name, address and birthdate, is ciphered before being stored on a backend, while the other data, such as sessions and scales, is not ciphered on the backend, since they point out to the ID of a patient, not its personal data.
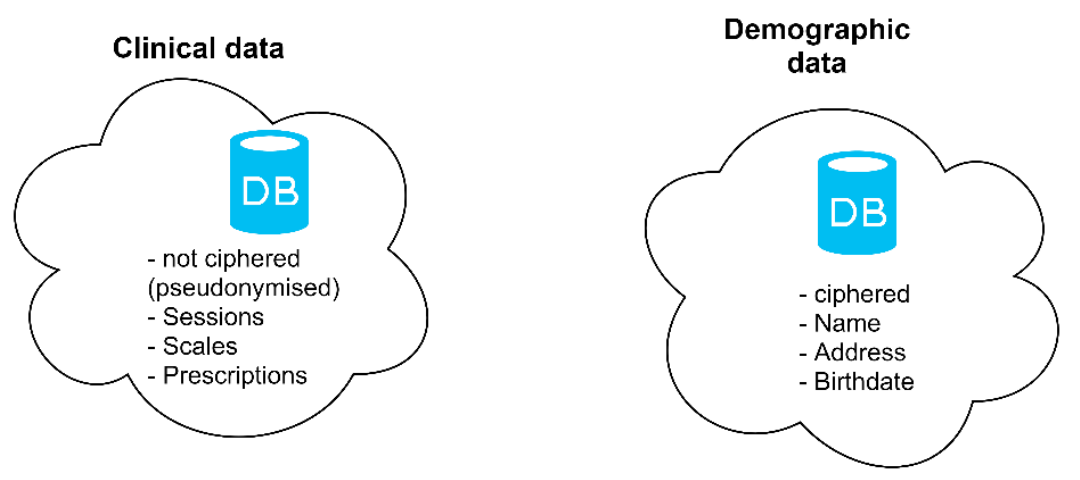

Figure 50 - separation between clinical and demographical data on the backend

The cryptographic operations take place on the mobile device running the application; symmetric key ciphering is used instead of asymmetric key ciphering, since the latter would imply part of the operations took place on the backend. The Advanced Encryption Standard (AES) is used to cipher a JSON containing the data of each patient, the key being generated by a hash function applied to the junction of the unique user's ID and password (Figure 51).

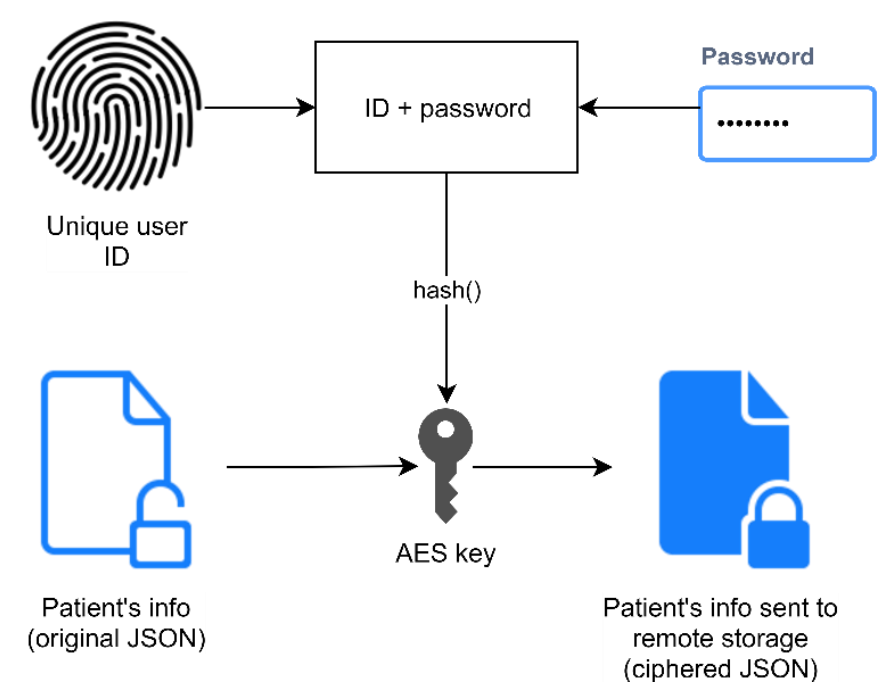

Figure 51 - cipher process for patient's personal information 
There is regulation in the European Union about data handling, mainly Regulation (EU) 2016/67 [41]. CNPD defined the 10 measures to prepare the adoption of this regulation [42]. One of them talks about a new role, Data Protection Officer (DPO), who is responsible to assure data protection rules are followed. These rules are out of scope for this work and should be responsibility of the entity that wishes to continue the work of this dissertation.

The proper authorization for storing patient data by the Portuguese data protection authority was planned for a later stage; meanwhile, though implemented, the associated modules in GeriatricHelper are kept disabled.

\section{4 - System Testing and Quality Assurance}

Besides the usability and acceptance tests performed by users, we adopted quality assurance practices related to unit and functional testing; unit tests verify the correctness of each component individually, while functional tests are applied to the complete system, i.e., they evaluate the functionality.

Android provides a library for executing functional tests, Espresso ${ }^{31}$. Using Espresso, tests can be run on physical devices or emulators, simulating interactions made by a user. One of the relevant test scenarios is to compare results using the current and the proposed approaches with respect to scales result calculation. It is important to run those tests on different devices, choosing a broad range of screen sizes, API levels, etc; the more variables considered, the more reliable is the system.

\section{Testing with Espresso - Methodology}

To test with Espresso, first we record the steps in which a physician conducts a scale; then, the recorded script can be replayed to verify if the (new) version of the codebase produces the expected outputs. Having defined those tests, Firebase's Test Lab tool was used as a cloud testing platform, since it provides a tool to run this type of tests in virtual and real devices.

Functional tests were run in several devices, with API levels ranging from 18-26, the location set up as Portugal and orientation set to portrait (Table 23).

\begin{tabular}{|c|c|}
\hline Device & API level \\
\hline Samsung Galaxy S3 & 18 \\
\hline LG G3 & 19 \\
\hline Xperia Z2 & 21 \\
\hline Nexus 4 & 22 \\
\hline Moto G4 & 23 \\
\hline Galaxy S7 & 24 \\
\hline Pixel & $25 / 26$ \\
\hline
\end{tabular}

Table 23 - devices and API levels used for functional testing with Espresso

Every scale was tested using functional tests. During nutritional assessment, one scale's result depends on the completion of a previous one, so they were conducted in succession.
31
"Espresso
Android
Developers."
[Online].
Available:

https://developer.android.com/training/testing/espresso/index.html. [Accessed: 05-Sep-2017]. 
Besides functional tests defined by the developer, there are also tests which automatically explore the app by simulating a user's input; these were also run since they could detect further issues with the app which were not focused on functional tests.

\section{Results and Discussion}

The tests ran successfully for every device, the only issue was with the Samsung Galaxy S3 (API 18), which encountered an OutOfMemoryError. This was caused by an image on in the initial screen of the app which, due to its large dimensions, caused the crash. The solution was to integrate the Glide library ${ }^{32}$ into the project, which is responsible for handling efficient image loading and caching.

Another effort to avoid this type of errors was to find other memory leaks in the app using LeakCanary ${ }^{33}$, an Android library which notifies the user when a leak occurs and where it occurs in the code. Some memory leaks were identified and later corrected, such as one where the initial screen was still being referenced after being displayed, occupying memory needlessly.

The quality assurance practices in use allow a higher level of confidence on the application.

32 "Glide v4: Fast and efficient image loading for Android." [Online]. Available: http://bumptech.github.io/glide/. [Accessed: 30-Sep-2017].

s3 "LeakCanary: A memory leak detection library for Android and Java." [Online]. Available: https://github.com/square/leakcanary. 


\section{Chapter 6}

\section{6 - PILOT TEST}

Considering that the current prototype met the initial requirements and their refinement along the iterative design and development, it was considered appropriate to undergo a pilot test. The objectives were to use the application in a real context, with physicians, to retrieve their feedback, which would serve for later instalments of GeriatricHelper. The pilot test is a major step since it implies the use of the application on a real context.

\section{1 - Methodology for pilot testing}

The pilot test was divided into three stages: initial task-driven think aloud session, pilot stage and filling of a SUS questionnaire. With respect to the protocol to use for the pilot test, we considered that an initial session for presenting GeriatricHelper to each physician would be important. To use this session to obtain feedback on first impressions and difficulties, we structured it as a goal driven think-aloud session: participants performed tasks (Table 24) and commented on their perceived difficulty. Later, they would enter in the pilot stage in which they used the app and made further comments; finally, they would fill out a satisfaction questionnaire (SUS), which conveyed quantitative results to be further analysed.

At the time of closing this document, the pilot test is still ongoing, but the data for two professionals has already been collected and is reported. The pilot test for the system targeted internal medicine physicians, who had been practicing the CGA on a weekly basis for one year at least. The two participants were chosen among GERMI physicians since they had the technical expertise on the subject. The duration of the pilot stage was 2 weeks.

\section{2-Results}

The results are divided into the three stages that comprise the pilot test, thinking-aloud, pilot, and SUS.

\section{Thinking-aloud}

One tester commented, during the last goal, that it was difficult to find how to repeat the app's tour guide; eventually the tester found out where it was located and suggested that option should be accessed from the Help screen. Another tester commented for goal 4 that the space occupied by a question was too big, leaving little space for displaying the answer choices.

Figure 52 depicts easiness level for each goal and Figure 53 the goal completion percentage. Average goal time and goal time by participant are displayed on Table 25. 
1 - Create a new CGA session, fill out both scales from the Functional State area with random values and finish session

2 - State the quantitative and qualitative results for both scales

3 - Create and view a PDF with the session's summary and then finish the session

4 - Create a new session, fill out Mini-Mental State Examination scale with random values (assuming a patient which attended the 6 th grade), leave a note and finish the session

5 - Create a new session, filling out the Nutritional assessment - screening test, assuming a patient with a height of $1.56 \mathrm{~m}$ and weighing $68 \mathrm{~kg}$

6 - Create a new session and then cancel it before filling out any scale

7 - Consult help topic regarding CGA's objectives

8 - Consult CGA guide for the Lawton \& Brody scale, stating for which score(s) a female patient has mild dependency

9 - Repeat tour guide of the app

Table 24 - Tasks for the initial think aloud session with the double goal of presenting GeriatricHelper features to physicians and obtaining feedback on first impressions on the application

\begin{tabular}{|c|c|c|c|}
\hline Goal & Average & Participant 1 & Participant 2 \\
\hline 1 & 67 & 64 & 69 \\
\hline 2 & 8 & 11 & 5 \\
\hline 3 & 8 & 5 & 10 \\
\hline 4 & 64 & 75 & 52 \\
\hline 5 & 41 & 40 & 42 \\
\hline 6 & 5 & 4 & 5 \\
\hline 7 & 8 & 6 & 10 \\
\hline 8 & 10 & 9 & 20 \\
\hline 9 & 37 & 53 & 10 \\
\hline
\end{tabular}

Table 25 - average goal time and goal time by participant (in seconds) 
Easiness level (1-very hard 5-very easy)

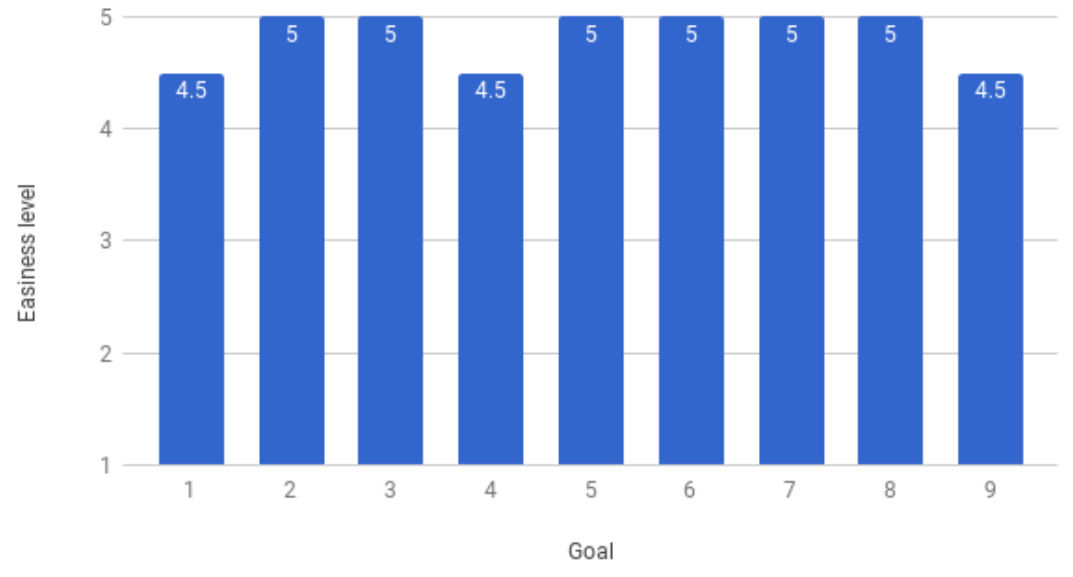

Figure 52 - easiness level for pilot test goals

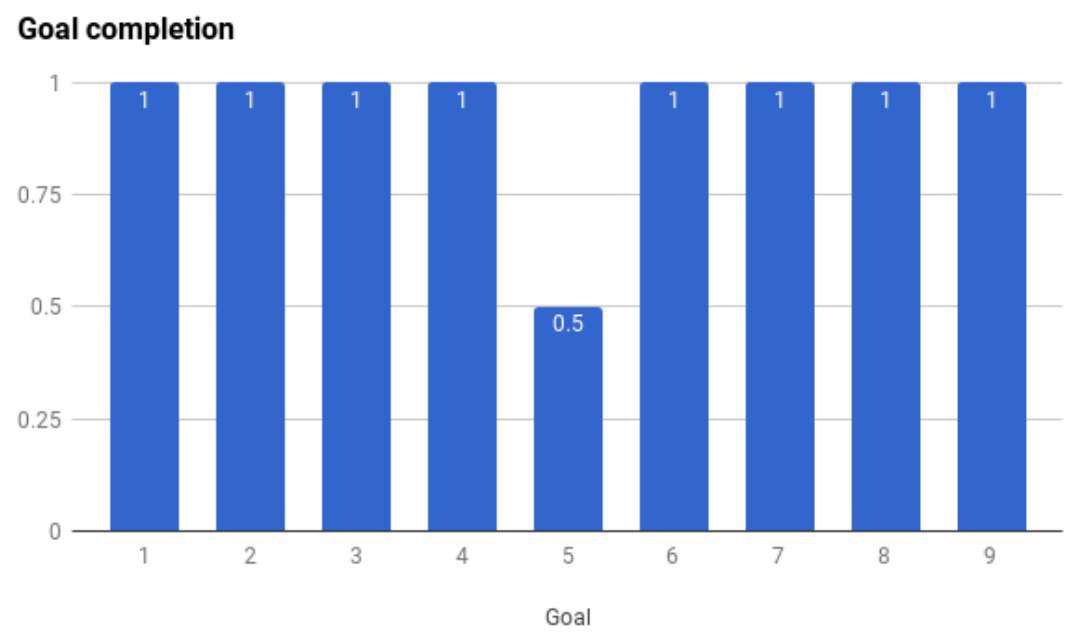

Figure 53 - goal completion for pilot test

\section{Pilot stage}

During the pilot stage, doctors made the following comments/suggestions:

- Images in Mini Mental State Examination do not show up when offline

- On Session's PDF, for scales with multiple categories, the result for each category should be present instead of just showing the overall

- Global nutritional assessment should not be available if the complementary screening assessment was not completed first

- Application crashed unexpectedly when executing Mini Mental State Examination scale and then minimizing the app

- The app is fast and very intuitive and the PDF document for the session is efficiently generated

- The application fulfils every geriatrician necessities when executing the CGA and makes the process more efficient and easier 
SUS scores are presented in Figure 54.

\section{SUS score by participant}

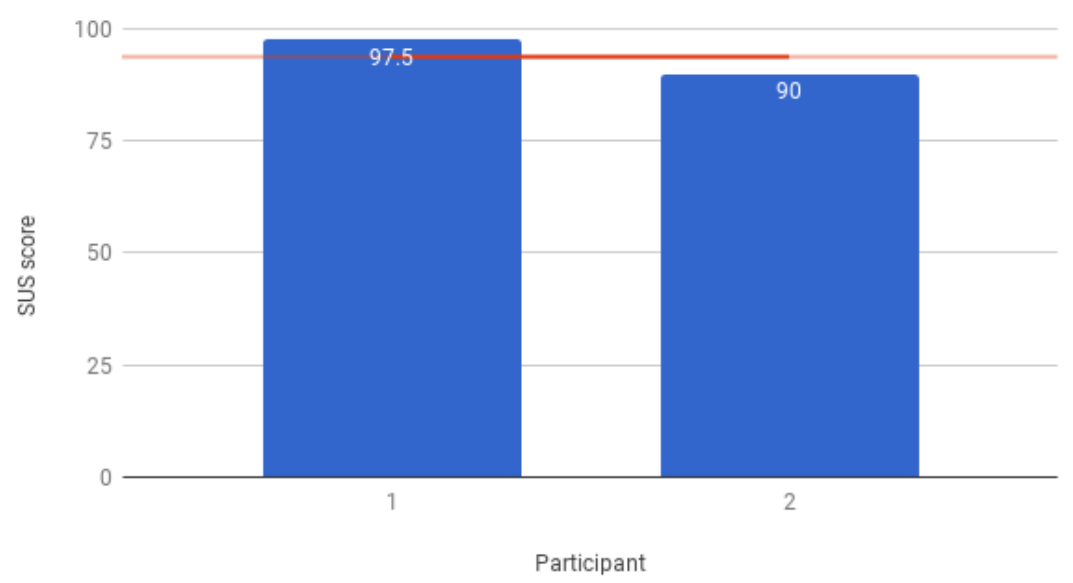

Figure 54 - SUS score by participant on the pilot test

\section{3-Discussion}

During the think-aloud stage, participants found goals to be easily achieved, with easiness levels ranging between 4.5 and 5 , and times taken to achieve goals were as anticipated. As expected, every goal was successfully completed, since no tester was unable to complete the tasks neither exceeded the time limit of the task. There was only one issue with a tester misreading the goal and, instead of executing the Nutritional Assessment - screening, conducted the global test and, since it depends on results from the screening, the app crashed because that case was not covered.

The comments and suggestions made by testers during the pilot stage target details which are only perceived after an extensive use of the application and which are easy to comply with in further instalments of GeriatricHelper. Most of them were suggestions to improve the system's functionality; the most significant issue reported was the application being prone to crashes when completing the Mini Mental State Examination scale. Positive comments regarding the app's intuitiveness and the fact that it envisages everything a HCP needs when conducting the CGA are a good indicator that this technological solution to the CGA is well implemented and valuable to physicians.

Analysing the SUS results from the two users (90 and 97.5), the obtained score is very good. 


\section{Chapter 7}

\section{7 - CONCLUSIONS AND FUTURE WORK}

We have presented a new method for applying the CGA based on a mobile application, shifting from a paper-based approach to one supported on a mobile device. Unlike the current practice, which requires the medical doctor to keep track of assessments conducted in different moments in time, the app allows to store and search the assessments for a patient.

The calculations to compute a scale result are now automatic and less error-prone, reducing the workload for HCPs.

Browsing clinical criteria is easier and faster: instead of having to skim through paper documents, the HCP just types the information to be consulted.

However, the proposed method may convey some problems, mainly acceptance by doctors who are not used to smartphone applications.

Table 26 presents an overview of the differences between the current and proposed methods for applying the CGA and related operations.

\begin{tabular}{|l|l|l|}
\hline \multicolumn{1}{|c|}{ Component } & \multicolumn{1}{|c|}{ Current method } & \multicolumn{1}{c|}{ Proposed method } \\
\hline Conduct CGA sessions & $\begin{array}{l}\text { Scale results calculated by } \\
\text { hand }\end{array}$ & $\begin{array}{l}\text { Scale results calculated by the } \\
\text { device }\end{array}$ \\
\hline Consult CGA information & $\begin{array}{l}\text { Consulted on official sources, } \\
\text { in separate sites, on } \\
\text { documents }\end{array}$ & $\begin{array}{l}\text { Consulted directly from the } \\
\text { application }\end{array}$ \\
\hline Consult Clinical criteria & Consulted in paper format & $\begin{array}{l}\text { Consulted inside the } \\
\text { application }\end{array}$ \\
\hline $\begin{array}{l}\text { Store and access information } \\
\text { about previous CGA sessions }\end{array}$ & $\begin{array}{l}\text { Information stored in paper } \\
\text { format }\end{array}$ & $\begin{array}{l}\text { Information stored digitally } \\
\text { on the local device with copies } \\
\text { on the backend }\end{array}$ \\
\hline
\end{tabular}

Table 26 - comparison between the current approach followed by physicians to perform different steps needed for the CGA and how GeriatricHelper supports those tasks.

The GeriatricHelper mobile application relies on Firebase as its backend. It is a native Android application, with a simpler iOS version. The Android application was validated, on usability and functionality, and was used in a pilot test with end users. The pilot test is the last development stage before making the system available to a broader audience.

Adopting a user centred iterative methodology conveys certain benefits, mainly being able to better understand the end-user needs, motivations and requirements, and the capacity to adjust and refine requirements throughout the process. 
The systematic evaluation, with different audiences, allowed to validate the proposed system and sustain its advance, understanding precisely what really mattered to the end users, leading to a reduction on the number of functionalities initially visible to facilitate the use by less experienced users, for example.

The developed work as well as the adopted methodology accomplish the initially proposed objectives, a support tool based in user centred design and development, and provide an important response to the initial requirements, creating a solid base for further evolution.

\section{Future work}

To satisfy a more specialized audience, the current application can evolve by including the Beers criteria in Portuguese (GERMI had not yet published them at the submission date). These need to be translated into a JSON format and then sent to the backend.

By targeting a less specialized audience, such as general practitioners, the CGA can be applied by more HCPs in a more transversal manner. This type of audience has yet to use the application and provide feedback.

On a more technical perspective, CNPD validation must be obtained, so that the HCP can track patients progress and associate prescriptions. The backend could be integrated with a system already used in Portugal, such as the Plataforma de Dados da Saúde ${ }^{s t}$, exporting there a subset of data of interest that is relevant to patients healthcare. The prescriptions component needs to aggregate contents from more resources, so it would benefit from integration with a database already in use that enables access to that information (e.g., Infarmed ${ }^{35}$ ).

The iOS version of the application needs further development, functional validating and testing, since it was created on the later stages of development. Another addition to the system could be transposing this mobile solution to a website, allowing to conduct CGA session from a HCP's personal computer.

34. "PDS - Plataforma de Dados da Saúde - SPMS.” [Online]. Available: http://spms.minsaude.pt/2013/11/pds-plataforma-de-dados-da-saude/. [Accessed: 23-Oct-2017].

${ }^{55}$ SNS, "Infarmed - INFARMED, I.P.," Autoridade Nacional do Medicamento e Produtos de Saúde, I.P., 2016. [Online]. Available: http://www.infarmed.pt/. [Accessed: 31-Oct-2017]. 


\section{REFERENCES}

[1] WHO, "Ageing and Health," Who, 2015. [Online]. Available: http://www.who.int/mediacentre/factsheets/fs404/en/. [Accessed: 21-Oct-2017].

[2] A. S. DUQUE, H. GRUNER, J. G. CLARA, J. G. ERMIDA, and M. T. VERÍSSIMO, "Avaliação Geriátrica," Núcleo Estud. Geriatr. da Soc. Port. Medician Interna, pp. 1-20, 2012.

P. Almeida, “Avaliação Geriátrica Global,” las Jordanas da USF do MAR. 2016.

A. S. M. Mosa, I. Yoo, and L. Sheets, "A Systematic Review of Healthcare Applications for Smartphones,” BMC Med. Inform. Decis. Mak., vol. 12, no. 1, p. 67, Dec. 2012.

[5] "Hazzard's Geriatric Medicine and Gerontology, 6e | AccessMedicine | McGraw-Hill Medical." [Online]. Available: http://accessmedicine.mhmedical.com/book.aspx?bookid=371. [Accessed: 22Nov-2017].

[6] P. Gallagher, C. Ryan, S. Byrne, J. Kennedy, and O. D. Mahony, "STOPP START Toolkit supporting Medication Review," Eur. J. Clin. Pharmacol., vol. 46, no. February, pp. 1-12, 2008.

C. Ryan, "The basics of the STOPP/START criteria."

Ags, F. O. R. P. Inappropriate, M. Use, and I. N. Older, “AGS Beers Criteria,” Most, pp. 2-5, 2012.

World Health Organization, "mHealth: New horizons for health through mobile technologies," Observatory, vol. 3, no. June, pp. 66-71, 2011.

[10] European Commission, "Green Paper on mobile Health ('mHealth’)," pp. 1-20, 2014.

[11] B. M. C. Silva, J. J. P. C. Rodrigues, I. De La, T. Díez, M. López-Coronado, and K. Saleem, "Mobilehealth: A review of current state in 2015," J. Biomed. Inform., vol. 56, pp. 265-272, 2015.

[12] E. Ozdalga, A. Ozdalga, and N. Ahuja, "The smartphone in medicine: A review of current and potential use among physicians and students," J. Med. Internet Res., vol. 14, no. 5, pp. 1-14, 2012.

[13] "Point of Care Medical Applications | Epocrates." [Online]. Available: http://www.epocrates.com/. [Accessed: 26-Sep-2017].

[14] "Eponyms (for students) on the App Store." [Online]. Available: https://itunes.apple.com/us/app/eponyms-for-students/id286025430? $\mathrm{mt}=8$.

[15] F. Sposaro and G. Tyson, "iFall: An android application for fall monitoring and response," in 2009 Annual International Conference of the IEEE Engineering in Medicine and Biology Society, 2009, vol. 2009, pp. 6119-6122.

[16] M. N. K. Boulos, S. Wheeler, C. Tavares, and R. Jones, "How smartphones are changing the face of mobile and participatory healthcare: an overview, with example from eCAALYX.," Biomed. Eng. Online, vol. 10, p. 24, Apr. 2011.

[17] R. Whittaker, "Issues in mHealth: findings from key informant interviews.," J. Med. Internet Res., vol. 14, no. 5, p. e129, Oct. 2012.

[18] S. Arora, J. Yttri, and W. Nilse, "Privacy and Security in Mobile Health (mHealth) Research.," Alcohol Res., vol. 36, no. 1, pp. 143-51, 2014.

[19] G. Catan, R. Espanha, R. V. Mendes, O. Toren, and D. Chinitz, "Health information technology implementation - impacts and policy considerations: a comparison between Israel and Portugal," Isr. J. Health Policy Res., vol. 4, no. 1, p. 41, Dec. 2015.

[20] C. Duque, J. Mamede, and L. Morgado, "mHealth initiatives in Portugal," in 2017 12th Iberian Conference on Information Systems and Technologies (CISTI), 2017, pp. 1-6.

[21] M. A. Hossain and D. T. Ahmed, "Virtual Caregiver: An Ambient-Aware Elderly Monitoring System,” IEEE Trans. Inf. Technol. Biomed., vol. 16, no. 6, pp. 1024-1031, Nov. 2012.

[22] J. Fontecha, R. Hervás, J. Bravo, and F. J. Navarro, "A mobile and ubiquitous approach for supporting frailty assessment in elderly people.,” J. Med. Internet Res., vol. 15, no. 9, p. e197, Sep. 2013.

[23] C. R. Wilkinson and A. De Angeli, "Applying user centred and participatory design approaches to commercial product development,” Des. Stud., vol. 35, no. 6, pp. 614-631, 2014.

[24] "Usability 101: Introduction to Usability." [Online]. Available: https://www.nngroup.com/articles/usability-101-introduction-to-usability/. [Accessed: 31-Mar2017 .

[25] J. Nielsen, Alertbox : current issues in Web usability. Nielsen Norman Group, 1995.

[26] W. Brown, P.-Y. Yen, M. Rojas, and R. Schnall, "Assessment of the Health IT Usability Evaluation Model (Health-ITUEM) for evaluating mobile health (mHealth) technology,” J. Biomed. Inform., vol. 46, no. 6, pp. 1080-1087, Dec. 2013.

[27] "Thinking Aloud: The \#1 Usability Tool." [Online]. Available: https://www.nngroup.com/articles/thinking-aloud-the-1-usability-tool/. [Accessed: 31-Mar2017]. 
[28] R. Yáñez Gómez et al., "Heuristic evaluation on mobile interfaces: a new checklist.," ScientificWorldJournal., vol. 2014, p. 434326, 2014.

[29] A. F. Rosa, A. I. Martins, V. Costa, A. Queiros, A. Silva, and N. P. Rocha, "European Portuguese validation of the Post-Study System Usability Questionnaire (PSSUQ)," in 2015 10th Iberian Conference on Information Systems and Technologies (CISTI), 2015, pp. 1-5.

[30] J. Sauro and J. R. Lewis, "When designing usability questionnaires, does it hurt to be positive?," in Proceedings of the 29th SIGCHI Conference on Human Factors in Computing Systems, 2011, no. January 2011 , pp. $2215-2223$.

[31] J. Brooke, "System Usability Scale (SUS)," pp. 2-4, 2017.

[32] R. Budiu, "Mobile: Native Apps, Web Apps, and Hybrid Apps," 2013. [Online]. Available: https://www.nngroup.com/articles/mobile-native-apps/. [Accessed: 04-Dec-2017].

[33] C. S. E. Allister Banks, Learning IOS security. 2015.

[34] S. a. Gunasekera, “Android Apps Security,” p. 236, 2012.

[35] N. Gok, Nizamettin; Khanna, Building Hybrid Android Apps with Java and JavaScript. 2013.

[36] M. Househ, M. Shubair, F. Yunus, A. Jamal, and B. Aldossari, "The Use of an Adapted Health IT Usability Evaluation Model (Health-ITUEM) for Evaluating Consumer Reported Ratings of Diabetes mHealth Applications: Implications for Diabetes Care and Management," Acta Inform. Medica, vol. 23, no. 5, p. 290, 2015.

[37] "Why You Only Need to Test with 5 Users." [Online]. Available: https://www.nngroup.com/articles/why-you-only-need-to-test-with-5-users/. [Accessed: 31-Mar2017].

[38] "Severity Ratings for Usability Problems: Article by Jakob Nielsen." [Online]. Available: https://www.nngroup.com/articles/how-to-rate-the-severity-of-usability-problems/. [Accessed: 27-Feb-2017].

[39] A. I. Martins, A. F. Rosa, A. Queirós, A. Silva, and N. P. Rocha, "European Portuguese Validation of the System Usability Scale (SUS)," Procedia Comput. Sci., vol. 67, pp. 293-300, 2015.

[40] "Firebase | App success made simple." [Online]. Available: https://firebase.google.com/. [Accessed: 28-Feb-2017].

[41] “EUR-Lex - 32016Ro679 - EN - EUR-Lex.” [Online]. Available: http://eur-lex.europa.eu/legalcontent/EN/TXT/?uri=CELEX:32016R0679. [Accessed: 16-Sep-2017].

[42] Comissão Nacional de Proteção de Dados, “10 Medidas para preparar a aplicação do RGPD,” p. 3, 2017. 
ANNEXES 


\section{Annex 1 - Use cases detailed description}

In this section, we present the list of use cases envisaged for the system with their detailed description.

\section{Register patient}

Brief description: Physician registers a new patient in the system

Step-by-step description:

1. Physician accesses the screen which allows to create a new Patient

2. Select the option to insert a new Patient in the system

3. View a screen with the different fields that can be used to characterize a Patient (name, date of birth, gender, etc)

4. Fills in the fields with the correct values concerning the Patient that is to be added

5. After all fields are complete, selects the option to confirm that indeed a new Patient is to be added

6. Receives confirmation that the Patient was successfully added

\section{Create CGA session with Patient}

Brief description: Physician creates a new CGA session for a Patient that is already registered in the system.

Step-by-step description:

1. Access Patient profile

1.1. Physician accesses a list or other form of representation that holds a digital representation of the Patients

1.2. Selects the Patient

1.3. Physician is displayed personal information about the selected Patient and previous evaluations

1.4. Selects the option to make a new evaluation

2. Conduct CGA session

2.1. Physician is displayed a screen with the available tests that can be performed

2.2. Select one of the tests

2.3. Screen displays all the questions associated to that test as well to store the answer for that question

2.4. Physician answers all the question related to the test and then goes back to the previous screen with the list of all available tests

2.5. After performing steps 2.2-2.4 for all the tests $\mathrm{s} /$ he wishes to apply to the Patient, $\mathrm{s} /$ he intends to finish the evaluation so selects the option to finish this evaluation

3. Review session

3.1. Session is finished, appearing on the screen a review screen with each scale and the possibility to create a PDF of the session

3.2. If option to create PDF is chosen, PDF is created; otherwise, the session is closed

\section{Alternate flow:}

Instead of selecting the patient first and then conducting the CGA session, a session can be created without associating a patient and later the physician can choose to associate it with a patient when finishing it. 


\section{Prescribe medicine to a Patient}

Brief description: Physician prescribes medicine for a Patient that is already registered in the system.

Step-by-step description:

1. Physician selects the patient (same as in "Create CGA session with Patient" first step)

2. Prescribe medicine

2.1. Physician selects the option to prescribe a new medicine

2.2. After browsing the drugs or searching by name, selects one of them

2.3. Medicine is added to the patient's profile, being accessible by date of prescription

\section{Browse patient's prescriptions}

Brief description: Physician checks the prescriptions currently associated with a patient

Step-by-step description:

1. Physician selects the patient (same as in "Create CGA session with Patient" first step)

2. Consult medicine

2.1. Physician switches to the Prescriptions tab, where prescriptions are grouped by date when they were prescribed

2.2. Browses by date and checks the prescriptions for that date. In case of a drug with associated medical criteria, that info is displayed

\section{Check prescription guidelines}

Brief description: Physician checks the guidelines regarding a certain drug.

Step-by-step description:

1. Physician selects on the screen the option to display the medicine prescription mode

2. A search field is displayed which allows to search by drug name

3. Physician searches by the name of a medicine

4. A list is show with the drugs corresponding to his (textual) search

5. Physician selects one of the drugs from that list

6. Information about that drug is displayed to the physician

\section{Alternative flow:}

Alternatively, the physician could consult the several criteria available by browsing other screens where information is organized by organ system of a particular criteria (Beers, Start or Stopp). This flow would be:

1. Select the criteria (Beers, Start or Stopp)

2. Select the organ system

3. View information about drugs for that organ system regarding the chosen criteria

\section{Assess patient progress}

Brief description: Physician assesses a patient's progress by checking the temporal progress in the application's dashboard.

Step-by-step description:

1. Physician selects the patient (same as in "Create CGA session with Patient" first step)

2. Selects option to display the temporal evolution 
3. Is displayed a screen which contains graphics or textual representation of the temporal progress of a Patient's score for a certain Test

\section{Consult CGA guide information}

Brief description: Physician consults the CGA guide section, browsing information about a certain scale.

Step-by-step description:

1. Physician opens the CGA guide section

2. Being displayed the CGA guide areas, selects the one which contains the scale to be consulted

3. The scales for the selected area appear on the screen, physician selects the one to be consulted

4. Scale is displayed on the screen, with every question

\section{Create CGA session without Patient}

Brief description: Physician creates a new evaluation without associating a Patient.

Step-by-step description:

1. Selects the option to make a new evaluation

2. Conduct session

2.1. A screen with the CGA areas appears

2.2. The physician selects the area which contains the scale to be performed

2.3. The screen shows the scales for that area. The intended one is selected.

2.4. Screen displays all the questions associated to that scale; the physician answers all the questions and saves the scale

2.5. After performing steps 2.2-2.4 for all the scales to be conducted, the option to finish the session is selected

3. Review session

3.1. Session is finished, appearing on the screen a review with each scale and the possibility to create a PDF of the session

3.2. If option to create PDF is chose, PDF is created; otherwise, the session is closed

\section{Browse Help section}

Brief description: Physician consults the help topics.

Step-by-step description:

1. Select the option to "know more" on the initial screen

2. Browse Help section

2.1. A screen with CGA help topics is displayed

2.2. Physician selects one of them and consults associated info

\section{Alternative flow:}

Alternatively, the physician could access the Help section from the app drawer where main areas are present. 


\section{Export results report}

Brief description: Physician generates a report containing the outcomes for a CGA session.

Step-by-step description:

1. Conduct a session with or without a patient (same as in "Create CGA session with/without Patient")

2. When reviewing the scale, select option to create a PDF is chosen; PDF can be viewed or sent by email

\section{Alternative flow:}

Alternatively, if the physician is logged in, the report can be created by accessing the sessions for a patient. 


\section{Annex 2 - First Usability Evaluation guide}

In this section, we present the guide each participant in the first usability evaluation received.

\section{Guide for heuristic evaluation of mobile app for assessing geriatric patients}

\section{Objective}

The objective of this heuristic evaluation is to identify usability issues with a prototype mobile application developed in the context of a dissertation. This document contains a brief introduction to the application, the heuristics to consider and then a table to be filled out. If the problems found by the evaluator do not fit the table, please use an additional sheet of paper. There is no wrong answer.

Every issue you detect will be a valuable contribution to this work.

\section{Mobile application}

This mobile application is to be used by gerontology physicians. Its purpose is to help the physicians when evaluating a patient during appointments; during those appointments, the physicians run one or more tests and from their results take measures, that can be simple advice or more complex approaches such as prescribing a medicine for the patient. When a patient goes to an appointment, the physician consults the results from the previous appointments to use as support for the current appointment.

Regarding drug prescription, certain drugs are appropriate for certain situations, while other should be avoided. These criteria include Start, Stop and the application of the criteria proposed by Beer, the first one about positive recommendations and the other two about what to avoid.

\section{Heuristics}

They are called "heuristics" because they are broad rules of thumb and do not specific usability guidelines. In what follows, you can find a list of heuristics, a brief definition of their meaning and some key points to have in mind while handling the mobile app. Please note that the provided definitions are just a first illustration of what each heuristic means. Feel free to detect any other problems that violate each heuristic.

1. Visibility of system status - the system should always keep users informed about what is going on, through appropriate feedback within reasonable time
- Actions feedback
- Feedback when app is loading in background
- Where am I? Where can I go next? What is the current page/section?
- Is it clear if the user is on a private or public area of the app?

2. Match between system and the real world - the system should speak the users' language, with words, phrases and concepts familiar to the user, rather than system-oriented terms

- Follow real-world conventions, making information appear in a natural and logical order.

- Self-explanatory icons and actions that mimic real life.

3. User control and freedom - users often choose system functions by mistake and will need a clearly marked "emergency exit" to leave the unwanted state without having to go through an extended dialogue

- Support undo and redo

- Are typing requirements minimal for question and answer interfaces? 
- Do not ask people to register on a mobile phone

- Can protected or confidential areas be accessed with certain passwords?

4. Consistency and standards - Users should not have to wonder whether different words, situations, or actions mean the same thing

- "Home" or "Homepage" both identify the main page, but only one should be used

- Different names for the same action violate this heuristic

5. Error prevention - even better than good error messages is a careful design which prevents a problem from occurring in the first place. Either eliminate error-prone conditions or check for them and present users with a confirmation option before they commit to the action.

- Are you sure you want to cancel/delete?

6. Recognition rather than recall - minimize the user's memory load by making objects, actions, and options visible. The user should not have to remember information from one part of the dialogue to another

- Instructions for use of the system should be visible or easily retrievable whenever appropriate

- I know what I need to do here

7. Flexibility and efficiency of use - accelerators -- unseen by the novice user -- may often speed up the interaction for the expert user such that the system can cater to both inexperienced and experienced users

- Allow users to tailor frequent actions

- "Shortcuts" for experienced users

8. Aesthetic and minimalist design - Dialogues should not contain information which is irrelevant or rarely needed. Every extra unit of information in a dialogue competes with the relevant units of information and diminishes their relative visibility

- Is this element really needed? Does it clutter the interface?

9. Help users recognize, diagnose, and recover from errors - error messages should be expressed in plain language (no codes), precisely indicate the problem, and constructively suggest a solution.

- Do not tell people something is broken and ca not be fixed

10. Help and documentation - even though it is better if the system can be used without documentation, it may be necessary to provide help and documentation. Any such information should be easy to search, focused on the user's task, list concrete steps to be carried out, and not be too large

- Help page with brief explanation on how to use the app to reach the user's purpose

- l easily become comfortable with my ability to use the app.

\section{Heuristic Evaluation Table}

Start by using the application once, freely exploring it to get acquainted with its features. Afterwards you can use the application as you wish, for the time you find necessary, to explore if any of the heuristics is being violated. For each violation, please state where the problem occurs and which heuristic is being violated, in the table.

Platform:

- Smartphone

- Tablet 


\begin{tabular}{|l|l|}
\hline Heuristic & Comments \\
\hline Visibility of system status & \\
\hline Match between system and the real world & \\
\hline User control and freedom & \\
\hline Consistency and standards & \\
\hline Error prevention & \\
\hline Use & \\
\hline Recognition rather than recall & \\
\hline
\end{tabular}

If you have any other comments which you find relevant in order to assess the usability of the app, please use the space below to do it. 


\section{Annex 9 - Second Usability Evaluation guide (participants)}

In this section, we present the guide each participant in the second usability evaluation received.

\section{Guide for usability evaluation of mobile app for assessing geriatric patients}

Please signal the platform:

- Smartphone

- Tablet

Objective

The objective of this usability evaluation is to identify usability issues with a prototype mobile application developed in the context of a dissertation. This document contains a brief introduction to the application, the evaluation protocol and tables to be filled out by the participant. If the problems found do not fit the table, please use an additional sheet of paper. There is no wrong answer. Every issue you detect will be a valuable contribution to this work.

Being a think aloud test, the participants are asked to use the system while thinking out loud, i.e., verbalizing their thoughts as they use it. The users are given a set of tasks to execute and their thoughts are recorded while they execute the tasks.

Mobile application

This mobile application is to be used by geriatric physicians and its objective is to help them when evaluating a patient during appointments. For assessing geriatric patients, the Comprehensive Geriatric Assessment (CGA) is used. It is divided in four spheres, Mental, Functional, Nutritional and Social; for each sphere, there is a group of scales that assess factors related to it. What a physician does in one of those appointments is to run scales that will inform the patient's status for each sphere.

The physicians run the scales and from their results take measures, that can be simple advice or more complex approaches such as prescribing a medicine. When a patient goes to an appointment, the physician consults the results from the previous appointments to use as support for the current one.

Regarding drug prescription for geriatric patients, due to their clinical condition,

certain drugs are appropriate for certain situations, while others should be avoided. There are clinical criteria that aid a physician when having to prescribe a drug to a geriatric patient. These criteria include Start, Stop and the application of the criteria proposed by Beers, the first one about positive recommendations and the other two about what to avoid. The three types of criteria are included in the app.

Tasks

Following is the list of tasks which you'll need to perform. Task completion is to be synchronized with the person responsible for the study, which will indicate when to start the task. When finishing the task please inform that person, since the time to complete a task needs to be measured.

The five rightmost columns, each one represents a grade in the Likert scale, which goes from strongly disagree to strongly agree. After finishing each task, please signal the answer for the question "Did you find it difficult to perform this task?". 


\begin{tabular}{|c|c|c|c|c|c|}
\hline \multirow[t]{2}{*}{ Tasks } & \multicolumn{3}{|c|}{$\begin{array}{l}\text { Strongly disagree } \\
\text { agree }\end{array}$} & \multicolumn{2}{|c|}{ Strongly } \\
\hline & 1 & 2 & 3 & 4 & 5 \\
\hline 1 - Create a new CGA session, fill out two scales and finish it & & & & & \\
\hline 2 - Register in the app & & & & & \\
\hline 3 - Create a new patient (from now on designated as $\mathrm{P}$ ) & & & & & \\
\hline $\begin{array}{l}4 \text { - Create a new evaluation without associating a patient, fill } \\
\text { out one scale from two different CGA sphere and then associate } \\
\text { it to } \mathrm{P}\end{array}$ & & & & & \\
\hline 5 - Consult the previous created evaluation & & & & & \\
\hline $\begin{array}{l}6 \text { - Create a new evaluation for } \mathrm{P} \text { and then cancel it before } \\
\text { filling any test }\end{array}$ & & & & & \\
\hline $\begin{array}{l}7 \text { - Create a new evaluation for } \mathrm{P} \text { and fill out the same scales } \\
\text { you filled up in the first evaluation }\end{array}$ & & & & & \\
\hline 8 - Check the progress for one of the scales & & & & & \\
\hline 9 - Add $\mathrm{P}$ to the favourites & & & & & \\
\hline 10 - Consult favourite patients & & & & & \\
\hline 11 - Remove P from the favourites & & & & & \\
\hline 12 - Erase a session from $\mathrm{P}$ & & & & & \\
\hline 13 - Remove P's record & & & & & \\
\hline 14- Consult the Start criteria for Metformin & & & & & \\
\hline $\begin{array}{l}15 \text { - Indicate for which medical conditions Bladder } \\
\text { antimuscarinic drugs are not recommended }\end{array}$ & & & & & \\
\hline 16 - Perform logout & & & & & \\
\hline
\end{tabular}




\section{System Usability Scale}

Having finished the tasks, the next procedure is relative to the general usability perceived by the participant. Please fill the following table signalling your level of agreement with each affirmation.

\begin{tabular}{|c|c|c|c|c|c|}
\hline \multirow[t]{2}{*}{ Affirmations } & \multicolumn{3}{|c|}{$\begin{array}{l}\text { Strongly disagree } \\
\text { agree }\end{array}$} & \multicolumn{2}{|c|}{ Strongly } \\
\hline & 1 & 2 & 3 & 4 & 5 \\
\hline 1 - I think that I would like to use this system frequently. & & & & & \\
\hline 2 - I found the system unnecessarily complex. & & & & & \\
\hline 3 - I thought the system was easy to use. & & & & & \\
\hline $\begin{array}{l}4 \text { - I think that I would need the support of a technical person to } \\
\text { be able to use this system. }\end{array}$ & & & & & \\
\hline $\begin{array}{l}5 \text { - I found the various functions in this system were well } \\
\text { integrated. }\end{array}$ & & & & & \\
\hline 6 - I thought there was too much inconsistency in this system. & & & & & \\
\hline $\begin{array}{l}7 \text { - I would imagine that most people would learn to use this } \\
\text { system very quickly. }\end{array}$ & & & & & \\
\hline 8 - I found the system very cumbersome to use. & & & & & \\
\hline 9 - I felt very confident using the system. & & & & & \\
\hline $\begin{array}{l}10 \text { - I needed to learn a lot of things before I could get going with } \\
\text { this system. }\end{array}$ & & & & & \\
\hline
\end{tabular}

If you have any other comments which you find relevant in order to assess the usability of the app, please use the space below to do it. 


\section{Annex 4 - Second Usability Evaluation guide (person conducting evaluation)}

In this section, we present the guide for the person conducting the second usability evaluation.

Platform:

Guide for person conducting second usability evaluation

- Smartphone

- Tablet

Participant number:

Goals

\begin{tabular}{|c|c|c|}
\hline Goal & $\begin{array}{l}\text { Time to } \\
\text { achieve } \\
\text { goal }\end{array}$ & Comments \\
\hline 1 - Create a new CGA session, fill out two scales and finish it & & \\
\hline 2 - Register in the app & & \\
\hline 3 - Create a new patient (from now on designated as $\mathrm{P}$ ) & & \\
\hline $\begin{array}{l}\text { 4- Create a new evaluation without associating a patient, fill out one scale from } \\
\text { two different CGA sphere and then associate it to P }\end{array}$ & & \\
\hline 5 - Consult the previous created evaluation & & \\
\hline 6 - Create a new evaluation for $\mathrm{P}$ and then cancel it before filling any test & & \\
\hline $\begin{array}{l}7 \text { - Create a new evaluation for } \mathrm{P} \text { and fill out the same scales you filled up in the } \\
\text { first evaluation }\end{array}$ & & \\
\hline 8 - Check the progress for one of the scales & & \\
\hline 9 - Add $\mathrm{P}$ to the favourites & & \\
\hline 10 - Consult favourite patients & & \\
\hline 11 - Remove P from the favourites & & \\
\hline 12 - Erase a session from $\mathrm{P}$ & & \\
\hline 13 - Remove P's record & & \\
\hline 14 - Consult the Start criteria for Metformin & & \\
\hline $\begin{array}{l}15 \text { - Indicate for which medical conditions Bladder antimuscarinic drugs are not } \\
\text { recommended }\end{array}$ & & \\
\hline 16 - Perform logout & & \\
\hline
\end{tabular}




\section{Annex 5-Second Usability Evaluation results}

In this section, we describe the results from the second usability evaluation. They comprise the comments made by participants, their characterization in terms of experience with mobile platforms, and the difficulty level while conducting tasks.

\section{Smartphone}

\begin{tabular}{|c|c|}
\hline Goal & Comments \\
\hline $\begin{array}{l}1 \text { - Create a new CGA } \\
\text { session, fill out two scales } \\
\text { from the Functional State } \\
\text { area with random values } \\
\text { and finish session }\end{array}$ & $\begin{array}{l}\text { Text size a little small (single choice scale) - } \mathrm{P}_{1} \\
\text { Did not know if all questions had to be filled - } \mathrm{P} 1, \mathrm{P} 2, \mathrm{P} 5 \\
\text { Spelling mistakes in some scale contents - } \mathrm{P} 1, \mathrm{P} 2 \\
\text { Done button instead of back arrow - } \mathrm{P} 7 \\
\text { Does not know if session is saved - } \mathrm{P} 7 \\
\text { Did not know if was already inside scale or not - P9 } \\
\text { When creating a session, it is strange that no patient gets associated - } \\
\mathrm{P} 11 \\
\text { The popup with information about a scale or a CGA area should have a } \\
\text { button to close it or be closed when clicking on it - P11 } \\
\text { When a scale is filled up and going back to view all the scales for an } \\
\text { area, the size of the card representing the scale increases in size to show } \\
\text { more information related to the scale; this can be a little confusing, try } \\
\text { to maintain the same size - P } 11\end{array}$ \\
\hline $\begin{array}{l}2 \text { - Register as user in the } \\
\text { application }\end{array}$ & $\begin{array}{l}\text { Register icon not present, log in and register are not separated - P } 1 \\
\text { When registering person's name, it is not automatically set to capital } \\
\text { letter - P } 1 \\
\text { Register icon not visible - P9, P } 11 \\
\text { If patient not registered, there could be a message about that - P9, P11 } \\
\text { Tried to perform login without having registered beforehand, which } \\
\text { led the application to crash - P } 11 \\
\text { There should be given feedback that the user is not registered when } \\
\text { trying to login if that is the case - P } 11 \\
\text { After registering go to the Login menu and not to the list of patients - } \\
\text { P } 11 \\
\text { Introduce the same password twice in the register to avoid using a } \\
\text { wrong one and not be able to retype it - P } 11\end{array}$ \\
\hline $\begin{array}{l}3 \text { - Create a new patient } \\
\text { called Manuel (use random } \\
\text { values in for other fields) }\end{array}$ & $\begin{array}{l}\text { No feedback that patient was created - P1 } \\
\text { When entering new patient's name, it should be automatically set to } \\
\text { capital letter - P1 } \\
\text { Limit the number of spaces when entering address - P7 } \\
\text { Month, day or year validation is missing - P9, P11 }\end{array}$ \\
\hline
\end{tabular}




\begin{tabular}{|c|c|}
\hline & $\begin{array}{l}\text { Buttons used to create new patient and save the new patient's profile } \\
\text { are in different places of the screen (former on the bottom and the latter } \\
\text { on the top) - P11 } \\
\text { Took some time to find the save button, could be placed after the fields } \\
\text { - P11 } \\
\text { Add patient from the navigation menu - P11 }\end{array}$ \\
\hline $\begin{array}{l}4 \text { - Create new session } \\
\text { without associating a } \\
\text { patient, fill out Valoración } \\
\text { Socio-Familiar scale with } \\
\text { random values, finish the } \\
\text { session and associate it to } \\
\text { patient Manuel }\end{array}$ & $\begin{array}{l}\text { When creating a session, after filling out the last scale, the only way to } \\
\text { save it is to go back to the main screen where all CGA areas are } \\
\text { displayed it and click the Save button; this action could be done right } \\
\text { from the scale's screen, also users may think that when they go back } \\
\text { between the information from the original screen can be lost - P1, P11 } \\
\text { Did not know if was already conducting a Session - P2 } \\
\text { Done button instead of back arrow - P7 } \\
\text { Names in lowercase are out of order - P7 } \\
\text { Clicked info icon instead of scale since it is the only one visual queue - } \\
\text { P9 } \\
\text { Saving icon is not fully perceptible - P9 } \\
\text { Mistake user session (after registering) with evaluation session - P7 } \\
\text { Going back from session should be considering as finishing and saving } \\
\text { the session, not cancelling it - P } 11 \\
\text { When choosing patient to be associated with this session, the user can } \\
\text { choose the wrong patient by mistake and there is no way to }\end{array}$ \\
\hline $\begin{array}{l}5 \text { - Access session created in } \\
\text { previous task, state the } \\
\text { qualitative result regarding } \\
\text { Valoración Socio-Familiar } \\
\text { scale }\end{array}$ & $\begin{array}{l}\text { Difficulty to find out which was the qualitative result for a scale - P1, } \\
\mathrm{P}_{2}\end{array}$ \\
\hline $\begin{array}{l}6 \text { - Create a new session for } \\
\text { patient Manuel and then } \\
\text { cancel it before filling out } \\
\text { any scale }\end{array}$ & $\begin{array}{l}\text { When in Sessions view and creating a new Session, instead of selecting } \\
\text { the patient's gender the first step should be selecting a patient from the } \\
\text { list or creating a new one, allowing to create right from the start a } \\
\text { session for a patient from the Sessions screen, which presently can only } \\
\text { be done from the patient's profile - P1 } \\
\text { Cancel button not perceptible - P9 } \\
\text { Cancelled using back instead of Cancel button - P9 } \\
\text { There should be a title like "New CGA session - Patient name" - P11 }\end{array}$ \\
\hline $\begin{array}{l}7 \text { - Create a new session for } \\
\text { patient Manuel and fill out } \\
\text { again the Valoración Socio- } \\
\text { Familiar scale (with random } \\
\text { values) }\end{array}$ & $\begin{array}{l}\text { Save button could be on the scale view }-\mathrm{P} 1, \mathrm{P} 2 \\
\text { When saving a session does it end? - } \mathrm{P} 7 \\
\text { Feedback that session was created too fast - } \mathrm{P} 7 \\
\text { Quantitative result for a Session could be visible in the Session card } \\
\text { inside the Patient's profile - P9 }\end{array}$ \\
\hline
\end{tabular}




\begin{tabular}{|c|c|}
\hline & $\begin{array}{l}\text { There should be a message like "do you wish to save or not?" instead of } \\
\text { clicking on the save button and saving automatically - P } 11 \\
\text { Save button is missing inside the scale - P } 11\end{array}$ \\
\hline $\begin{array}{l}8 \text { - Verify patient's progress } \\
\text { relatively to the Valoración } \\
\text { Socio-Familiar scale (has he } \\
\text { got better, worse or there is } \\
\text { no change) }\end{array}$ & $\begin{array}{l}\text { The result, on the table, could be more straight-forward, so a person } \\
\text { would not need to analyse the table to retrieve the data, i.e., the patient's } \\
\text { progress - P1 } \\
\text { Saw the progress straight from the sessions - P7 }\end{array}$ \\
\hline $\begin{array}{l}9 \text { - Add patient Manuel to } \\
\text { the favourites }\end{array}$ & $\begin{array}{l}\text { Favourite icon is in reverse, i.e., if patient is not added as favourite the } \\
\text { icon should be solid, otherwise it should only show the borders around } \\
\text { it, and not the other way around - } \mathrm{P} 1 \\
\text { Feedback that patient was added to the favourites could take more time } \\
\text { - P7 }\end{array}$ \\
\hline $\begin{array}{l}10 \text { - Consult favourite } \\
\text { patients list e remove } \\
\text { Manuel form the favourites }\end{array}$ & $\begin{array}{l}\text { Patient could be removed right from the favourites list without having } \\
\text { to see the patient's profile first - P7 } \\
\text { Favourite icon is in reverse, i.e., if patient is not added as favourite the } \\
\text { icon should be solid, otherwise it should only show the borders around } \\
\text { it, and not the other way around - P11 }\end{array}$ \\
\hline $\begin{array}{l}11 \text { - Eliminate the most } \\
\text { recent session from Manuel }\end{array}$ & $\begin{array}{l}\text { Since there is only a single action (delete), could use a delete icon or } \\
\text { image instead - P7 } \\
\text { Tried long click - P9 } \\
\text { Icon to open pop-up menu not perceptible - P9 } \\
\text { Tried swipe gesture to erase Session - P9 } \\
\text { Tried long click in session card - P11 }\end{array}$ \\
\hline $\begin{array}{l}12 \text { - Eliminate Manuel's } \\
\text { profile from the application }\end{array}$ & \\
\hline $\begin{array}{l}13 \text { - Consult the Start } \\
\text { criteria associated to } \\
\text { Metformin }\end{array}$ & $\begin{array}{l}\text { Search icon when consulting Start criteria does not work - P1, P5 } \\
\text { Create a search for Start screen - P9 } \\
\text { The list with all the drugs and the three types of criteria could be } \\
\text { accessed in different screens - P } 11\end{array}$ \\
\hline $\begin{array}{l}14 \text { - Indicate for which } \\
\text { medical conditions Bladder } \\
\text { antimuscarinic drugs are to } \\
\text { be avoided }\end{array}$ & $\begin{array}{l}\text { Use a colour code when displaying all the types of criteria associated to } \\
\text { a single drug - P } 9 \\
\text { Going back should not close the application - P11, instead should } \\
\text { prompt the user if wants to log out or not - P } 11\end{array}$ \\
\hline $\begin{array}{l}15 \text { - Log Out from the } \\
\text { application }\end{array}$ & Is logging out equivalent to closing the application - P11 \\
\hline
\end{tabular}


Tablet

\begin{tabular}{|c|c|}
\hline Goal & Comments \\
\hline $\begin{array}{l}1 \text { - Create a new CGA session, fill out two scales from } \\
\text { the Functional State area with random values and } \\
\text { finish session }\end{array}$ & $\begin{array}{l}\text { Did not know if all questions had to be filled - P3, } \\
\mathrm{P} 4 \\
\text { Feedback informing scale is completed is too fast } \\
-\mathrm{P} 3 \\
\text { Tried swipe between scale with multiple } \\
\text { categories - P6 } \\
\text { Give feedback that session had finished - P6 } \\
\text { Go back automatically to the scales list when } \\
\text { current scale is completed - P6, P10 } \\
\text { All answer options should appear in the list and } \\
\text { not just after clicking - P10 } \\
\text { There could be a review of each CGA area when } \\
\text { conducting a Session - P10 }\end{array}$ \\
\hline 2 - Register as user in the application & $\begin{array}{l}\text { Did not find out where to register - P3 } \\
\text { Register text fields should not occupy the whole } \\
\text { width of the screen, the person may think s/he } \\
\text { must input much information - P10 } \\
\text { When entered email is invalid, show example of a } \\
\text { valid one - P10 } \\
\text { Log in should be in Portuguese - P10 }\end{array}$ \\
\hline $\begin{array}{l}3 \text { - Create a new patient called Manuel (use random } \\
\text { values in for other fields) }\end{array}$ & $\begin{array}{l}\text { Button used to create a new patient not too visible } \\
\text { - P3 } \\
\text { When inputting birth date, should not allow } \\
\text { invalid values; also, day and month fields should } \\
\text { have two spaces only - P3, P10 } \\
\text { When inputting birth date, instead of having to } \\
\text { select month field after filling out day, that } \\
\text { transition should be made automatically - P4 } \\
\text { Save button when creating new patient profile is } \\
\text { too small when this is the only action, the button } \\
\text { could be below the patient fields - P10 }\end{array}$ \\
\hline $\begin{array}{l}\text { 4. - Create new session without associating a patient, } \\
\text { fill out Valoración Socio-Familiar scale with random } \\
\text { values, finish the session and associate it to patient } \\
\text { Manuel }\end{array}$ & $\begin{array}{l}\text { Did not know if had to perform logout to create a } \\
\text { session without patient - P } 3 \\
\text { Hamburger icon to open menu is not very } \\
\text { intuitive for users lacking smartphone experience } \\
\text { - P6 }\end{array}$ \\
\hline
\end{tabular}




\begin{tabular}{|c|c|}
\hline & $\begin{array}{l}\text { When associating patient to session, clicked } \\
\text { patient icon but only patient's name was } \\
\text { responsive-P10 } \\
\text { There should be feedback that session was } \\
\text { associated to patient-P10 }\end{array}$ \\
\hline $\begin{array}{l}5 \text { - Access session created in previous task, state the } \\
\text { qualitative result regarding Valoración Socio-Familiar } \\
\text { scale }\end{array}$ & $\begin{array}{l}\text { Patient's notes can be mistaken with session's } \\
\text { notes - P10 } \\
\text { When viewing notes for a patient, the person may } \\
\text { think is adding a new note, but instead adds a new } \\
\text { session - P10 }\end{array}$ \\
\hline \multicolumn{2}{|l|}{$\begin{array}{l}6 \text { - Create a new session for patient Manuel and then } \\
\text { cancel it before filling out any scale }\end{array}$} \\
\hline $\begin{array}{l}7 \text { - Create a new session for patient Manuel and fill out } \\
\text { again the Valoración Socio-Familiar scale (with } \\
\text { random values) }\end{array}$ & Save button could be on the scale view - $\mathrm{P} 4$ \\
\hline $\begin{array}{l}8 \text { - Verify patient's progress relatively to the } \\
\text { Valoración Socio-Familiar scale (has he got better, } \\
\text { worse or there is no change) }\end{array}$ & $\begin{array}{l}\text { Instead of displaying qualitative result, use } \\
\text { quantitative result }-\mathrm{P} 4\end{array}$ \\
\hline \multicolumn{2}{|l|}{9 - Add patient Manuel to the favourites } \\
\hline $\begin{array}{l}10 \text { - Consult favourite patients list and remove Manuel } \\
\text { form the favourites }\end{array}$ & $\begin{array}{l}\text { Favourite patients list icon is a solid star, and if } \\
\text { the patient is added to favourites the icon is a star } \\
\text { with only the borders around - } \mathrm{P} 4, \mathrm{P} 10 \\
\text { The favourite area for a patient is not all of it } \\
\text { responding to touch - } \mathrm{P} 10\end{array}$ \\
\hline 11 - Eliminate the most recent session from Manuel & $\begin{array}{l}\text { Button used to open popup menu where option to } \\
\text { remove session is present is too small, task was } \\
\text { not completed - } \mathrm{P} 3, \mathrm{P} 4 \\
\text { The eliminate action, being a negative one, } \\
\text { should not take that much space on the screen - } \\
\text { P10 } \\
\text { Since there is only a single action (delete), could } \\
\text { use a delete icon or image instead - P7 } \\
\text { There should be the possibility of erasing a } \\
\text { session when viewing its contents, since a patient } \\
\text { can be removed when viewing its profile as well - } \\
\text { P10 }\end{array}$ \\
\hline \multicolumn{2}{|l|}{12 - Eliminate Manuel's profile from the application } \\
\hline 13 - Consult the Start criteria associated to Metformin & \\
\hline
\end{tabular}


14 - Indicate for which medical conditions Bladder antimuscarinic drugs are to be avoided

a

Columns for medical condition and risk inside Beers criteria should be separated - $\mathrm{P}_{4}$

The list with all the drugs could support fast scroll - P8

\section{Experience with mobile platforms}

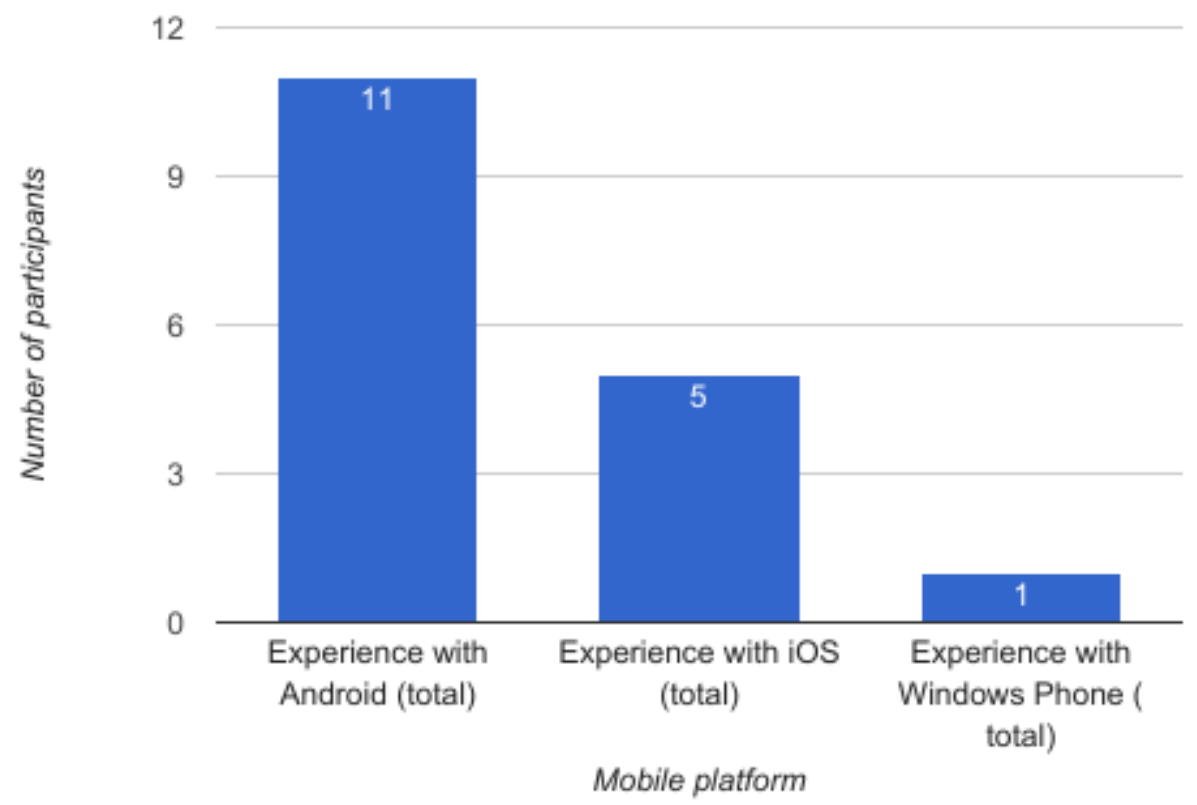



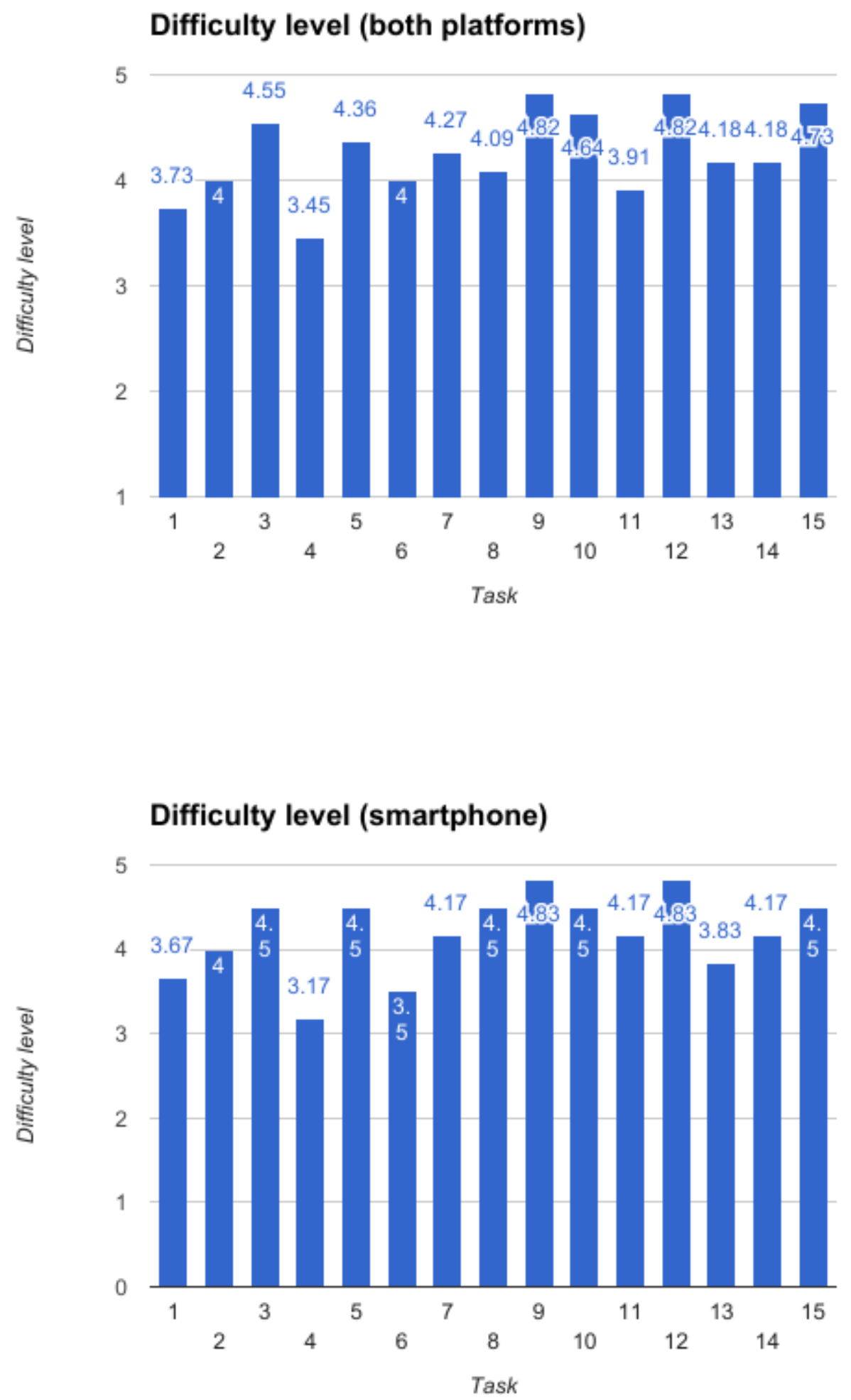


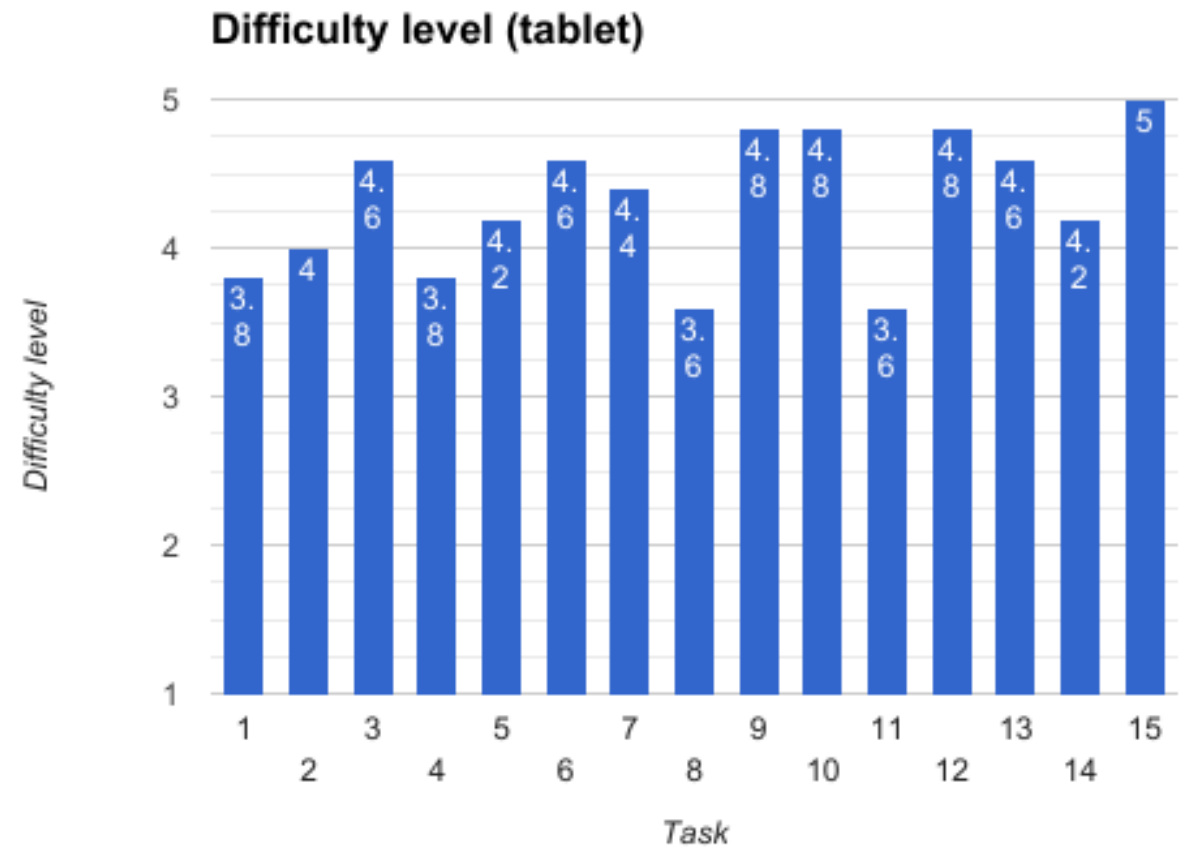




\section{Annex 6 - Pilot test guide (participants)}

The pilot test guide for participants includes: global context and objectives for the pilot test, fields for participant's characterization, overview of the system's functionalities, three phases (tasks, pilot stage and SUS) with corresponding questions, and finally a field for comments.

\section{Pilot test for GeriatricHelper, mobile application for assessing geriatric patients}

\section{Global Context}

The objective for this pilot test is to test GeriatricHelper, an application for aiding geriatric physicians on clinical context, allowing to obtain information about its applicability in real contexts. This pilot test is divided into three stages, executing typical tasks (1), pilot stage (2) and a satisfaction guaranteeing questionnaire at the end of the pilot stage (3) This document contains a brief introduction to the application, the protocol to be followed and tables to be filled up by the participant. Each problem you detect or difficulty you signal will be of valuable contribution to this work.

You may finish your participation at any time if you wish to.

Tester's profile

Age:

Average number of geriatric appointments per week:

For how long have you been practicing the Comprehensive Geriatric Assessment:
Do you use mobile devices (smartphone, tablet) with touch interface on a regular basis?

- Yes

- $\quad$ No
Operating systems experience:
- Android
- iOS
- Windows Phone

\section{GeriatricHelper: functionalities}

This mobile app will be used by geriatric physicians and its objective is to aid them assessing patients during appointments. GeriatricHelper's current version allows to conduct the Comprehensive Geriatric Assessment (GGA) without associating a patient, as well as consulting a CGA guide in which each application area and scales are explained. New functionalities will be included on later versions.

\section{Phase 1 - tasks}

The following tasks include main app functionalities and pretend to give you a first vision of what can achieve. At the same time, it is supposed to obtain your opinion about the difficulty degree they have offered. With the person coordinating the test's coordination execute each task one by one with attention to verbally express your thoughts when using the app, mainly difficulties felt and observations. Your performance is not being evaluated, only the easiness using the application and its utility.

For each of the tasks, after its execution, please signal the difficulty level felt during completion, signalling the corresponding column, on a scale from very difficult to very easy. 


\begin{tabular}{|c|c|c|c|c|c|}
\hline \multirow[t]{2}{*}{ Tasks } & \multicolumn{3}{|c|}{$\begin{array}{l}\text { Very difficult } \\
\text { easy }\end{array}$} & \multicolumn{2}{|c|}{ Very } \\
\hline & 1 & 2 & 3 & 4 & 5 \\
\hline $\begin{array}{l}1 \text { - Create a new CGA session, fill out both scales from the Functional } \\
\text { State area with random values and finish session }\end{array}$ & & & & & \\
\hline 2 - State the quantitative and qualitative results for both scales & & & & & \\
\hline $\begin{array}{l}3 \text { - Create and view a PDF with the session's summary and then finish } \\
\text { the session }\end{array}$ & & & & & \\
\hline $\begin{array}{l}\text { 4- Create a new session, fill out Mini-Mental State Examination scale } \\
\text { with random values (assuming a patient which attended the } 6 \text { th grade), } \\
\text { leave a note and finish the session }\end{array}$ & & & & & \\
\hline $\begin{array}{l}5 \text { - Create a new session, filling out the Nutritional assessment - } \\
\text { screening test, assuming a patient with a height of } 1.56 \mathrm{~m} \text { and weighing } \\
68 \mathrm{~kg}\end{array}$ & & & & & \\
\hline 6 - Create a new session and then cancel it before filling out any scale & & & & & \\
\hline 7 - Consult help topic regarding CGA's objectives & & & & & \\
\hline $\begin{array}{l}8 \text { - Consult CGA guide for the Lawton \& Brody scale, stating for which } \\
\text { score }(s) \text { a female patient has mild dependency }\end{array}$ & & & & & \\
\hline 9 - Repeat tour guide of the app & & & & & \\
\hline
\end{tabular}

\section{Phase 2 - Pilot phase}

During this phase, you are free to use the app during appointments with your patients. Use the black space below to write your comments, suggestions or ideas, related to GeriatricHelper and its use. 


\section{Phase 3 - Global usability assessment}

The last phase is relative to the overall usability perceived by the participant. Please fill out the following table signalling the concordance degree for each one of the sentences.

\begin{tabular}{|l|l|l|l|l|}
\hline \multicolumn{2}{|l|}{ Affirmations } & \multicolumn{2}{l}{ Strongly disagree } \\
agree
\end{tabular}




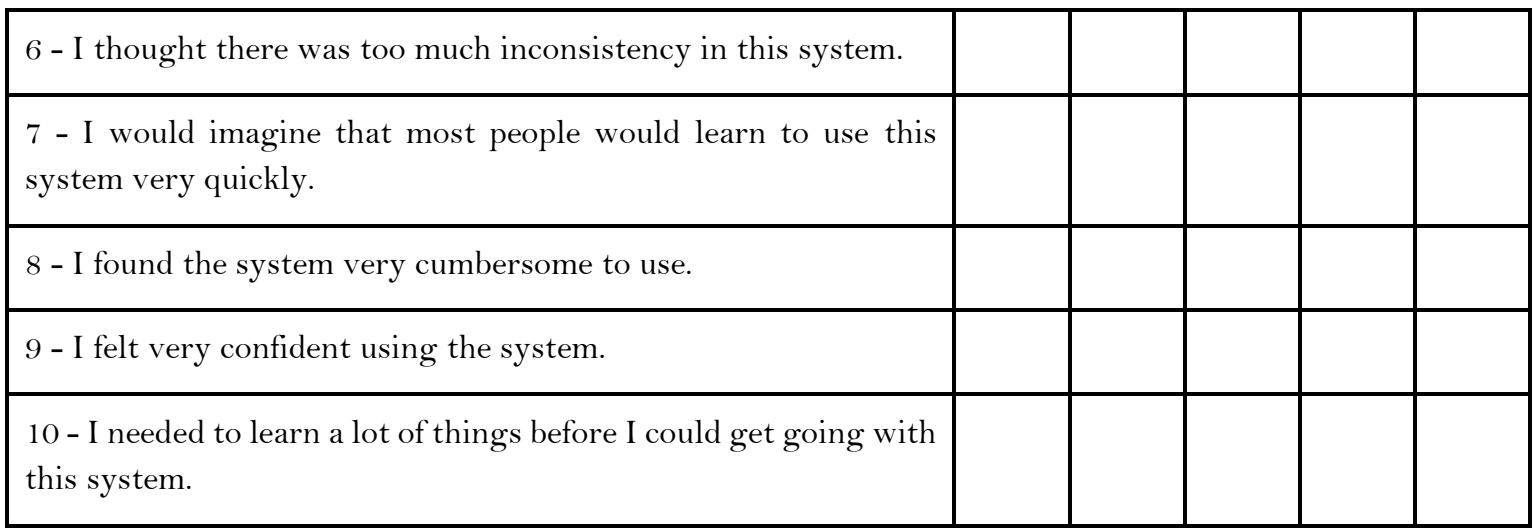

In case you have any other comments regarding GeriatricHelper's functionality or other improvement suggestions use the space below to write them.

Thank you for your participation and contribution to the growth of GeriatricHelper 


\section{Annex 7 - Pilot test guide (person conducting evaluation)}

The pilot test guide for the person conducting the evaluation includes: platform and participant number, a table with the goals and fields for time taken to achieve the goal and comments.

\section{Guide for person conducting pilot test}

Platform:

- Smartphone

- Tablet

Participant number:

\section{Goals}

\begin{tabular}{|c|c|c|}
\hline Goal & $\begin{array}{l}\text { Time to } \\
\text { achieve goal }\end{array}$ & Comments \\
\hline $\begin{array}{l}1 \text { - Create a new CGA session, fill out both scales from the Functional State } \\
\text { area with random values and finish session }\end{array}$ & & \\
\hline 2 - State the quantitative and qualitative results for both scales & & \\
\hline $\begin{array}{l}3 \text { - Create and view a PDF with the session's summary and then finish the } \\
\text { session }\end{array}$ & & \\
\hline $\begin{array}{l}4 \text { - Create a new session, fill out Mini-Mental State Examination scale with } \\
\text { random values (assuming a patient which attended the } 6 \text { th grade), leave a note } \\
\text { and finish the session }\end{array}$ & & \\
\hline $\begin{array}{l}5 \text { - Create a new session, filling out the Nutritional assessment - screening } \\
\text { test, assuming a patient with a height of } 1.56 \mathrm{~m} \text { and weighing } 68 \mathrm{~kg}\end{array}$ & & \\
\hline 6 - Create a new session and then cancel it before filling out any scale & & \\
\hline 7 - Consult help topic regarding CGA's objectives & & \\
\hline $\begin{array}{l}8 \text { - Consult CGA guide for the Lawton \& Brody scale, stating for which } \\
\text { score }(s) \text { a female patient has mild dependency }\end{array}$ & & \\
\hline 9 - Repeat tour guide of the app & & \\
\hline
\end{tabular}




\section{Annex 8-Android app wireframe}

The GeriatricHelper Android app wireframe makes an overview of how navigating inside the app takes place. 


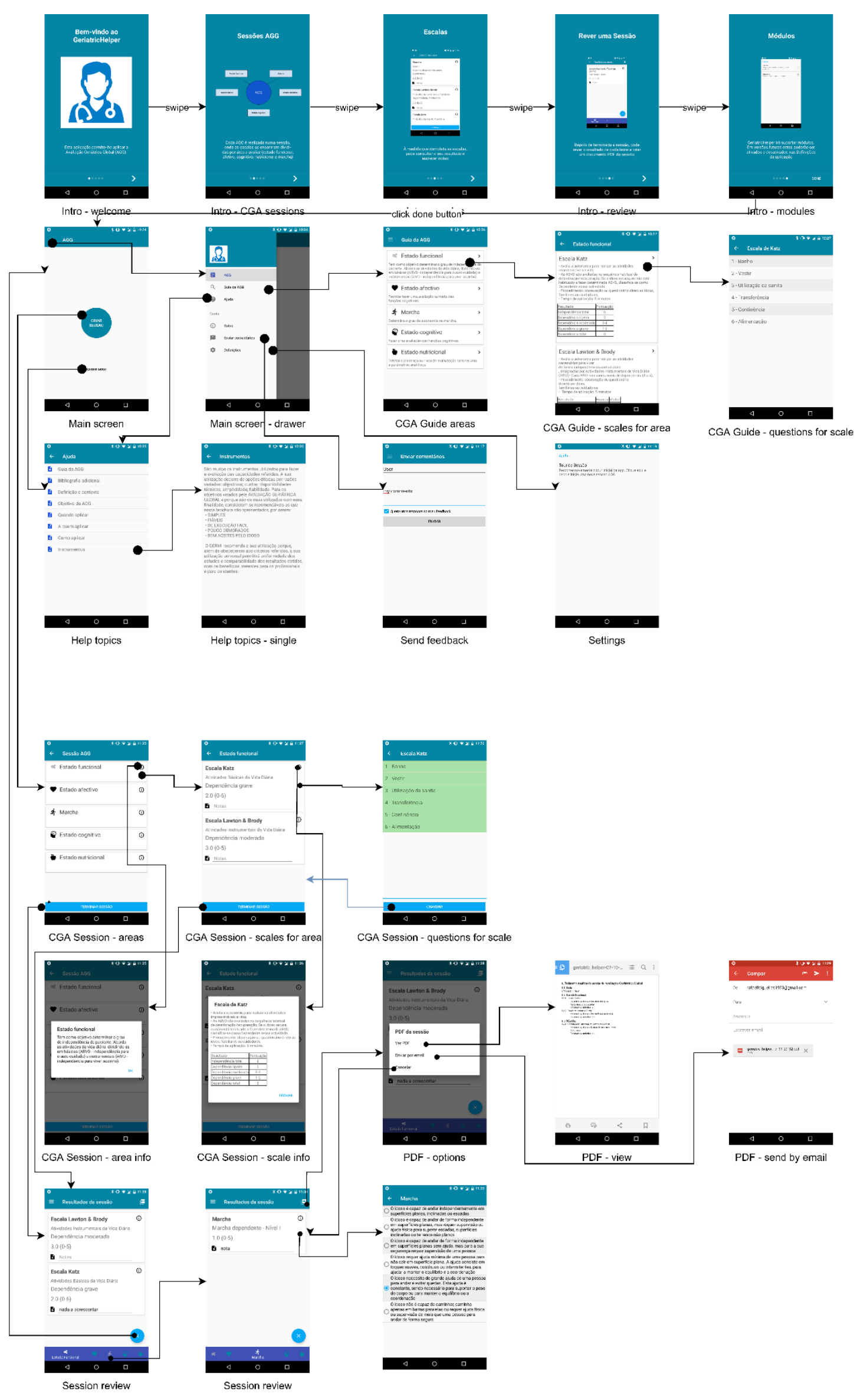




\section{Annex 9-iOS app wireframe}

The GeriatricHelper iOS app wireframe makes an overview of how navigating inside the app takes place. 


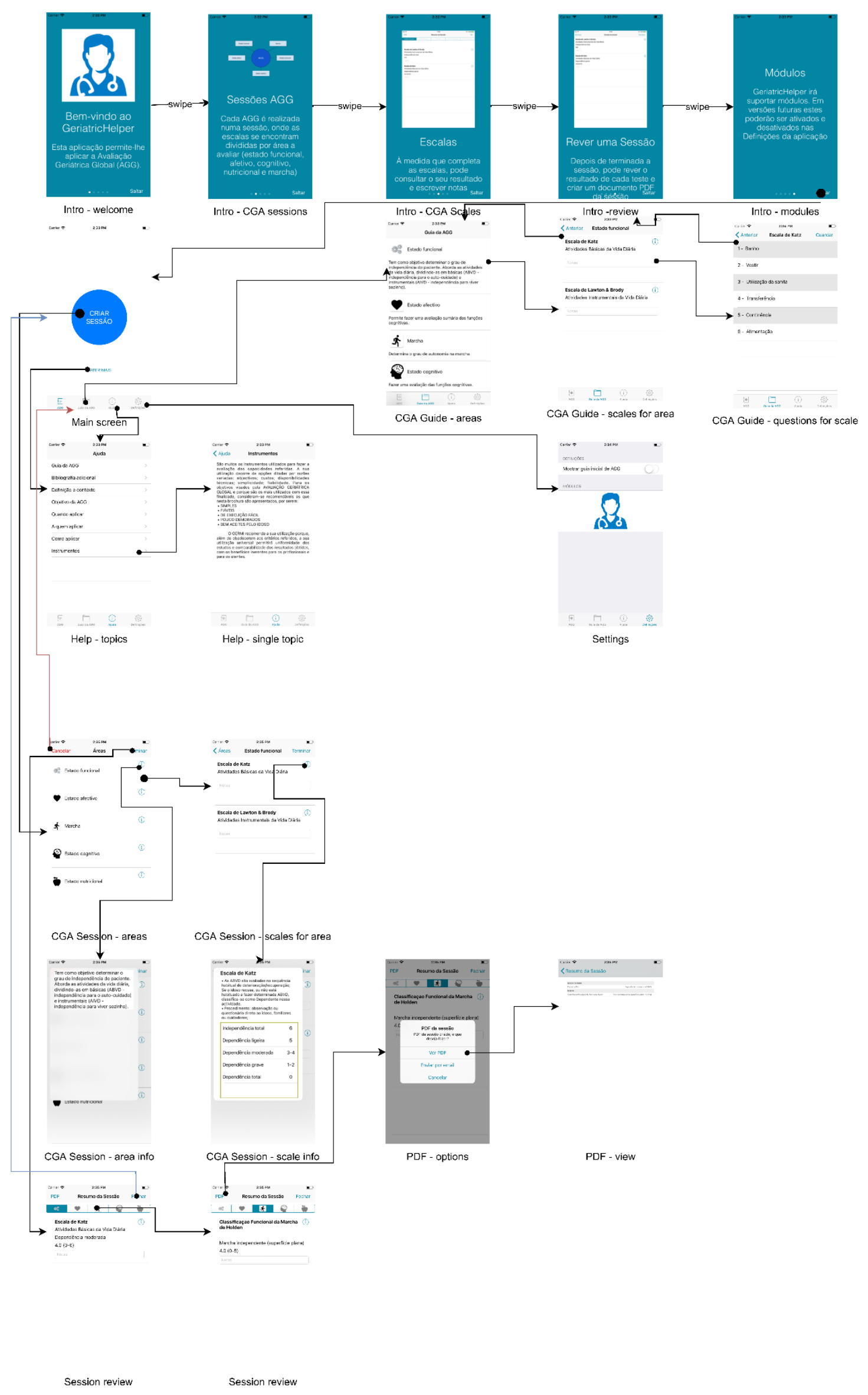

